\title{
Model Documentation Report: Macroeconomic Activity Module (MAM) of the National Energy Modeling System
}

February 1997

\section{RECEIVED \\ MAR 061907 \\ OSTI}

\author{
Office of Integrated Analysis and Forecasting \\ Energy Information Administration \\ U.S. Department of Energy \\ Washington, DC
}




\section{DISCLAIMER}

Portions of this document may be illegible in electronic image products. Images are produced from the best available original document. 


\title{
Model Documentation Report: Macroeconomic Activity Module (MAM) of the National Energy Modeling System
}

\author{
February 1997 \\ Office of Integrated Analysis and Forecasting \\ Energy Information Administration \\ U.S. Department of Energy \\ Washington, DC
}

This report was prepared by the Energy Information Administration, the independent statistical and analytical agency within the Department of Energy. The information contained herein should not be construed as advocating or reflecting any policy position of the Department of Energy or any other organization. 


\section{Table of Contents}

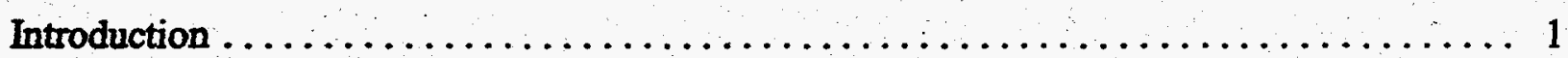

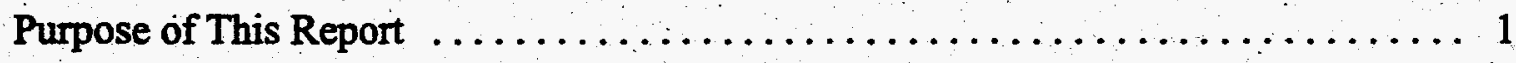

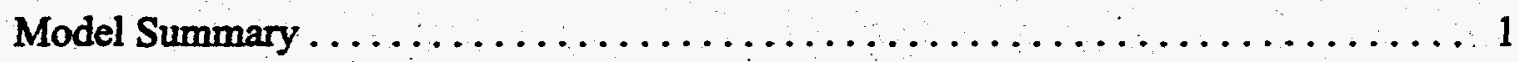

Organization of this Report $\ldots \ldots \ldots \ldots \ldots \ldots \ldots \ldots \ldots \ldots \ldots \ldots \ldots, 7$

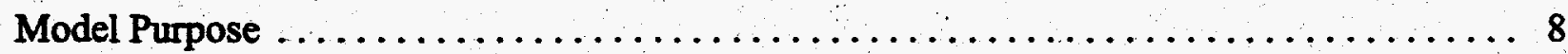

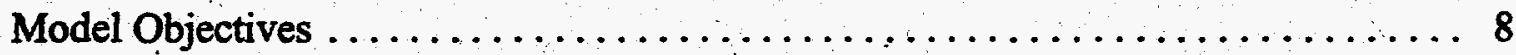

Relationship of MAM to other NEMS Modules $\ldots \ldots \ldots \ldots \ldots \ldots \ldots \ldots \ldots, 9$

Model Overview and Rationale $\ldots \ldots \ldots \ldots \ldots \ldots \ldots \ldots \ldots \ldots \ldots \ldots \ldots \ldots \ldots$

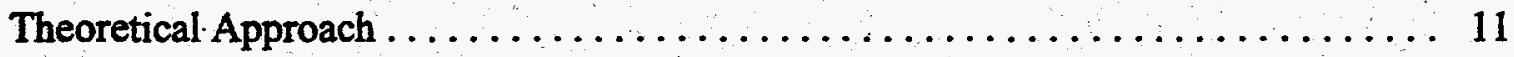

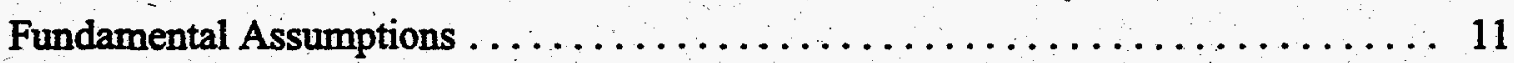

Alternative Macroeconomic Modeling Approaches and Reasons for Selection . .... 17

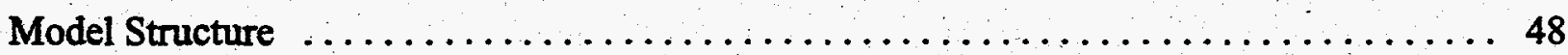

Key Computations and Equations $\ldots \ldots \ldots \ldots \ldots \ldots \ldots \ldots \ldots \ldots \ldots, 57$

Appendix A: Model Input and Output Inventory $\ldots \ldots \ldots \ldots \ldots \ldots \ldots \ldots \ldots \ldots \ldots \ldots \ldots \ldots \ldots \ldots$

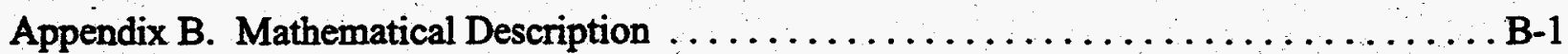

Appendix C. Bibliography $\ldots \ldots \ldots \ldots \ldots \ldots \ldots \ldots \ldots \ldots \ldots \ldots \ldots \ldots \ldots \ldots \ldots \ldots \ldots \ldots \ldots, 1$

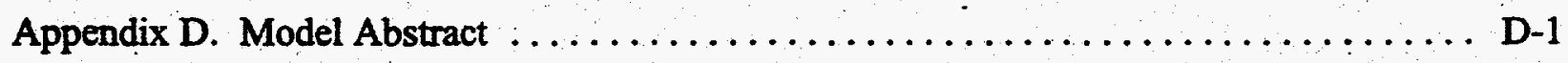

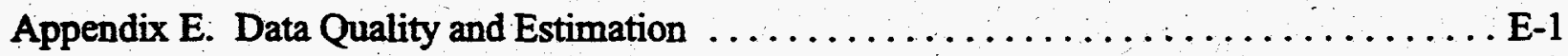




\section{Introduction}

\section{Purpose of This Report}

This report documents the objectives, analytical approach, and development of the National Energy Modeling System (NEMS) Macroeconomic Activity Module (MAM) used to develop the Annual Energy Outlook for 1997 (AEO97). The report catalogues and describes the module assumptions, computations, methodology, parameter estimation techniques, and mainframe source code.

This document serves three purposes. First, it is a reference document providing a detailed description of the NEMS MAM used for the AEO 1997 production runs for model analysts, users, and the public. Second, this report meets the legal requirement of the Energy Information Administration (EIA) to provide adequate documentation in support of its models (Public Law 94-385, section 57.b.2). Third, it facilitates continuity in model development by providing documentation from which energy analysts can undertake model enhancements, data updates, and parameter refinements as future projects.

\section{Model Summary}

The MAM of NEMS is composed of four submodules: the National Submodule, the Interindustry Submodule, Employment Submodule and the Regional Submodule. The National Submodule, Employment Submodule, and the Interindustry Submodules are response surface representations of the large, proprietary econometric models developed by Data Resources, Inc/McGraw-Hill (DRI). The Regional Submodule consists of a set of regional shares that are 
used to disaggregate the results from the National and Interindustry Submodules to the nine Census Division level. The regional shares used in the module change over the forecast period, reflecting the changing growth patterns across regions over time.

The MAM provides forecasts of economic driver variables to the NEMS system. The MAM also forecasts the impacts of changes in energy market conditions on the aggregate economy. The set of forecasts generated by the National Submodule includes interest rates, final demands for goods and services, housing starts, and disposable income. The Interindustry Submodule calculates the industrial output needed to satisfy the final demands forecasted by the National Submodule. The NEMS Residential Sector Demand Module, Commercial Sector Demand Module, and Industrial Sector Demand Module require regional forecasts of such driver variables as housing starts, commercial floorspace, and industrial output. The Employment Submodule calculates employment by manufacturing industries at a 2 digit SIC level as well as construction, services and trade aggregation. The Regional Submodule disaggregates the forecasts generated by the National, Employment, and Interindustry Submodules so that they can be used by the NEMS demand modules.

The National Submodule of MAM is a response surface representation of the DRI U.S. Quarterly Macroeconomic Model. The Interindustry Submodule of MAM is a response surface approximation of DRI's Personal Computer Input-Output (PCIO) Model. The Employment Submodule of MAM is a response surface approximation of DRI's Employment Model. The Regional Submodule is a straightforward sharing algorithm that applies factors based on simulations of DRI's U.S. Quarterly, PCIO, and Regional Models. DRIs U.S. Quarterly Model, PCIO Model, Employment Model, and Regional Model are designed to work in tandem with each other. DRI's PCIO uses final demands generated by the DRIU.S. Quarterly Model as inputs, DRIs Employment model uses the output generated by PCIO as well as some macroeconomic concepts as inputs, and the DRI Regional Model uses the DRI U.S. Quarterly Model and PCIO Model outputs as inputs for the regionalization algorithm. Similarly, the response surface representations developed from the DRI models to create the MAM are also 
designed to work in tandem with each other.

\section{MAM Approach}

The goal of the response surface models in MAM is to replicate the effects of changing energy prices in the DRI full scale models. There are four DRI models that are used to create any macroeconomic baseline: the DRI U.S. Quarterly Macroeconomic Model, the DRI Personal Computer Input-Output Model (PCIO), the DRI Employment Model, and the DRI Personal Computer Regional Model. For the AEO 1997, MAM uses response surface models developed from the U.S. Quarterly Model, Employment Model, and the PCIO for the National, Employment and Interindustry Submodules respectively. The Regional Submodule of MAM used for the AEO 1997 consists of a set of regional shares developed using the DRI Regional Model in conjunction with the other three DRI large models listed above.

\section{MAM National Submodule}

The MAM National Submodule is a response surface representation of the DRI Quarterly Model of the U.S. economy, modeled using annual data. The National Submodule supports the NEMS energy supply, demand, and conversion modules by providing mid-range macroeconomic and industrial output forecasts for the period of 1990-2015. The National Submodule also provides feedback effects for analyses of different energy scenarios by capturing the macroeconomic effects of variations in energy prices. Three macroeconomic growth path scenarios are provided in the National Submodule: baseline, high, and low growth.

The National Submodule responds to two sets of information: wholesale and retail energy prices. The NEMS system determines the reaction of energy prices to changes in events or policies. These energy price impacts are passed to the National Submodule of MAM and the economy reacts, producing altered macroeconomic variables. These altered variables are then passed back to the other NEMS modules for the next iteration. In developing AEO97 forecasts, only wholesale energy price information is used to calculate macroeconomic feedback. 
The growth potential of the economy is rooted in the growth of the factors of production, specifically, labor, capital, and energy, and the aggregate productivity of these factors. The user may opt for one of the three growth scenarios provided in the National Submodule (baseline, high, or low growth) and subsequently incorporate energy price feedbacks. Additional discussion of the National Submodule methodology is provided in Chapter 4 of this Volume. A listing of inputs and outputs to the National Submodule is provided in Appendix $A$ to this Volume.

\section{Econometric Model of Employment by Industry.}

The Employment Submodule calculates deviations from a given baseline employment projection. The Employment Submodule calculates the employment impacts of altered energy market conditions based on the following causal relationships. When energy prices change, the level and composition of macroeconomic final demands are affected. In turn, the level and composition of interindustry gross outputs required to satisfy the new final demands are changed. Finally, faced with new demands for their products, industries will adjust the number of workers employed. The response surface Employment Submodule represents this last link in the chain.

\section{MAM Interindustry Submodule}

The Interindustry Submodule provides interindustry projections to the NEMS Industrial Demand Module. The Interindustry Submodule also calculates the interindustry energy policy impacts based upon feedback from the final demand forecasts generated by the National Submodule. The feedback mechanism in the Interindustry Submodule is modeled in an analogous manner to the DRI-PCIO modeling mechanism.

The Interindustry Submodule contains detail for thirty-five regional industrial sectors and ten nonregional service outputs and develops projections for the period of 1990-2015. The Interindustry Submodule calculates deviations from a given baseline interindustry projection when macroeconomic final demands change. Because of the structure of input-output modeling, the Interindustry and National Submodules do not iterate directly with each other, but are instead 
processed sequentially. However, through their effect on the projections of the energy supply and demand submodules, which in turn alter the macroeconomic outlook, changes in interindustry projections affect the results of the National Submodule. The NEMS energy supply and demand modules determine the reaction of energy prices to changes in events and policies. These energy price effects are passed to the National Submodule and the economy reacts to the altered price paths. The altered macroeconomic final demands are in turn passed to the Interindustry Submodule, which calculates the effects on interindustry activity. The altered interindustry projections are then passed back to the other NEMS modules, and the system iterates until convergence is attained. Additional discussion of the inputs and outputs to the Interindustry Submodule is provided in Appendix A to this Volume.

\section{MAM Regional Submodule}

The Regional Submodule is a set of share parameters based upon simulations of the DRI U.S. Quarterly Macroeconomic Model, the DRI PCIO Model, and the DRI Regional Model. These share parameters are utilized to disaggregate some of the National and Interindustry forecasts to the nine Census Division level of detail. The shares vary across regions and over time through the forecast period.

The national level forecasts generated by the National and Interindustry Submodules are inputs to the Regional Submodule, and the aggregation of the regional totals produced by the Regional Submodule is identical to the national figures generated by the National and Interindustry Submodules. Therefore, to the extent that national output grows, regional output also grows. In addition, the results generated by the Regional Submodule are consistent with production in energy producing sectors and industrial energy prices generated by the NEMS system.

\section{Response Surface Modeling}

The use of response surface approximations, also known as reduced form equations, of the proprietary DRI models allows distribution of the MAM to users outside of EIA. The response surface approximations are constructed by estimating the large DRI models discussed above on 
"pseudo data" generated by repeated simulations of the DRI models (further discussed in Appendix $E$ to this report). The MAM response surfaces are generated from scenarios of the DRI models that primarily vary energy prices, since the goal of the MAM in NEMS is to provide energy price feedback to the NEMS system. The resulting changes to the macroeconomic variables of interest are recorded, and then each of these macroeconomic variables is regressed on all of the exogenous variables to obtain a single response surface equation for each dependent variable. The resulting response surface model is a macroeconomic feedback model that responds to changes in energy prices in a way that replicates the behavior of the much larger and more complex DRI models upon which the response surface is based:

\section{Archival Media}

MAM has been archived on a drive compatible IBM RS-6000 590 series, as part of the National Energy Modeling. System production runs that generate the AEO 1997.

\section{Model Contact}

Kay A. Smith, Economist

Office of Integrated Analysis and Forecasting

Energy Demand and Integration Division

Integrated Economic Intemational Forecasting Branch

\section{Telephone}

(202) 586-1455 


\section{Organization of this Report}

Section 2 of this report discusses the purpose of MAM, detailing its objectives, primary input and output variables, and the relationship of MAM to the other modules of the NEMS integrated system. Section 3 of the report describes the rationale behind the MAM design, providing insights into firther assumptions utilized in the model development process to this point. Section 3 also reviews alternate macroeconomic modeling methodologies drawn from the literature, providing a comparison to the MAM approach. Section 4 details the module structure, using graphics and text to illustrate model flows and key calculations.

The Appendices to this report provide supporting documentation for the MAM files currently residing on the EIA mainframe. Appendix A lists and defines the MAM input data, parameter estimates, forecast variables, and outputs. A table referencing the equation(s) in which each variable appears is also provided in Appendix A. Appendix B contains a mathematical description of the computational algorithms used in MAM, including equations and variable transformations. Appendix $C$ is a bibliography of reference materials used in the development process. Appendix D consists of a model abstract, and Appendix E discusses data quality and estimation methods. 


\section{Model Purpose}

\section{Model Objectives}

EIA is currently engaged in an extensive effort to enhance its ability to forecast and evaluate developments in world and domestic energy markets. NEMS, the result of this effort, is a comprehensive mid-term energy forecasting and policy analysis tool. NEMS projects energy supply, demand, prices, and environmental emissions, by region, given assumptions about the state of the economy, international markets, and energy policies. The MAM links NEMS to the rest of the economy by providing macroeconomic inputs and industrial sector activity to the energy modules of NEMS. Macroeconomic variables such as GDP, disposable income, prices, interest rates, and unemployment drive energy demands and are important determinants of energy prices and quantities. Similarly, changes in energy supplies and prices can affect GDP, prices, interest rates, and other macroeconomic variables. To capture these effects, NEMS allows for feedback to and from the maćroeconomy. For example, disposable income, mortgage interest rates, and housing starts are important determinants of the residential demand for energy. Disposable income and population over age 16 are relevant to forecasted fuel demands in the transportation sector. Forecasted levels and changes in industrial output are important determinants of industrial sector energy requirements.

The configuration of MAM is flexible. If an energy demand model is modified to require a new macroeconomic variable, MAM can be expanded to add the new driver, as long as the new variable is contained in the full DRI model. Currently, MAM forecasts over 180 macroeconomic variables, a subset of which are passed back to the NEMS data structure to be used by the energy demand models. The data base used to develop the MAM coefficients is available to the public from the Energy Information Administration. Additional information regarding this data base is obtainable from Dr. Kay Smith, Economist, Office of Integrated Analysis and Forecasting, Energy Demand and Integration Division, Integrated Economic International Forecasting Branch (see Model Contact discussion above). 


\section{Relationship of MAM to other NEMS Modules}

The National Submodule of MAM provides forecasts of variables used as inputs in other NEMS modules, including interest rates for residential and commercial consumers, final demands for goods and services, housing starts, commercial floorspace, and disposable income. The National Submodule is a national response surface approximation of the DRI U.S. Quarterly Model that relates percentage changes in macroeconomic variables to the changes in energy prices generated by the NEMS system, producing a percentage change from a DRI baseline forecast of productivity and labor force growth rates. The most important role of the National Submodule in NEMS is to capture the macroeconomic impacts of energy price change and energy tax feedbacks. Table A-2 of Appendix A to this report details the 109 outputs of the full-scale DRI U.S. Quarterly Model that are . used to develop the NEMS MAM National Submodule forecast. Table A-3 describes the forecasts provided by the Employment Submodule and Table A-4 provides the forecasts of the Interindustry Submodule. Appendix A, Tables A-5 through A-7 provide additional detail regarding the input and output variables used in the MAM.

The Interindustry Submodule of MAM calculates the industrial output needed to satisfy the final demands that are forecasted by the National Submodule. The outputs of the Interindustry Submodule, specifically the levels of industrial output, are used by the NEMS Industrial Sector Demand Module and Transportation Sector Demand Module to calculate energy consumption for each of these sectors.

Since the Residential, Commercial, Transportation, and Industrial Sector Demand Modules are regionally disaggregated, the MAM Regional Submodule allocates the subset of macroeconomic variables required by the energy demand and conversion modules to the nine Census Division level of detail. The subset of macroeconomic variables that are not required by the NEMS system are not regionally disaggregated. 
MAM receives energy prices from the Electricity Market Module, Natural Gas Supply Module, and Petroleum Market Modules of NEMS in order to calculate the energy price feedback to the macroeconomy. The calculated feedbacks are then translated into changes in the macroeconomic variables, which are then passed back to the NEMS system to be used in the demand modules as described above.

The NEMS demand modules and the primary macroeconomic outputs received by each module from MAM are summarized below. Variable names and descriptions as included in the MAM are provided in Appendix A to this report.

\section{NEMS Demand Sector Module}

Commercial

Industrial

Residential

Transportation

\section{MAM Outputs used by the Demand Module}

Commercial floorspace, 10 year Treasury bill interest rate

Industry-specific final demands

Housing starts, population

Disposable income, population over 16 years of age 


\section{Model Overview and Rationale}

\section{Theoretical Approach}

The version of MAM that is integrated into the NEMS system contains three response surface models of the DRI models. The National, Employment, and Interindustry Submodules of MAM are response surface models of DRI's U.S. Quarterly Model, Employment Model, and the PCIO Model. The regional results of the National Submodule are derived using simulations of a DRI Regional Model compatible with the other DRI models. The theoretical structure of the DRI models is described in the Alternative Approaches section of this Volume.

\section{Fundamental Assumptions}

\section{MAM National Submodule}

The National Submodule is able to address the macroconomic impacts associated with changing energy prices and alternative macroeconomic growth cases.

Energy Price Changes. Energy price changes represent a critical source of interaction between energy and the economy. Consumers facing higher prices for energy may reduce their energy consumption. Nonetheless, since a large component of energy expenditures is non-discretionary, nominal expenditures are likely to rise, comprising a larger share of the household budget. As a result, consumers are assumed to reduce expenditures on other goods and services.

Energy services also represent a key intermediate input in the production of goods and services. After energy prices increase, production costs rise per unit of output for firms. Reacting to higher prices in general, wages increase as consumers attempt to maintain real disposable income. Higher wage costs and spillover price effects on other variable costs further escalate production costs throughout the economy. This process places upward pressure on the nominal prices of all 
intermediate goods and final goods and services in the economy. As prices increase, so do interest rates. The increase in interest rates in turn causes reductions in interest-rate sensitive components of aggregate demand. Aggregate demand declines, leading to reductions in output as a result of rising energy prices.

In addition to the world oil price, the National Submodule receives information on the wholesale fuel prices for industrial coal, natural gas, refined products, and electricity, and final demand prices for fuel oil, coal, gasoline, electricity, and natural gas.

Alternative Economic Growth Rates. The growth potential of the economy is essentially grounded in the growth of the factors of production - labor, capital, and energy - and the aggregate productivity of these factors. Three altemative growth trajectories for the economy exist in the National Submodule: baseline, high, and low growth.

\section{MAM Employment Submodule}

The Employment Submodule calculates the employment impacts of altered energy market conditions based on the following causal relationships. When energy prices change, the level and composition of macroeconomic final demands are affected. In turn, the level and composition of interindustry gross outputs required to satisfy the new final demands are changed. Finally, faced with new demands for their products, industries will adjust the number of workers employed. The response surface Employment Submodule represents this last link in the chain.

The Employment Submodule projects national level employment for twenty manufacturing industries (the twenty two-digit SIC categories within manufacturing), as well as for ten more aggregated sectors outside manufacturing, annually for the period 1990-2015 (Table 1). The summation of sectors two through thity gives total non-agricultural employment (EEA). 
Table 1. Variables Projected by the Employment Submodule

\begin{tabular}{|c|c|}
\hline Varible Name & Description \\
\hline EEA & Total Non-Agricultural Employment \\
\hline EC & Construction Employment \\
\hline EGF & Federal Government Employment \\
\hline EFIR & Finance, Insurance, and Real Estate Employment \\
\hline EMI & Mining Employment \\
\hline ESV & Services Employment \\
\hline EGSL & State \& Locai Government Employment \\
\hline ER & Truasportation, Communications, \& Public Utilities Employment \\
\hline ETR & Retail Trade Employment \\
\hline ETW & Wholesale Trade Employment \\
\hline E24 & Lumber \& Wood Products Employment \\
\hline E25 & Furniture \& Fixtures Employment \\
\hline E32 & Stone, Clay, \& Glass Employment \\
\hline E33 - & Primary Metals Employment \\
\hline E34 & Fabricated Metal Products Employment \\
\hline E35 & Machinery (except Electrical) Employment \\
\hline E36 & Electrical Machinery Employment \\
\hline E37 & Transportation Equipment Employment \\
\hline E38 & Instruments Employment \\
\hline E39 & Miscellaneous Manufacturing Employment \\
\hline E20 & Food \& Prớducts Employment \\
\hline E21 & Tobacco Manufactures Employment \\
\hline E22 & Textile Mill Products Employment \\
\hline E23 & Apparel \& Other Textile Products Employment \\
\hline E26, & Paper \& Products Employment: \\
\hline E27. & Printing \& Publishing Employment \\
\hline E28 & Chemicals \& Allied Products Employment \\
\hline E29 & Petroleum Products Employment \\
\hline Eso & Rubber \& Miscellaneous Products Employment \\
\hline E31 & Leather \& Products Employment \\
\hline EAG & Agricultural Employment \\
\hline
\end{tabular}




\section{MAM Interindustry Submodule}

As described previously in this report, consistency between the National and Interindustry Submodules is critical to ensuring meaningful macroeconomic and interindustry results. The DRI Model on which the response surface Interindustry Submodule is based, DRT's PCIO, is a standard input-output model. DRIs PCIO takes as inputs final demand components from the DRI U.S. Quarterly Model and determines the level of interindustry activity. The MAM National and Interindustry Submodules are joined similarly, with the main difference that changes in interindustry activity are determined by changes in final demand components in MAM.

This type of input-output model represents a top-down approach to interindustry modeling. Aggregate demand, in the form of the final demand components, is calculated first by the macroeconomic module, and is used in determining the detailed output required of the interindustry sectors to achieve this level of aggregate demand. The disaggregation can be made along several lines which have theoretical appeal: homogeneity of product, homogeneity of process, homogeneity of energy service, etc. From a practical standpoint however, the choice of disaggregation is limited by the availability of data. The input-output model is disaggregated into 114 output sectors. The output groupings are listed in Table 2. The Industrial Sector Demand Module does not require this level of detail. Therefore, interindustry projections provided to the NEMS system are an aggregation of the input-output sectors to the level requested by the Industrial Sector Demand Module. Because of the structure of the input-output model, and of input-output modeling in general, it is not necessary to directly link the full DRI-PCIO model with NEMS in order to capture meaningful changes in interindustry activity. 
Table 2. Output Groupings within full DRI-PCIO Model

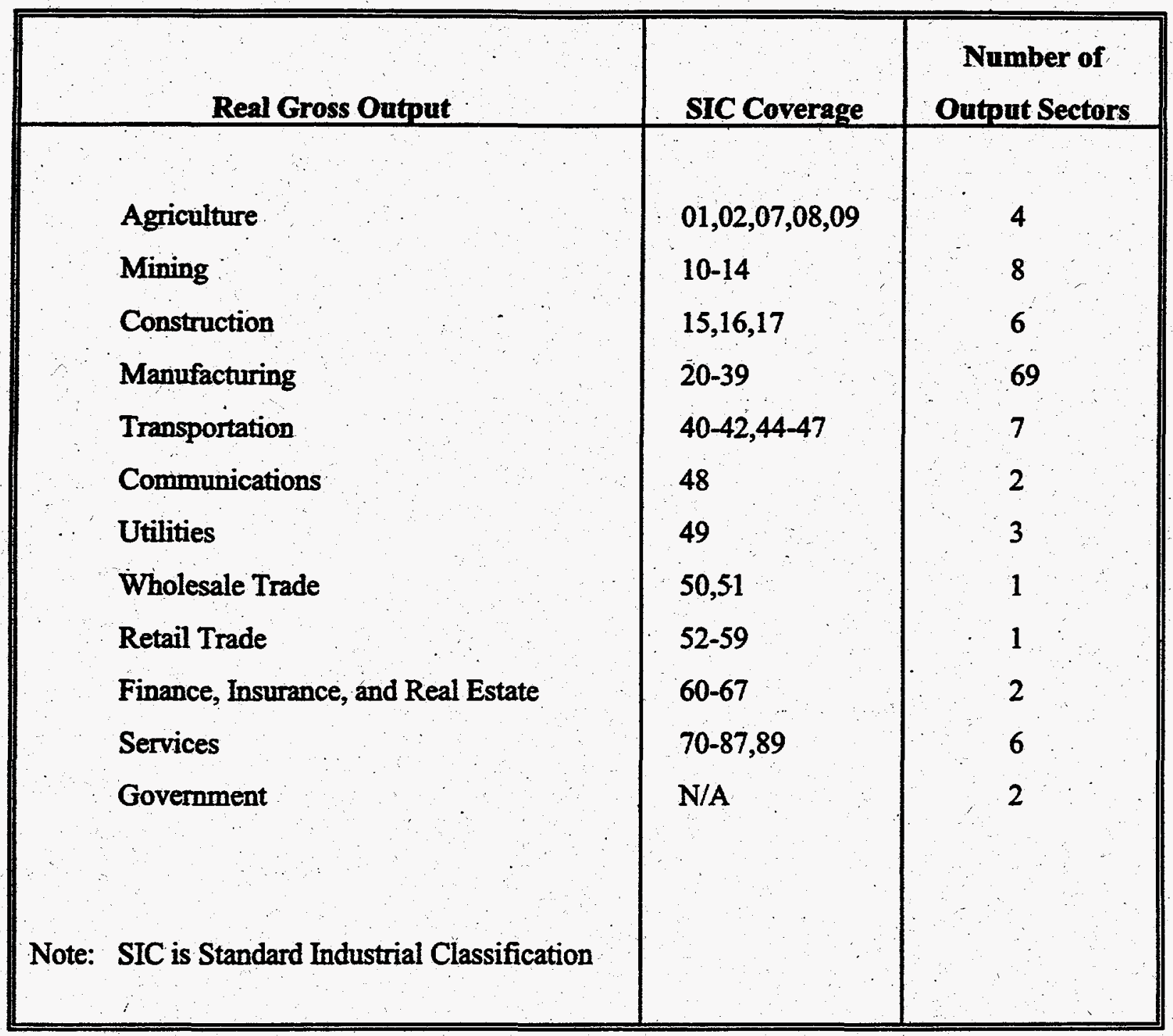

\section{MAM Regiona/ Submodule}

The MAM Regional Submodule models economic activity at the nine Census Division level of detail by applying share factors to the National and Interindustry Submodule forecasts of economic activity. The aggregation of the regional forecasts produced by the Regional Submodule is identical to the National and Interindustry Submodule forecasts. As the national economy expands over forecast period, the regional results reflect this expansion. The Regional Submodule is also consistent with 
production in energy producing sectors and the regional energy prices generated by the NEMS system.

Some limitations to the Regional Submodule exist. Regional variations in capital costs are not generated, and all regions are assumed to react to the same national set of interest rates. Technology change influences total factor productivity, and is captured through the derivation of potential GDP at the national level only. However, the various energy modules within NEMS capture the entry of new technology at the regional level. Last, MAM addresses only national decisions on fiscal policy through the National Submodule. State tax policy, such as a change in state gasoline taxes, is not directly considered.

\section{The Role of Uncertainty in Model Design}

As discussed previously, MAM utilizes response surface approximations of the DRI U.S. Quarterly Macroeconomic Model and the DRI PCIO Model. The uncertainty issues underlying the full DRI models; and therefore, the MAM response surface approximations, are not addressed in this report, but are topics for DRI's documentation of the U.S. Quarterly and PCIO Models.

\section{Response Surface Modeling}

The response surface approach adopted for the NEMS MAM utilizes assumptions regarding the choice of input variables, the regression methodology, and the choice of lag structures and terms in the regression equations. The input variables used to develop the regression coefficients that characterize the NEMS MAM are documented in Appendix $E$ to this report. These variables are drawn from the DRI full-scale model approach, which is further discussed and compared to MAM in the next section of this report. The regressions utilized to develop the MAM are linear, and include lagged terms as presented in Appendix $\mathrm{E}$ to this report. As in the case of the input variables, the regression structure draws upon the approach used in the DRI full-scale models. Additional support for these assumptions is a topic for DRIs documentation of the full-scale models. 


\section{Alternative Macroeconomic Modeling Approaches and Reasons for Selection}

\section{National Submodule}

This section identifies and critically discusses alternative macroeconomic and interindustry modeling approaches. The discussion first treats the most widely used large macroeconomic models. Small structural macroeconomic models are next reviewed as possible alternatives to the chosen response surface approach. General equilibrium models that focus on the long-run growth path of the economy are then addressed. A discussion of input-output based macroeconomic models that attempt to bridge between the large macroeconomic models and the general equilibrium approaches is provided next. Last, vector autoregressive models are explored.

Large Macroeconomic Models. DRI, The WEFA Group, and other macroeconomic forecasters produce large econometric models of the U.S. economy. The DRI model has been used at EIA for many years. A large macroeconomic model such as the DRI model has the advantage of sufficient detail that it is likely to be able to address the majority of requested analyses. Such models also have large staffs devoted to the maintenance and improvement of the model and the provision of base case forecasts.

The DRI Quarterly model is composed of 1200 equations.' It provides detail on final demands, aggregate supply, prices, incomes, interest rates, industrial production, and U.S. trade flows. The DRI model incorporates short-term specification of financial conditions, output, and prices into a long-term growth model. The level of inflation-adjusted demand is driven by prices, income, wealth, expectations, and financial conditions. The capacity to supply goods and services is keyed to a production function combining the basic inputs of labor, capital, and energy. Prices adjust when there is excess demand or supply or when the prices of inputs change.

Brinner, Roger E. "Philosophy and Properties of the DRI Model of the U.S. Economy." Quarterlv Model of the U.S. Fconomy: Version US89A, March 1990. 
The DRI Quarterly Model excels at short-rin and mid-term analyses and forecasts and does reasonably well in long term analyses through the potential GDP equation and its components. It is extremely useful in the assessment of the time-profile of the adjustment path over the 5 to 20 year horizon. The DRI model is capable of analyzing the effects of energy or goods price changes, or any policy having only direct price effects, such as energy taxes. It is also able to differentiate estimates of both short-run and long-rin adjustment costs, with the long-run being dependent on their depiction of one long-term aggregate production function.

The types of analysis in which the DRI model is suboptimal include the effects of incorporation of specific types of energy technology changes and the issue of efficiency in energy use. DRI includes energy use as part of its long-run production function. However, the long-term general equilibrium constraints imposed in the model are weak.

There is also a fundamental inconsistency in the use of any of these models as a part of NEMS. Since NEMS focuses primarily on energy, the system objective of MAM, as one of twelve modules in NEMS, is to provide the feedbacks between the energy markets and the rest of the economy. Large macroeconomic models are designed as stand alone models, and therefore typically possess detailed energy sectors within their own structure. Consequently, use of these large models implies the use of two energy models: EIA's and the energy sector in the macroeconomic model. These two energy models may not be consistent.

A second alternative is to utilize a large macroeconomic model and replace its energy sector representation with a set of equations that replicate NEMS behavior for the energy sector. In one mode, the macroeconomic model's energy equations are disabled and simply pass through unaltered the energy price and quantity calculated from the other NEMS components. In another mode, the macroeconomic model energy equations are run separately from the energy model if standalone macro simulations are appropriate. It must be recognized, however, that stripping out the energy sector of a macro model is not trivial and may significantly alter the behavior of the remaining equations. 
Small Macroeconomic Models. One alternative to a large macro model is a small model tailored precisely to the needs of the NEMS system. A small model has the advantages of ease of development and maintenance. However, one problem with this approach, and any approach in which an independent macroeconomic model is developed, is lack of support for the provision of base case forecasts and resource costs needed to develop a macroeconomic model.

The lack of detail in a small macroeconomic model is also of potential concern. A small model may. not provide sufficient detail to execute all scenarios that a large model is able to address. Also, small models suffer from the criticism that important linkages are necessarily omitted in their design. Small models also have the potential to grow into large models, since adding a new variable required by a demand module may involve creating one or more sectors of the model consisting of several additional equations. The result may be a much larger model than originally intended with attendant increases in the time and resource costs of maintenance.

General Equilibrium Models. The fundamental theme of the general equilibrium model is that the production side of the economy (the transformation of commodities into other commodities) is distinguished from the consumption side (the acquisition and eventual consumption of goods and services). The two are then linked to provide a simultaneous determination of equilibrium balances between the production and consumption sides of the economy. ${ }^{2}$

Stocks of commodities, which may be consumed directly, maintained as inventories or offered as factors of production, are owned by households in their physical form or by means of a variety of

2. Much of the general equilibrium analysis draws heavily from the following sources: Applied General Equilibrium Analysis by Herbert Scarf and John Shoven, Cambridge University Press, 1984 and Dale Jorgenson and Peter Wilcoxen, "Environmental Regulation and U.S. Economic Growth", Energy and Environmental Policy Center Discussion Paper, November 1989. 
financial instruments. Each consumer's income, or wealth, is determined by evaluating the consumer's stock of commodities in terms of those prices at which the commodities can be sold. Income and a knowledge of relative prices permit the consumer to express demands for goods and services and supply of labor that are made available for the productive side of the economy.

In the general equilibrium model, producers are assumed to be informed of the prices of all inputs and the prices at which outputs can be sold. These prices are taken to be independent of the scale and composition of productive activity; each producer then selects, from the technically available choices, the production plan that maximizes profits. The general equilibrium model explicitly addresses the substitutability of factors of production (or consumption) by either incorporating separate translog production functions (such as Jorgenson's DGEM model ${ }^{3}$ ) or CES functions for each industry and then obtaining the aggregate production.

A standard procedure has evolved among general equilibrium modelers to calibrate the whole model to a benchmark observation coupled with use of literature estimates for certain key parameters, particularly elasticities: A sequence of data adjustments is frequently used to force equilibrium conditions on observed data before calibration begins. With these adjustments in mind, no test of the model to data is employed, and sensitivity analysis is widely used for parameters whose values are uncertain and/or crucial to the results.

The assumption of an "observable" equilibrium leads directly to the construction of a data set that fulfills the equilibrium conditions for some form of general equilibrium models. A benchmark equilibrium data set is a collection of data in which equilibrium conditions of an assumed underlying equilibrium model are satisfied. If equilibrium is reflected, demands equal market supplies for all commodities and supplies ańd demands can be separately disaggregated by agent. Four sets of equilibrium conditions satisfied by most of the constructed benchmark equilibrium data sets are: (1)

3. Dale Jorgenson and Peter Wilcoxen, "Environmental Regulation and U.S. Economic Growth," Energy and Environmental Policy Center Discussion Paper, November 1989. 
Demands equal supplies for all commodities; (2) Nonpositive profits are made in all industries; (3) All domestic agents (including the government) have demands that satisfy their budget constraints; and (4) The economy is in zero external sector balance.

These conditions are not all satisfied in input-output or other national income account data. In constructing benchmark data sets, various adjustments are necessary to the blocks of data involved and the nature of these adjustments varies from case to case as alternate sets of benchmark accounts are constructed to fit differing models. The data usually refer to a single year, although some averaging across years is done in constructing portions of those data sets where substantial volatility occurs.

Although most general equilibrium models use literature estimates of crucial elasticities, Jorgenson's model uses econometrically estimated values of these elasticities. The endogenous variables in his model of producer behavior are the value shares of sectoral inputs for the four commodity groups. There are 14 unknown parameters for each industry. These parameters are estimated using data from 1974-1985 for each industry, subject to restrictions implied by the monotonicity of the input value shares. Some authors have argued that there is an hierarchy of submodels, and that the number of restrictions required to estimate the parameters for each industry may present interpretational problems. ${ }^{4}$

In addition, the general equilibrium models are full employment models. These models cannot calculate disequilibrium costs since the models describe equilibrium points. Factors of production are treated as perfectly mobile between altermative uses and the allocation of factors by industry in equilibrium equalize the returns received net of taxes and gross of subsidies in all industries. The models solve for a steady-state equilibrium, but ignore the path of adjustment.

4. See Chapter 3, "Numerical Specification of Applied General Equilibrium Models: Estimation, Calibration, and Data," written by Mansur and Whalley in the Scarf and Shoven book. 
Much of the policy analysis that the macroeconomic models analyze implies some calculation of the adjustment costs. Some authors have argued that the general equilibrium model results show relatively rapid change in capital stock in the face of a price change. Additionally, neither the financial nor the international sectors are fully modeled and the working assumption is that all private and public agents are bound by the budget constraint. ${ }^{5}$

The difficulty in incorporating system energy price and quantity results is a significant drawback to incorporating a general equilibrium macroeconomic model for NEMS, because estimates of energy's substitutability in the production functions and the consumer choice equations are implicit in the general equilibrium component.

A more fundamental problem with general equilibrium models is that their scope is far beyond that of macroeconomic analysis; they embody a fully developed energy-economy feedback mechanism. As such, general equilibrium models have even more fully developed energy sectors than the large macroeconomic models and are capable of substituting for the entire NEMS system. It would be extremely difficult to strip out the energy sector from a general equilibrium model and make it exogenous. Also, because general equilibrium models are academic rather than commercial tools, it is not clear that support is available for provision of base case forecasts.

General equilibrium models have the advantage that they explicitly incorporate general equilibrium constraints, are based on optimizing behavior on the part of economic agents, and have a considerable amount of detail for investment decisions. The latter point makes these models particularly well equipped to analyze the capital costs of environmental policies and the introduction of new technologies. The inability to address the path of adjustment is a problem. They are therefore of little use in answering questions concerning the short-run disequilibrium costs associated

3. See the preface of the Scarf and Shoven book for a good description of the advantages and disadvantages to general equilibrium modeling. See also John Shoven and John Whalley, "Applied General-Equilibrium Models of Taxation and International Trade: An Introduction and Survey," in the Joumal of Economic Literature, Vol. XXXI, September 1984, pp. 1007-1051. 
with energy taxes, although they are well equipped to predict long-term impacts.

Input-Output Based Macro Models. The LIFT (Long-term Interindustry Forecasting Tool) available from INFORUM at the University of Maryland is a large macroeconomic model based on a 78-sector input-output model..$^{6}$. The advantage of this approach is that, like the DGEM model, the computable general equilibrium constraints imposed by theory are maintained by the model so that the model is theoretically satisfying. The bottom up approach to modeling is ideal for analyses of technology, productivity change and capital costs.

LIFT is a blend of the econometrically estimated equations coupled with the general equilibrium emphasis on building a model of the aggregate economy based on producer and consumer decisions. While conforming to these equilibrium conditions, the model forecasts the path to the equilibrium. Final demands are determined by behavioral equations, which were estimated with econometric techniques. These categories are based on the National Income and Product Accounts (NIPA). It uses input-output coefficients that change over time to calculate industrial output.

LIFT consists of three general blocks. The first block calculates output for 78 industrial sectors, using dynamic input-output coefficients. The second part of the model is the price block, which calculates factor income, by estimating the components of gross product originating by industry (value-added) and unit prices by product. The final component is what Inforum refers to as the accountant. This is the part of the model that insures that the aggregations of individual components are calculated, and is concerned with macroeconomic variables that are not industry-specific, such as the savings rate, interest rates, government sector, and the unemployment rate.

The LIFT analysis draws heavily from the following sources: "The INFORUM Approach to Interindustry Modeling" by Clopper Almon and "LIFT: INFORUM's Model of the U.S. Economy" by Margaret Buckler McCarthy. Both articles are contained in special issue of Economics Systems Research. Vol. 3, No. 1, 1991. 
Personal consumption expenditure (PCE) equations have been estimated for the categories corresponding to the NIPA. The PCE equations are derived from a two-stage estimation procedure. First, from cross-sectional data, parameters are estimated for the level and distribution of consumption expenditures by income size class, the age structure, and other demographic characteristics. Second, the cross sectional estimates are combined with time series data to estimate parameters for relative prices, changes in income, and trends. Total consumption is disposable income less savings.

A strength of the model lies in its treatment of investment decisions. Investment consists of equipment, construction, and inventory change, corresponding to the NIPA. The level of disaggregation available in the model is a distinguishing feature. Equipment investment equations have been estimated for approximately 50 industries. Investment depends on changes in industry. output and changes in the relative prices of capital, labor, and energy, with a lag of 5 years. Construction is determined for approximately 30 categories of structures. The private residential categories depend upon consumption or income, interest rates, stocks, and demographic data. The private non-residential categories depend upon industry outputs, interest rates, and stocks.

The input-output model determines the unit prices for the 78 products by solving the dual pair of equations. The real side of the model is in terms of products. Income is defined in terms of industries. This portion of the model contains a bridge that translates value added between its product and industry classification. In the equation formulation, there are variables that capture the tightness of the economy in determining prices and incomes.

The model derives aggregated totals consistent with the detailed information contained in the other two components concerning production techniques and consumption equations. It also consists of macroeconomic variables that are not industry-specific yet are needed in order to arrive at industry totals. Examples of such variables include the government sector, interest rates, unemployment rates, and the savings function. 
The LIFT model derives aggregate totals of final demands based on a detailed specification of industrial output. In addition, investment categories are analyzed in terms of the 78 industrial sectors, so capital stock changes reflect detailed investment specifications. Third, LIFT is capable of addressing income distributional effects as the consumption equations are estimated with data from 20 income groups, aggregated in the model to five income classes.

The LIFT model, having large amounts of detailed sectoral information, requires more analysis of both inputs and model results. The complexity and integrated.aspects of LIFT increase the challenge and time required to identify and analyze the contributing factors underlying anomalous results obtained from a model run.

The model contains an accounting system that considers both income and price effects, with a complete representation of both the production and consumption sides of the economy. In this respect, the model resembles the general equilibrium models. Unlike general equilibrium models, LIFT does not focus on the derivation of the steady state equilibrium, but instead on the path to reach the equilibrium. The model is explicit in the treatment of investment, and capital cost effects when energy prices change are better handled in these models. However, the ease of use and the relative simplicity of calculating energy price feedback effects may be sacrificed.

Vector Autoregressive Models. VAR models are pure time series models estimated on historical data. The approach is non-theoretic in that the theoretical linkages between variables (the model structure) are ignored. The model is entirely specified by the length of lags and the endogenous variables. For example, if five endogenous variables are to be forecasted, then there are five equations in the model and each equation contains the lags of the dependent variable and lags of all of the other endogenous variables. If the lag length is one, then each of the five equations would contain five lagged variables. If the lag length is two, then each equation would have ten arguments, etc. 
Ease of model development is the primary advantage of the VAR approach. Implementation requires only the list of variables to be predicted and the correct lag length. One drawback to VAR models is their tendency to become cumbersome as the number of variables increases, since the lag terms required for this approach impact the degrees of freedom and result in potential collinearity issues. In addition, it is difficult to specify the correct lag length, since too many lags implies inefficiency while too few implies omitted variable bias. Imposing a priori constraints is difficult in that there is little guidance from theory and the behavior of the model is fundamentally altered with each constraint.

Another consideration with this approach is that VAR models are fundamentally altered whenever an equation is added or removed. If a sixth variable is added to the original five equation model, the model behavior is likely to change. This feature is a source of instability and unreliability as the model develops. Finally, it is difficult to imagine the ability of a VAR model to address the analysis of a gasoline tax with revenue neutrality.

Comparison of approaches. The time period of the forecast varies among the model approaches reviewed. The DGEM currently extends the furthest to 2050 , while the DRI model forecasts to the year 2020 and LIFT goes to 2015. The theoretical underpinnings of each approach differ, and impact the level of support for long-run analysis. Accordingly, the applicability of a functional form is partly dependent upon the forecast horizon.

Most large scale macroeconomic models such as DRI and WEFA are essentially demand-driven and contain key equations to address the aggregate supply curve of the economy. In the short and midrun, this structure may be the most desirable depiction of the economy. The DRI and WEFA models are capable of extension to the year 2030 , but this strains the credibility of a quarterly model. The theoretical structure of the LIFT model lends itself to extension to the year 2030, but the model is data intensive and the extension challenging and difficult to support. DGEM exclusively focuses on the long-term. 
The path of adjustment to the new equilibrium is an important component of the modeling system. The general equilibrium approach addresses the supply and demand of each industrial sector and consumer group assuming no short-run dislocation costs in getting from one equilibrium position to another. These models are capable of comparing two steady-state situations, where all factors are fully employed, as compared to explicit modeling of dislocation costs. . .

Large macroeconomic models, such as those developed by DRI and WEFA, are strongest in evaluating short to mid-term changes in aggregate demand, as opposed to detailed sectoral demands. These models incorporate aggregate supply constraints, but not at the sectoral level of detail. Consequently, aggregate supply is determined by a single production function driven by labor supply, the aggregate capital stock, energy, and a technology trend. This results in a weak treatment of the sectoral tradeoffs among capital, labor, energy, and other materials. This lack of detail fundamentally weakens the large models' ability to address long-run issues.

The LIFT model represents an effort to blend explicit treatment of the adjustment path into a longnun general equilibrium view of growth. LIFT represents both the production and demand sides of the model, incorporating detailed industrial and investment detail.

All three modeling systems provide extensive industrial detail, but differ fundamentally in the industrial structure development. The DRI approach is top-down, responding to the question "what is the level of industrial output needed to satisfy a given level of final demand?" The DGEM and LIFT approaches both are bottom-up. The industrial outputs are integral to the determination of the level of the aggregate economy. Conceptually, the bottom-up view of the economy is more appealing, but the models relying on this view are typically larger and more complex to understand and operate. 


\section{Employment Submodule}

Maintaining consistency between the Interindustry and Employment Submodules is critical to ensuring meaningful interindustry and employment results. The DRI Econometric Model of Employment by Industry, on which the response surface Employment Submodule is based, uses interindustry gross output from DRIs Personal Computer Input-Output (PCIO) Model $^{8}$ as its major imput when determining employment. Final demand components are used to calculate interindustry gross outputs, which in turn are used to determine employment.

The DRI Econometric Model of Employment by Industry provides the baseline employment projections for use within MAM. It is linked to forecasts of real Industry output produced by PCIO, and to aggregate macroeconomic variables from the U.S. Quarterly Model. Employment for each sector is derived as labor hours divided by the average number of hours worked per employee:

$$
\text { Employment }=\text { (LaborHours) / (Hours Worked per Employee) }
$$

Labor hours are calculated as:

$$
\text { LaborHours }=\text { (Realoutput) / (Hourly Output per Employee) }
$$

Real output for each industry is an exogenous input passed from the PCIO model. Hourly output per employee (productivity) is the ratio of total output from an industry to the total labor hours required to produce the output. Explanatory variables for labor hours by industry include:

${ }^{7}$ DRI/MeGraw-Hill, An Econometric Model of Employment by Industry, (Lexington, MA, May 1994).

${ }^{8}$ DRIMCGraw-Hill, Description and User Guide for PCIO, the ELA Input-Output Model for the IBM PC, (Washington, DC, August 1990). 
- year-over-year change in output

- ratio of wages to product prices

- ratio of wages to capital costs

- aggregate sector productivity

- exogenous shifts, represented by time trends

Explanatory variables for hours worked per employee (average hours) include:

- year-over-year change in employee hours.

- ratio of actual to potential output

- aggregate hours per week

- ratio of non-wage compensation

The sectoring chosen for the Employment Submodule is based on that used for the Interindustry Submodule, but is somewhat less disaggregated for two reasons. The first is that the raw employment data upon which the structural model was based did not allow for some of the industry disaggregations supported by the gross output data. The second is that some of the manufacturing sectors maintained in the Interindustry Submodule are large in terms of energy use, but small in terms of employment. In these cases, the energy-intensive three- and four-digit SIC manufacturing sectors are combined to the two-digit level in the Employment Submodule. 


\section{Interindustry Submodule}

The modeling methodology for industrial activity is linked directly with the choice of the model used for the national economy. Issues introduced in the previous section describing alternative national economic modeling approaches apply to modeling industrial activity as well. The discussion of LIFT and the general equilibrium models are examples of embedded industrial modeling within a national framework. The Industrial Submodule must model industrial activity to support the Industrial Energy Demand Model, as well as other energy modules in NEMS. The choice of which industrial activity model to use as part if MAM depends on several criteria. First, is the industrial model consistent with the National Submodule? Second, does the industrial model forecast output for the energy consuming industries in the detail required by the Industrial Energy Demand Module? Third, is the industrial activity model flexible enough to handle possible future changes in industrial aggregation needed by other NEMS energy modules?

Using an input-output model directly linked to the macroeconomic model which estimates national economic impacts satisfies all of these criteria needed for the Industrial Submodule of MAM. The following section describes input-output modeling in general, along with the extensions to standard input-output analysis that makes the input-output model used by MAM more flexible.

Input-output analysis was developed by Wassily Leontief in the late 1930s to determine the level of output that each of the $\boldsymbol{n}$ industries in an economy must produce in order to just satisfy the total demand for each product, with no shortages or surpluses. A representative equation of this model (for interindustry sector 1 ) can be expressed as:

$$
x_{1}=a_{11} x_{1}+a_{12} x_{2}+\cdots+a_{12} x_{n}+a_{1}
$$

where

$$
\begin{aligned}
& \text { is output from industry } 1, \\
& \text { NEMS Macroeconomic Activity Module Documentation Report }
\end{aligned}
$$




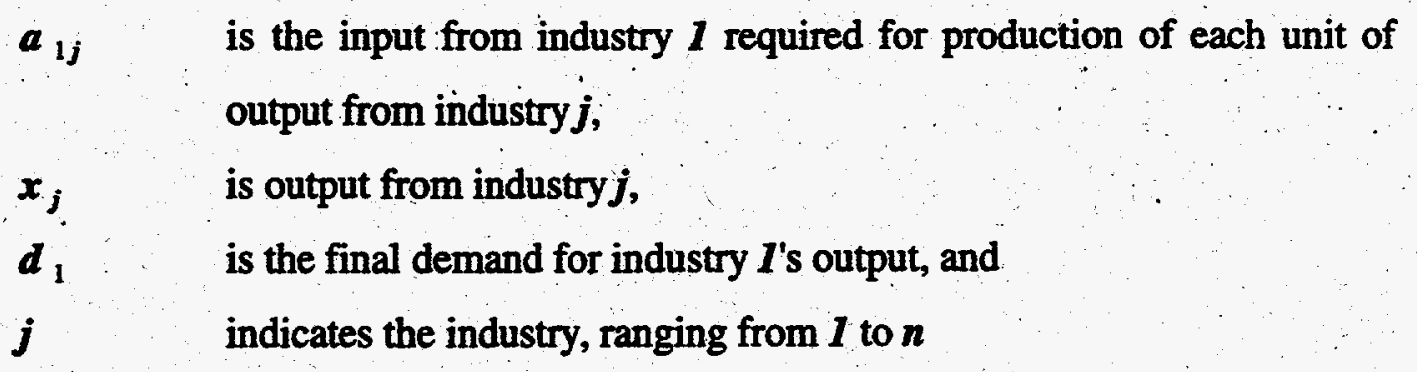

Rearranging terms in the above equation gives:

$$
\left(1-a_{11}\right) x_{1}-a_{12} x_{2}-\ldots-a_{1 n} x_{n}=d_{1}
$$

The variables representing output of every sector within the economy $\left(x_{i} s\right)$ appear on the left side of equation (5). A similar equation is constructed to represent the output of each industrial sector. The system of equations for the entire economy then consists of a square matrix of dimension $\boldsymbol{n}$ whose elements are all $-a_{i j}$ except for those which lie along the principal diagonal of the matrix, which are $\left(1-a_{n k}\right)$, multiplied by the column vector of variables that represent each industry's output, and equated to the column vector of final demands. Switching to matrix notation for brevity, the system can be expressed as:

$$
(I-A) * x=d
$$

where

$$
\begin{array}{ll}
I & \text { is the } n \times n \text { identity matrix, } \\
A & \text { is the } n \times n \text { input coefficient matrix, } \\
x & \text { is the } n \times 1 \text { variable vector, } \\
d & \text { is the } n \times 1 \text { final demand vector, and } \\
n & \text { is the number of industrial sectors }
\end{array}
$$


The matrix $(I-A)$ is called the technology matrix. In order to solve the above system for interindustry activity, the matrix $(I-A)$ must be inverted, which is possible as long as $(I-A)$ is nonsingular. Premultiplying both sides by $(I-A)^{-1}$ gives:

$$
\bar{x}=(I-A)^{-1} * d
$$

where

$$
\begin{array}{ll}
x & \text { is the column vector of computed output, } \\
(I-A)^{-1} & \text { is the inverse of the technology matrix, and } \\
d & \text { is the column vector of final demand }
\end{array}
$$

The model given by equation (7) translates final demand by industrial sector into total output by each sector. However, the Nationai Submodule provides final demands by macroeconomic concepts. These macroeconomic final demands must be passed through a bridge matrix that translates them into the form required by the input-output model.

The model described to this point is a static model. Because the technology matrix is fixed in the model described to this point, a specific level of final demand in one category requires the same level and proportions of output from all interindustry sectors, regardless of the year to which the forecast pertains. This is an unduly restrictive and unrealistic assumption for the purposes of long-term forecasting, especially given the long delays accompanying release of input-output benchmark tables and updates. In order to provide a more reasonable forecast, DRI employs two methods within the model that introduce temporal change to the interindustry forecasts. The first uses a unique bridge matrix for each year of the forecast (through 2015). The second applies row-scalars to the 
technology matrix.

The purpose of the bridge matrix is to allocate final demand by macroeconomic concept to those industries which produce the final products. By using a unique bridge matrix for each year of the forecast period, a given level of macroeconomic final demand does not translate into the same levels of final demand broken out by industrial sectors for each year. How the bridge matrix allocates final demand across a number of industrial sectors can be illustrated by looking at the final demand component Non-Residential Producers' Durable Equipment - Other (excludes Automobiles and Office \& Computing Equipment). Within the DRI model, final demand in this category is allocated across 47 of the 114 industrial sectors, including: Farm \& Garden Machinery; Construction \& Mining Machinery; Metalworking Machinery \& Equipment; Electrical Machinery; and Radio, TV and Communications Equipment. Because the bridge matrix simply translates final demand by macroeconomic concepts into final demand by industrial sectors, each column of the bridge matrix must sum to 1.0. Therefore, a unique bridge matrix for each year indicates that the interindustry mix of final products required to satisfy a given level of macroeconomic final demand changes over time. As an illustration of a changing bridge matrix it may be that in the future more Electrical Machinery and less Farm \& Garden Machinery is required to satisfy a given level of Non-Residential Producers' Durable Equipment - Other macroeconomic final demand. In this case the Electrical Machinery coefficient within the Non-Residential Producers' Durable Equipment - Other bridge matrix column rises while that for Farm \& Garden Machinery falls. The full DRI-PCIO Model develops projections through a logistic time trend, which is adjusted using recent historical values corresponding to the model components.

The second method of introducing change, applying row-scalars to the technology matrix, has a different intent and a different effect. A row-scalar is a number that changes over time, and is used to multiply all elements in one row of the direct requirements matrix. The row scalars introduce general trends in technical requirements to the input-output modeling framework, but should not be construed as a method for representing specific technological changes within industry. Since each row of coefficients in the matrix represents the usage of that industry as an input into all other 
industries, the row scalar multiplies the proportion of input usage into all other industries by the same factor for each year. This does not allow for cell-by-cell adjustment of the technical coefficients. The historical row scalars are reconciling terms. Actual historical final demand is provided to the static input-output model. If the resulting computed output exceeds the actual output for a given industry, the row scalar for that industry and that year is less than one. If the computed output is less than the actual output for a given industry, the row scalar for that industry and that year is greater than one. Making this comparison for all industries results in time-series of row scalars over the historical period. Regression on these historical row scalar time-series results in forecasted annual row scalars for each industry through the year 2020. These forecasted row scalars are then analyzed and adjusted if the historical trends are not expected to continue in the future.

The final model, including the bridge matrix and row scalars, is:

$$
\overline{x_{i, t}}=\left[I-\left(A_{i j} \times r s_{i 1, t}\right)\right]^{-1} *\left(B_{i k, t} * d_{k 1, t}\right)
$$

where

$$
\begin{aligned}
& \bar{x} \quad \text { is the column vector of computed output, } \\
& I \quad \text { is the } \boldsymbol{n} \boldsymbol{x} \boldsymbol{n} \text { identity matrix, } \\
& A \text { is the } \boldsymbol{n} \boldsymbol{x} \boldsymbol{n} \text { direct requirements matrix, } \\
& r_{1} \text { is the column vector of row scalars for year } t \text {, } \\
& B, \quad \text { is the bridge matrix for year } t \text {, } \\
& \text { d is the column vector of final demand for year } t \text {, } \\
& i, j \text { is the interindustry sector, ranging from } I \text { to } n \text {, and } \\
& k \text { is the final demand component, ranging from } 1 \text { to } m
\end{aligned}
$$


The full DRI model does not calculate the Leontief inverse matrix $\left((I-A)^{-1}\right)$ when computing a solution. Instead, an iterative technique is used because it is computationally simpler than calculating the inverse matrix for each year of the forecast; and it provides a close approximation to the actual Leontief inverse matrix. The technique is based on the identity:

$$
(I-A)^{-1}=I+A+A^{2}+A^{3}+A^{4}+\cdots
$$

where

$$
\begin{aligned}
& I \text { is the identity matrix, and } \\
& \text { is the direct requirements matrix, with each component } \\
& a_{i j} \text { showing the proportion of good } i \text { used in the } \\
& \text { production of good } j
\end{aligned}
$$

Intuitively, this identity expresses the multiplier impact of a change in final demands. The total requirements resulting from a given level of final demand $(I-A)^{-1}$ equals the direct impact $I$, plus the first round input requirements of the direct impact $A$, plus the second round input requirements resulting from the first round $A^{2}$, all the way through the $n$th round when the process converges. Usually about eight to ten iterations are required for convergence with the current approach.

The Interindustry Submodule structure in MAM is grounded in the classical approach to I-O modeling. Alternative I-O modeling approaches build upon the framework presented by Leontief and described above, but the foundation is structurally similar for this class of model.

9 See Chiang, Eundamental Methods of Mathematical Economics. Third Edition, pp.120-122 for a discussion of approximating an inverse matrix in the context of input-output modeling.

Energy Information Administration NEMS Macroeconomic Activity Module Documentation Report 


\section{MAM Regional Submodule}

Regional models generally fall into three broad classes: top-down models, bottom-up models, and input/output models. Each class of models has a particular set of characteristics. Top-down or shiftshare models are desirable from the perspective of consistency and short-run forecasting capability. A top-down model contains simple sharing techniques that assure that the sum of the parts equals a predetermined national total. In addition, because shares do not change radically over the shortterm horizon, the top-down approach forecasts well in the short run. One drawback to top-down models is that they are not designed to explain why one region gains in share at the expense of another.

Bottom-up models are better suited to explain interregional shifts in national market share. These are structural models of a region's economy. There are limitations to bottom-up models. In a national system, each regional model is estimated separately. As a consequence, the sum of the parts rarely equals a predetermined national total. Another disadvantage relates to the unconstrained nature of estimating the models. Because of the unconstrained nature of the models, the elasticities of regional employment or value added with respect to national employment or production may be significantly different from one. In the long run, these models tend to over- or under-forecast economic activity if these elasticities are greater or less than one when aggregated over all.regions. Since the data needed to develop detailed models that forecast regional economic activity is not readily available, there is substantial cost of developing and maintaining large-scale, well developed regional econometric models for the nation as a whole..$^{10}$

Regional input-output models are frequently discussed in regional economics literature. Input-output tables contain information about interindustry flows and simulate well over the historic period from which they are constructed. There is nothing in an input-output table that can determine why a state

An article by Farrell and Hall (1991) described the extent to which regional economists were engaged in measuring and forecasting local economic activity. They conducted a survey of regional economists and found that roughly 12 percent of the respondents were measuring and forecasting local activity and that data collection was the foremost problem encountered in forecasting regional economic activity. 
or region is gaining or losing share or why a region's industry mix is changing. In addition, the time path of impacts is difficult to determine using regional input/output multipliers.

Most regional models described in the literature are detailed representations of a particular region of the U.S. as opposed to a regional representation of a national model. Few organizations maintain regional models of the nation as a whole, and those that do use different methodologies depending on the time horizon of the forecast, detail of industrial aggregation, and consistency with national macroeconomic forecasts. WEFA, for example, has 51 state models and does regional analysis, but the WEFA state models are not linked to yield a national aggregate consistent with their national forecasts.

Of the regional models that incorporate the entire national economy, there are different methodologies, corresponding generally to the three types of regional models. Each class of models has strengths for certain types of analyses. The discussion below focuses on different examples of these classes of regional modeling. Four regional models are presented: the DRI Regional Information Service (RIS), the Bureau of Economic Analysis (BEA) National-Regional Impact Evaluation System (NRIES), the BEA Regional Input-Output Modeling System (RMMS), and the Regional Economic Models, Incorporated (REMI) Economic-Demographic Forecasting and Simulation (EDFS) Model. These models contain regional representations of a model that is national in scope, rather than separate regional models that are not automatically consistent to a national aggregate. In addition, these models are used frequently by other govemment agencies and businesses in analyzing regional impacts in both forecast and impact analyses.

DRI Regional Information Service (RIS). The RIS uses a system of quarterly models to forecast over 100 concepts for each state and region. " The forecast horizon is 25 years, to 2015 . The principal indicator of sectoral economic activity is employment, which is forecast separately for 20 manufacturing and about 10 nonmanufacturing industries. Wage rates and major components of

in Data Resources, Inc., "An Overview of DRI's Regional Information Service." 
income are modeled, and the housing sector is examined in detail, with forecasts of single- and multi-family housing starts, and the corresponding actual and desired stocks. Population, labor force, and unemployment rates are also predicted within the model. Variations in regional energy prices also determine regional output; however, only regional industrial electricity prices are used as part of the RIS model.

The RIS model analyzes the different parts of the U.S. in a two-stage procedure. The country is first broken down into nine regions (approximately the nine Census Divisions ${ }^{12}$ ) in the core model and then individual state models use the regional results to derive state impacts. This approach has been adopted both because it reduces the costs of solving whenever the complete 50-state detail is not required, and also for theoretical reasons. DRI argues that the factors determining the choice of location are different at the regional than at the state level.

The focus of DRTs core nine-region model is an analysis of the relative success of each geographical area in attracting and retaining the types of industries that serve national markets. This leads directly to the study of industrial location, in which context it is clear that the factors determining the choice of location are different at the regional level and the state level. For example, when a firm is deciding whether to set up in the West or the South, it considers general cost comparisons, proximity to markets, and general attractiveness. The choice between San Diego and Phoenix, however is more likely to be influenced by many other considerations such as tax burdens and home prices as examples.

One of the fundamental features of the DRI RIS system of nine regional models is the direct link to the other models in the DRI system. In particular, the regional totals are constrained to yield the national control totals from the macro model for key variables such as employment by industry, wage rates, population, and the labor force. While it is possible that the summation of the nine regions

12. Two Census regions, the Pacific and Mountain, are instead split into Pacific Northwest and Pacific Southwest. 
may yield different results, a balancing procedure ensures consistent results between the national and regional estimates. The model forces regional relocation and adjustment in order to attain a national result.

The RIS system focuses squarely on the determination of employment by region. Three factors essentially drive the regional growth differentials: national industrial mix, amplitude of the business cycle in each industry, and regional cost differentials. Regional costs, in turn are functions of wage rates, tax burdens, energy prices, unionization and education of the labor force, and home prices. The determination of regional output is derivative from the employment growth patterns given a fixed set of productivity by industry measures. Also, regional investment patterns follow movements in regional employment growth.

Even at only the nine-region level, the RIS model is large and requires much hands on experience to effectively run the system. It is accessible only through the DRI mainframe and is run through the DRI proprietary software package, Economic Programming System (EPS). At present, no one outside of DRI personnel runs the model. The expense of completing an integrated run in conjunction with a DRI macro forecast precludes extensive examination of alternative cases. In addition, because the regional model is so large, it requires a large amount of training in order to become familiar enough with its properties to use model results for policy analysis. The derivation of baseline regional forecasts consistent with a baseline macro forecast, is certainly feasible as is the limited investigation of specific policies or key economic growth paths.

Using the DRI RIS system directly as the regional macroeconomic model in NEMS is not feasible for several reasons. First, the size and specification of regional detail in the model makes it too large for NEMS uses, especially when the purpose of NEMS is to forecast regional energy variables as opposed to regional macroeconomic concepts. Second, it is possible to derive regional shares using forecasts from the DRI RIS model; however, the shares would not change as energy prices change. Third, the complexity and size of the DRI RIS model requires a substantial investment in training of EIA personnel to adequately incorporate the full RIS model into NEMS. 
National-Regional Impact Evaluation System (NRIES II). NRIES II is an annual econometric project and impact model used to estimate the distribution of impacts of alternative policies and to provide short-to medium-term projections of state economic activity. The model is maintained by the Regional Economic Analysis Division within the BEA at the Department of Commerce. ${ }^{13}$

NRIES consists of 51 individual state econometric models, a national model, and a set of indexes that measure trade flows among states. The forecast horizon is ten years, through the year 2000 . NRIES is structured so that (1) coefficients of equations pertaining to variables that differ little among states, such as Federal fiscal and monetary variables, are estimated within the national model, and (2) coefficients of equations pertaining to variables that differ substantially among states, such as industry product, employment, and income, are estimated within the individual state models.

Variables projected within the national model are termed "top-down" while those projected within the state models are termed "bottom-up". When bottom-up variables are aggregated to national totals, they are termed "sum-of-states" and these aggregations are the national projections. Changes in individual state economics can both affect, and be affected by, changes in the national economy.

The 51 individual state models form the core of the system. Each state model forecasts output, employment, wage rates, nonwage sources of income, population, state and local government revenues and expenditures, investment, labor force, unemployment, and retail sales. The national model derives such variables as final demand components, Federal government receipts and expenditures, money supply, interest rates, consumer and producer prices, tax rates, and various Social Security variables. The model also captures interstate commodity flows.

The focus of the state models is on the derivation of output for the 20 two-digit SIC manufacturing sectors and 10 one-digit nonmanufacturing sectors. Manufacturing activity is mainly a function of

13 J.R. Kort, J.V. Cartwright, R.M. Beemiller, "Linking Regional Economic Models for Policy Analysis," Regional Economic Analysis Division Bureau of Economic Analysis, Department of Commerce, July 1984. 
relative costs of business, interstate flow transactions, and national model variables such as consumption, investment, and interest rates. Output in the nonmanufacturing sectors is mainly a function of local-demand variables such as state disposable income or population and national variables such as interest rates.

Employment is essentially derived as a function of industry output. Investment in nonresidential structures and equipment is specified as a function of interest rates and state total output, but not at the industry level.

The NRIES is particularly useful for evaluating the interregional distributional effects with its explicit representation of interregional flows. Also, NRIES derives a simultaneous solution at the regional and national levels. The bottom-up nature of the model assures complete consistency between the national and regional results. The national model on top provides needed control to assure that the simple summation of the state results does not yield a systematic over or understatement of the growth potential of the aggregate economy.

However, there are limits to its immediate usefulness. First, the model currently projects only through 2000. An extension to the year 2015 would be a major effort and could be done only through BEA. Model size is also a consideration. The bottom-up aggregation of 51-states nature of the model makes it large and cumbersome. But perhaps the most difficult methodological issue is consistency with the National Submodule results. The National Submodule, based on the structural DRI Model of the U.S. Economy, is capable of addressing a large variety of policy issues ranging from specific energy initiatives to accommodating monetary or fiscal policy to supply side effects related to capital formation. These issues cannot be adequately covered using the strict bottom-up approach as typified by NRIES.

Regional Input-Output Modeling System (RIMS II). RIMS is also developed and maintained by BEA. RIMS represents a set of regional input-output coefficients and multipliers for use in 
estimating the regional impacts of economic policies. ${ }^{14}$ Coefficients and multipliers can be estimated for any county or group of counties in the U.S. and for all of the approximately 500 industries in the BEA set of benchmark input-output tables. RIMS can be used to estimate the impacts of project and program expenditures by industry on regional output, earnings, and employment.

The available detail, both in terms of the regional disaggregation and the industrial disaggregation, is the raison d'etre for the RIMS model. RIMS also has major limitations characteristic of other regional and national input/output models. The multipliers are derived from a linear Leontief production function which assumes constant returns to scale and no substitution among inputs. Also, RIMS does not identify the time paths of impacts, and does not take into account the interregional flows of goods and services. In addition, RIMS is a BEA model and is maintained and operated by BEA. The flexibility of a regional model that is directly linked to the NEMS system and operated by EIA personnel would be lost.

Regional Economic Models, Incorporated (REMI) Economic-Demographic Forecasting and Simulation (EDFS) Model. The REMI EDFS model, an annual regional forecasting and policy simulation of both the private and public sectors of the United States, has been publicly available since 1980. The model's forecast period extends to the year 2035 and the regions covered include the $\mathbf{5 0}$ states and Washington, D.C. Model runs from post sample period forecasts for these 51 regions indicate the model may be more successful in long-term forecasting. ${ }^{15}$

The REMI EDFS model, composed of five blocks, employs a highly simultaneous model structure where most interactions between blocks flow both ways. The structure of the model incorporates interindustry transactions and endogenous final demand feedbacks. The model includes substitution

14 "Regional Multipliers: A User handbook for the Regional Input-Output Modeling System (RIMS In), Bureau of Economic Analysis, Department of Commerce, May 1986.

15 The REMI EDFS analysis draws heavily from George I. Treyz, Dan S. Rickman, Gang Shao, "The REMI Economic-Demographic Forecasting and Simulation Model" International Regional Science Review, Vol. 14, No. 3, p. 251, 1992. 
among factors of production in response to changes in relative cost factors, migration response to changes in expected income, wage response to changes in labor market conditions, and changes in the share of local and export markets in response to changes in regional profitability and production costs.

Block-1 of the model, output linkages, interacts extensively with the other blocks of the model. It includes output equations, consumption equations, real disposable income equations, investment equations, and government spending equations.

The output equations employ an input/output structure representing the interindustry and final demand linkages by industry. Outputs for 53 sectors ( 49 private non-farm industries and three government sectors) are calculated. Regional information is produced by applying regional purchase coefficients to historical and projected input/output tables from the Bureau of Labor and Statistics (BLS).

The consumption equations translate real disposable income into consumption demand. Real disposable income (personal income adjusted for taxes and the cost of living) data by sector is based on data from the BEA.

The investment equations are based on residential, non-residential, and equipment investment. Government spending is predicted for six components: federal civilian, federal military, state and local education, health and welfare, safety, and miscellaneous.

Block-2 of the model, factor demands, assumes industries demand profit-maximizing levels of factor inputs. The optimal choice of inputs demands two stages. First, industries demand fixed shares of composite value added and intermediate inputs and, second, industries choose optimal levels of the components of composite factors. Block-2 is composed of labor, capital, and fuel demands. While fuel demand is not explicit in the model, the cost of fuel enters the demands for labor and capital. 
Block-3 of the model, regional population and labor supply, determines the interaction of the model's demographic and economic sections. The cohort algorithm applies fertility and survival rates from state-specific 1980 data trended backward and forward by the Bureau of Census (BC). The migrants category consists of international, retired, former military and their dependents, and economic migrants. International migration is calculated by applying a fixed regional share to $\mathrm{BC}$ data.

Block-4 of the model consists of production, labor, and capital costs, along with prices and profits. Relative labor cost is based on several BC Current Population Surveys and REMI data.

Block-5 of the model, market shares, is based on the effects of national and regional industries in the region. The model uses the Department of Commerce's 1977 Census of Transportation data for manufacturing industries and subjective estimates for non-manufacturing industries.

Summary of Regional Models Reviewed. Similar to requirements for the national macroeconomic model, three system requirements must be addressed by the Regional Submodule: (1) develop a baseline path for regional economic activity, (2) calculate regional economic feedbacks internal to the modeling system, and (3) evaluate detailed regional impacts. However, decisions about the regional economic modeling are directly tied to decisions about the macroeconomic system of models.

Regional consequences of energy actions and events are partially addressed through the supply and demand models directly. For example, energy production and energy price impacts are derived within the energy components of the system. The regional component of the macroeconomic model addresses the secondary effects which arise because of regional reactions to regional energy issues or regional effects caused by national impacts. For example, the regional macroeconomic model is intended to incorporate economic impacts of differences in regional energy prices and labor costs.

Based upon the above discussion, a system that fully integrates the interindustry structure into the 
aggregate economy has specific advantages. Bottom-up interindustry/macro modeling is attractive for numerous reasons, which may not apply to regional/interindustry bottom-up models (as in NRIES II). This assertion requires some critical design and segmentation considerations in the sectoral detail versus regional detail. In addition, bottom-up regional models may not be able to confront the type of detailed energy policy options that NEMS requires. For example, neither the imposition of a national tax policy nor the consideration of the disposition of the collected revenues can be addressed using a bottom-up regional economic model.

The ability to address the fundamental determinants of growth is critical to the macroeconomic modeling. The regional models to date are demand-driven systems that simply do not address the underlying supply constraints on the economy. The macroeconomic models address investment behavior in detail; in the regional models, investment behavior is handled poorly or not at all.

Size of the system is a critical constraint. Regional modeling, particularly if bottom-up, forces the entire system to grow rapidly to an unmanageable size.

Conclusions on Regional Submodule Structure. Based upon the discussion of alternative regional modeling considerations presented above, the following conclusions are advanced:

1. The MAM Regional Submodule is compatible with the National and Interindustry Submodules and incorporates regional impacts by utilizing regional shares based on a smaller version of the DRI Regional Model estimäted using industrial outputs from the Interindustry Submodule.

2. Existing regional models have several drawbacks. First, the size and complexity of the DRI regional model is a major hindrance to direct incorporation within NEMS. The system of regional models maintained by BEA is unusable for NEMS because at least one of the following conditions holds: (1) the BEA system contains its own macroeconomic model (a simpler representation than what is required by NEMS analysis); (2) the BEA forecast periods do not match the NEMS requirements; (3) some BEA models are incapable of analyzing the stream of impacts over time: 
Using models that are maintained or updated on schedules over which EIA has no control would not add to NEMS flexibility.

3. The share approach has three primary advantages: (1) direct linkage and consistency with the national and interindustry models used in NEMS analysis; (2) regional output corresponds to national aggregates; and (3) the ability to generate regional forecasts consistent with the NEMS energy models' forecasts of production in industries such as refining and mining.

Summary. Three considerations underlie the decision to adopt the response surface approach for NEMS:

- EIA time and project resource constraints eliminate the option of developing a complete structural model in-house for the AEO97.

- Incorporating an existing proprietary model as the MAM would have raised the issues of disclosure and inconsistencies between the MAM energy equations and the NEMS view of energy market behavior.

o Removing the energy sector from an existing proprietary model and linking the remainder with NEMS would have raised disclosure issues and non-energy proprietary equations.

The response surface approach has the advantage of being able to avoid the common econometric problems of multicollinearity, limited sample variability, and short run disequilibria. Also, there can be no simultaneous equation bias because the exogenous variables are controlled and an approximation to the reduced form equations is estimated. The usefulness of the response surface is determined by the closeness with which it is able to approximate a complex surface by using a hyperplane. This is more of a numerical analysis issue as opposed to a statistical consideration.

Response surface models have been in use since 1959 when G.E.P. Box and colleagues began 
publishing papers on the subject. ${ }^{16}$ While response surface, or reduced form, models are widely used in the natural sciences, they have not been in common use among economists. A notable exception is the series of papers by James M. Griffin $(1977 \mathrm{a}, 1977 \mathrm{~b}, 1978,1979)$ that estimate cost functions based on pseudo data generated by repeated runs of linear programming models. Other applications of pseudo data in economics include Attanasi and Green (1981), Sav (1984, 1987), and Kolstad and Wolak (1983). The use of pseudo data for the estimation of economic models has been criticized (Maddala and Roberts, 1980) but not without a spirited reply by Griffin (1980). Finally, since the purpose of this model is to reproduce the output of a larger model, the only possible data for this purpose is pseudo data.

16 See Box and Draper (1987) for an excellent history and discussion of the technique. 


\section{Module Structure}

Figure 1 graphically illustrates the design and flow of the MAM within the NEMS system. Figures 2 through 6 provide supporting illustrations of the submodule flows. Key computations and equations used in MAM are described following their graphic representation.

Figure 1 depicts MAM in the context of the NEMS system. The four primary submodules of MAM: the National, Employment, Interindustry, and Regional Submodules, are shown in the diagram. The national level variables are calculated within the National Submodule. The interindustry activity variables are forecasted by the Interindustry Submodule. The regionalized variable forecasts are generated by the Regional Submodule. The whole of Figure 1 illustrates the role of MAM within the NEMS system. MAM receives energy price forecasts, system information, and refinery activity from the NEMS system.

Figure 2 illustrates the flow of the National Submodule. The system information (including the number of years, regions, price lag terms, and driver variables), the DRI macroeconomic baseline forecast generated externally to the NEMS system, and additional driver variable information are input to the National Submodule. The response surface approximation that comprises the National Submodule examines the percentage changes in the macroeconomic variables from the DRI baseline by including dynamic impacts of lagged exogenous variables. Final demands are calculated using this algorithm.

Figure 3 illustrates the flow of the Interindustry Submodule. System information, the historical years, the number of industries that are modeled, and additional information, along with the final demands calculated in the National Submodule, are input to the Interindustry Submodule. Changes in interindustry activity for a subset of the industries modeled are then calculated using the response surface approximation, followed by the calculation of industrial outputs, manufacturing outputs, service outputs, and total industrial output. Aggregations are performed to develop the composite 
outputs required by the NEMS Industrial Sector Demand Module. The interindustry final outputs are forecasted in this submodule.

Figure 4 illustrates the Growth Industry component of the Interindustry Submodule. This component models the industrial outputs from energy-producing industries that come from NEMS. These industries are: Coal Mining, Oil and Gas Mining, Petroleum Refining, Gas Utilities, and Electric Utilities. This component draws upon industry-specific inputs to estimate growth paths for these five sectors, based upon historical growth and the growth in the industry-specific inputs coming from the appropriate NEMS modules.

Figure 5 illustrates the Employment Submodule. System information along with the changes in gross output calculated by the Interindustry Submodule are inputs to the Employment Submodule. Changes in employment are then calculated using the response surface approximation. Employment by industry is forecasted in this submodule.

Figure 6 illustrates the Regional Submodule. The Regional Submodule operates upon a subset of the macroeconomic variables that are forecasted by the National and Interindustry Submodules, specifically, the macroeconomic variables that are required by the NEMS demand modules at the Census Division level of detail. The inputs to the Regional Submodule are the national final demands and the interindustry final outputs. The Regional Submodule applies regional shares to each input to calculate the Census Division levels of final demand and interindustry output. 
Figure 1. MAM Calculational Flows within NEMS

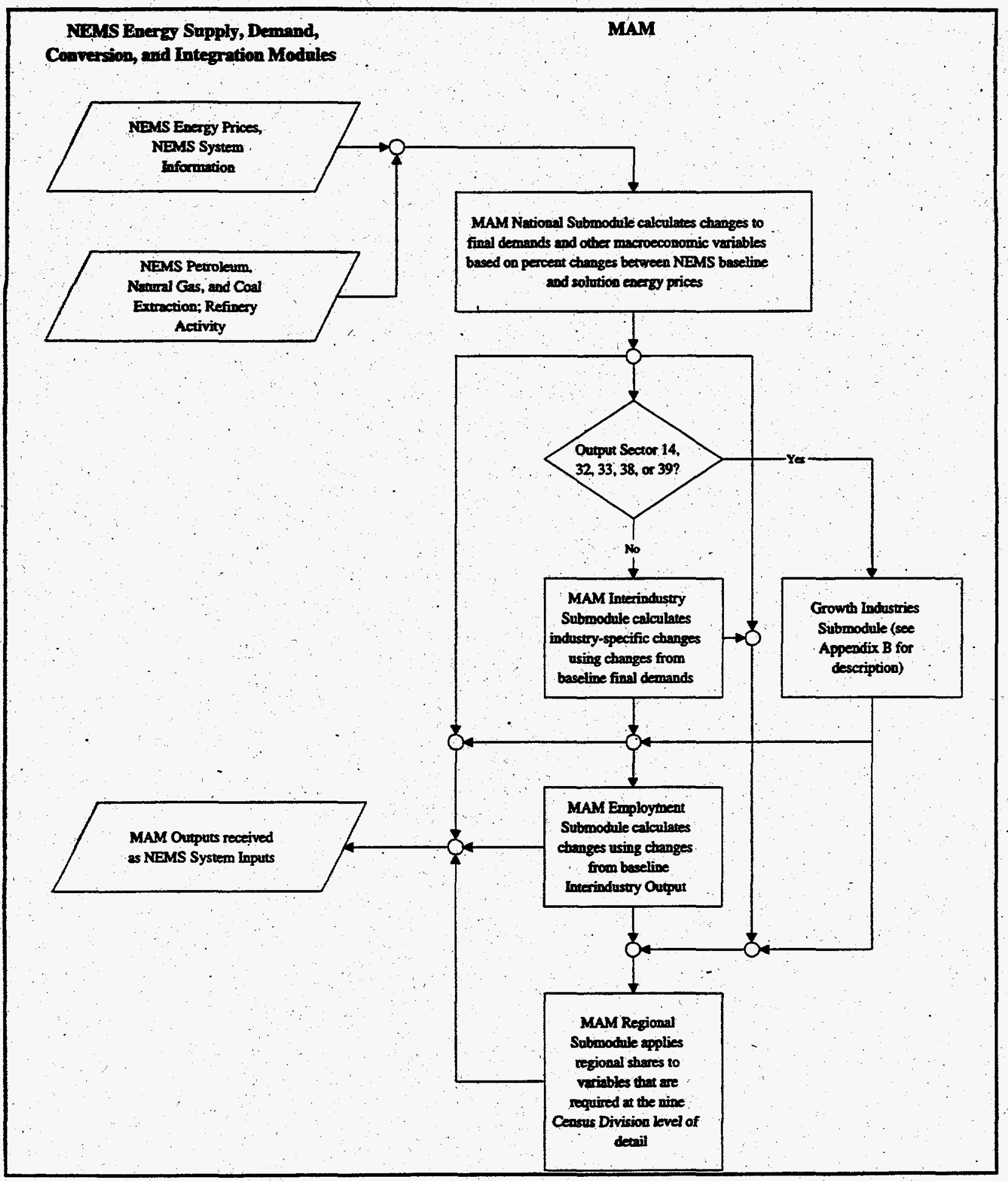

Energy Information Administration

NEMS Macroeconomic Activity Module Documentation Report 
Figure 2. National Submodule Flow ${ }^{17}$
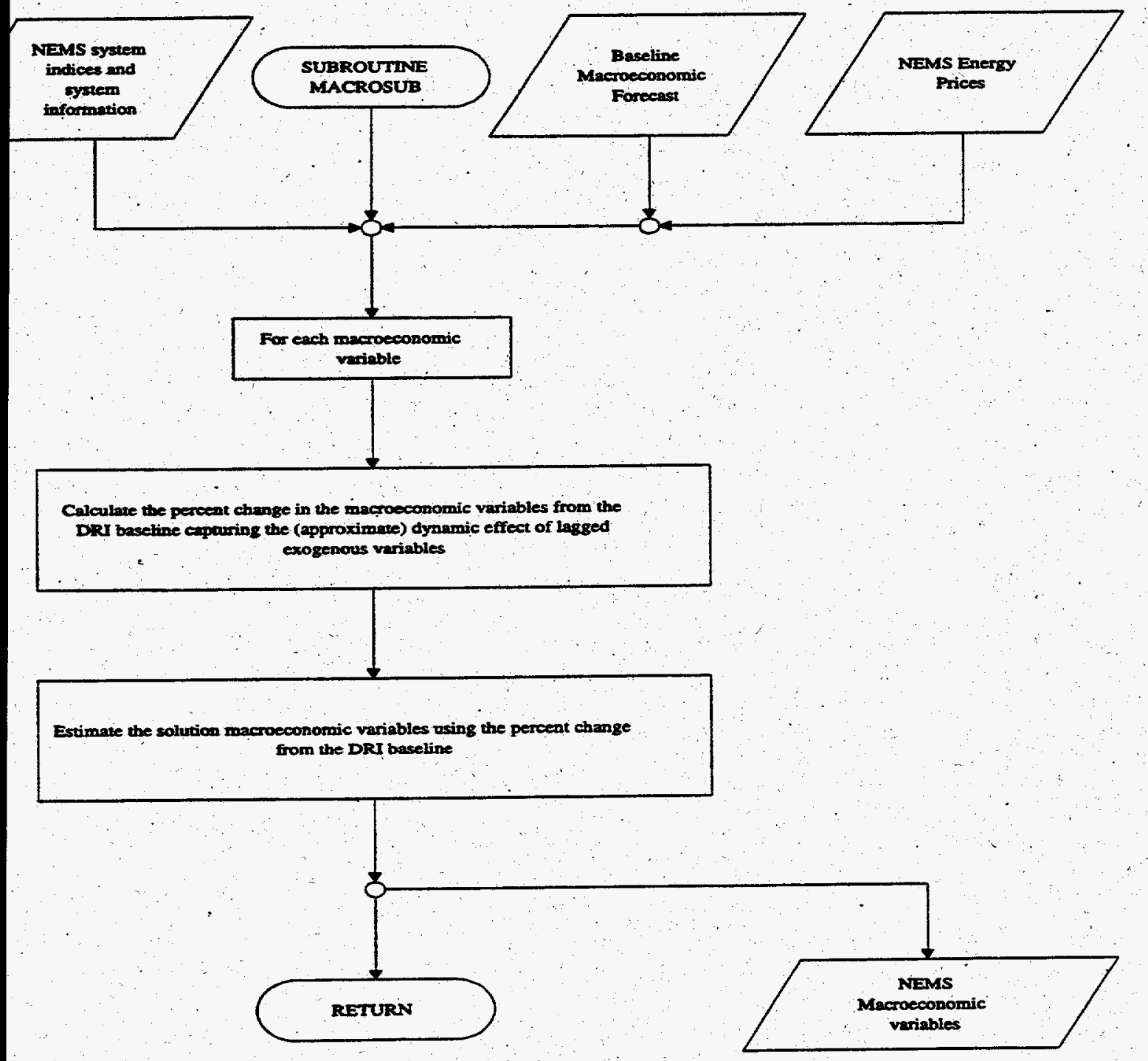

17 Tables A-7 and A-8 of Appendix A to this report provide the definitions, usage, calculation, and dimensions of the items contained in the input/output blocks (rhombi) of this diagram. The process blocks (rectangles) of this diagram are further discussed in the second section of Appendix B, "The National Submodule".

Energy Information Administration NEMS Macroeconomic Activity Module Documentation Report 


\section{Figure 3. Interindustry Submodule Flow ${ }^{18}$}

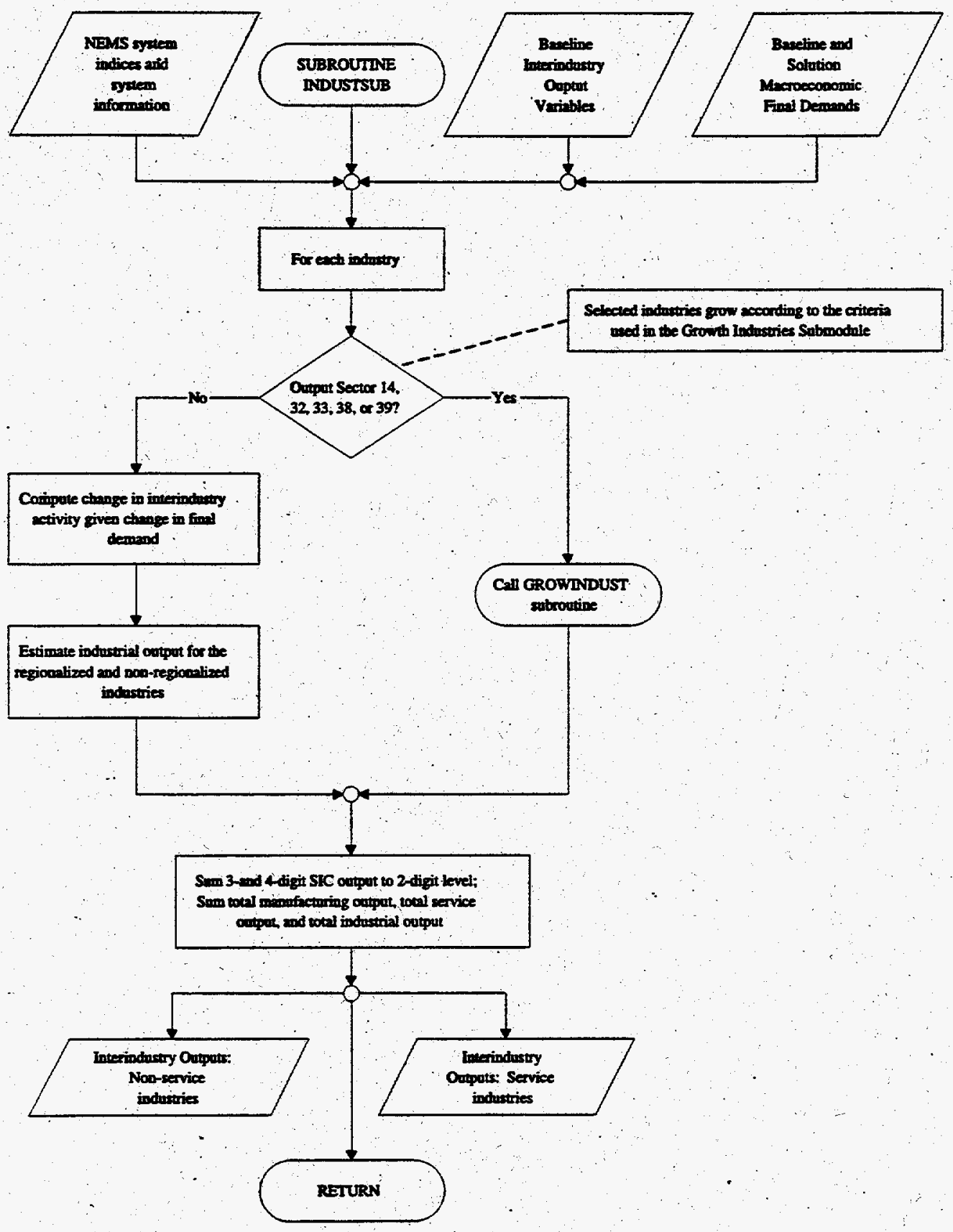

Tables A-4, A-6, A-7, and A-8 of Appendix A to this report provide the definition, dimensions, and usage of the interindustry components contained in the input/output blocks (rhombi) of this diagram. The calculational steps illustrated in the rectangular blocks of this diagram are further described in the fourth section of Appendix B to this report, "The Interindustry Submodule". 


\section{Figure 4. Growth Industry Component of Interindustry Submodule 19}

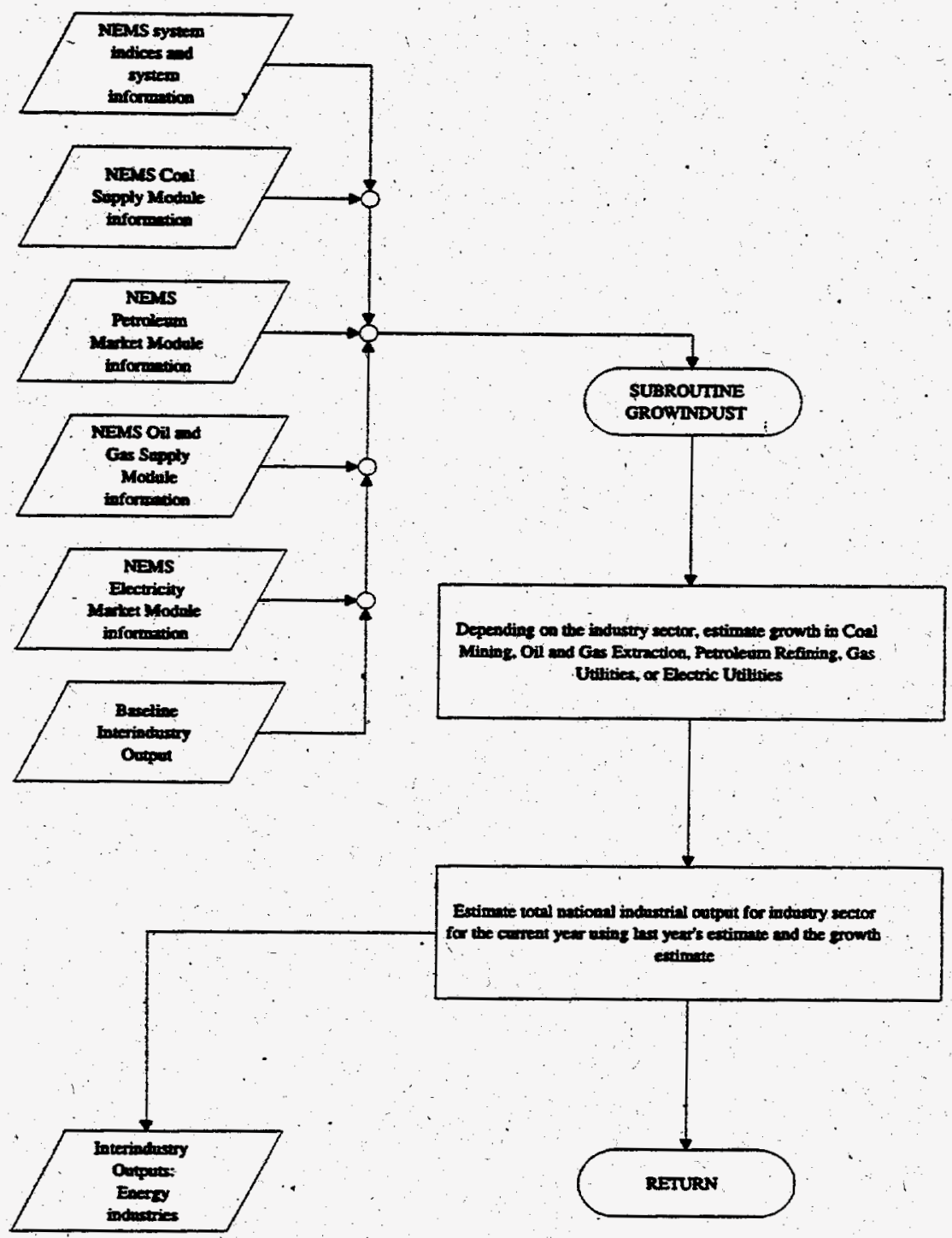

Tables A-4, A-6, A-7, and A-8 of Appendix A to this report provide the definitions, dimensions, and usage of the Growth Industry Component items referenced in the input/output blocks (rhombi) of this flow diagram. The calculational processes provided in the rectangular blocks of this diagram are further described in the fifth section of Appendix B to this report, "The Growth Industry Submodule"

Energy Information Administration NEMS Macroeconomic Activity Module Documentation Report 


\section{Figure 5. Employment Submodule 20}

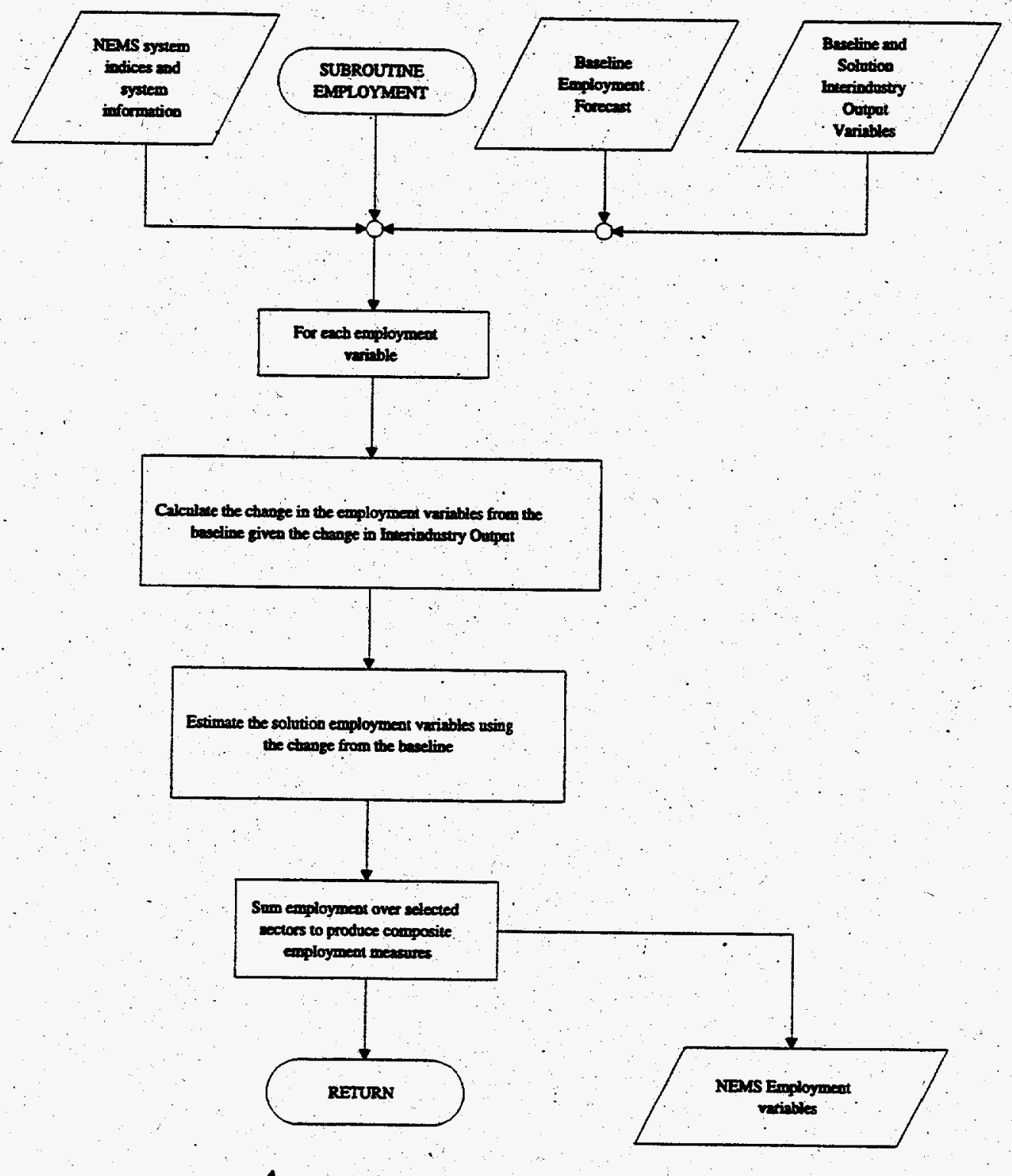

Tables A-3, A-7, and A-8 of Appendix A to this report provide the definition, dimensions, and usage of the Employment Submodule as illustrated in the input/output blocks (rhombi) of this diagram. The calculational steps illustrated in the rectangular blocks of this diagram are further described in the third section of Appendix B to this report, "The Employment Submodule".

Energy Information Administration NEMS Macroeconomic Activity Module Documentation Report 
Figure 6. Regional Submodule Flow ${ }^{21}$

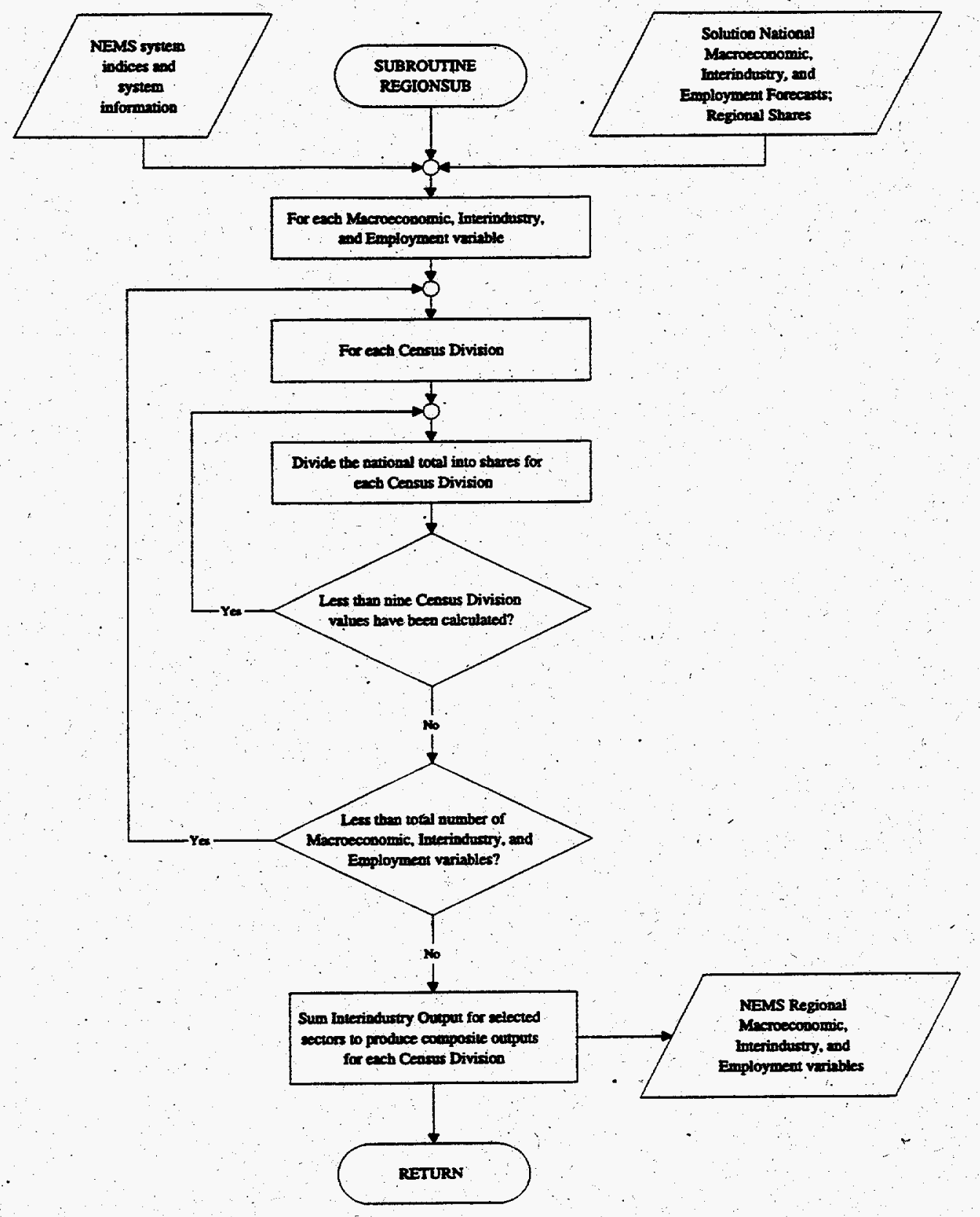

21 Table A-1 of Appendix A to this report defines the NEMS system information and indices required by the Regional Submodule as illustrated in the inputoutput blocks in the upper right corner of this flow diagram and the decision blocks (diamonds) appearing throughout the diagram. The calculations described in the rectangular blocks of the diagram are further detailed in the sixth section of Appendix B to this report, "The Regional Submodule".

Energy Information Administration NEMS Macroeconomic Activity Module Documentation Report 


\section{Key Computations and Equations}

\section{MAM Approach}

The goal of the MAM response surface models is to replicate the results of changing energy prices in the DRI models. Four DRI models are used to create any macroeconomic baseline: the DRI U.S. Quarterly Macroeconomic Model, the DRI Employment Model, the DRI Personal Computer InputOutput Model (PCIO), and the DRI Personal Computer Regional Model. For the AEO97, MAM uses response surface models developed from the U.S. Quarterly Model, the Employment Model, and the PCIO for the National, Employment, and Interindustry Submodules respectively. The Regional Submodule of MAM used for the AEO97 is a set of regional shares developed through simulations of the DRI models.

\section{MAM National Submodule}

The National Submodule of the MAM is a response surface representation of the DRI U.S. Quarterly Macroeconomic Model. To create the outputs from the DRI model (pseudo data), the DRI model is executed roughly 200 times varying designated input variables that ultimately become independent variables in the response surface equation ${ }^{22}$. Some simulations used to generate the pseudo data varied the world price of oil. This truly exogenous variable directly impacts the domestic energy supply price (WPI05). When the world oil price simulations were run, the personal consumption (PC) deflators for fuels (PCNFUEL, PCNGAS, PCSHHOPE, and PCSHHOPG), were not constrained. The model was allowed to change these variables as WPI05 changed. This approach was adopted because, if these variables had been held constant, the DRI model would have produced anomalous results for the macroeconomic variables of interest, including GDP, disposable income, interest rates. Similarly, when the energy consumption deflators were varied, WPI05 was allowed to vary. Thus, the variables on the right hand side of the regression specification are not truly exogenous, although they are exogenized when the full-scale DRI model is run. Table 3 shows the energy price variations, which were determined by incorporating AEO energy price ranges.

See Table 3 for the range of changes in energy prices. 
Table 3. Energy Price Variations for Pseudo-Data Generation

\begin{tabular}{|l|l|}
\hline Energy Price Series & Range of Percent Changes \\
\hline World Oil Price & $30 \%$ to $60 \%$ (plus and minus) \\
\hline PCNFUEL (Residential Fuel Price) & $3 \%$ to $32 \%$ (plus and minus) \\
\hline PCNGAS & $2 \%$ to $22 \%$ (plus and minus) \\
\hline PCSHHOPE & $3 \%$ to $26 \%$ (plus and minus) \\
\hline PCSHHOPG & $2 \%$ to $17 \%$ (plus and minus) \\
\hline
\end{tabular}

The exogeneity consideration is addressed as follows. To create the pseudo data base for the regressions, all induced price effects were treated as if $\mathrm{dX}_{j}$ (the percent change from base) was zero in the resulting output data set for the remaining explanatory variables, even though these variables are nonzero in the original model output. Similarly, when the energy consumption deflators are varied, no variables were constrained in the full-scale DRI model run, but the induced deviations of WPI05 and the other explanatory variables from the base were set to zero, holding them at the baseline. Consequently, the coefficients on WPIO5 and all of the other price indices capture all effects of a change in the energy supply price, including the effects that occur through induced changes in other energy price deflators.

The regression takes the form:

$$
d Y_{t}=\sum_{j=1}^{5} \alpha_{j} d X_{j t}+\sum_{j=1}^{5} \beta_{j} d X_{j, t-1}+\sum_{j=1}^{5} Y_{j} d x_{j, t-2}+\delta_{1} d Y_{t-1}+\delta_{2} d Y_{t-2}
$$

where $d Y$ and $d X_{j}$ refer to the percent change from base of the dependent and independent variables respectively. The dependent variables are further described in Appendix A to this report. The independent variables are: 
$\mathrm{X} 1=\mathrm{PCSH} H \mathrm{OPE}$

$\mathrm{X} 2=\mathrm{PCSHHOPG}$

$X 3=P C N F U E L$

$\mathrm{X} 4=$ PCNGAS

X5=WPI05
(PC deflator for electricity)

(PC deflator for natural gas)

(PC deflator for heating oil)

(PC deflator for gasoline)

(wholesale price deflator for fuels)

The purpose of the MAM is to link the macroeconomy to the energy sector. The whole simulation process begins with the specification of a base macroeconomic case. However, once NEMS begins iterating, it computes its own estimates of the relevant fuel prices. These prices are received by MAM from NEMS, aggregated to WPI05, multiplied by the coefficient $\alpha_{5}$ in the above equation and - the resulting change in the macroeconomic variable is passed back to NEMS.

The coefficients on variables X1-X5.provide the ability to calculate the effects of various energy policies. For example, a tax on gasoline would affect the personal consumption deflator for gasoline directly and federal excise tax receipts, but it would not directly affect the wholesale price of gasoline. Alternatively, a change in the wholesale price of gasoline would affect the price at the pump, which would directly impact the PC deflator for gasoline. The coefficient $\alpha_{5}$ estimates the entire effect of a change in the wholesale price of fuel. Therefore, the model does not include the effect of changes in the deflators and investment when these changes result from a change in the retail price. However, NEMS calculates its own estimates of the retail prices of the various fuels. Changes in these prices will have macroeconomic consequences. Thus, a method is required to calculate the macroeconomic impacts of changes in the retail prices of fuels when the changes come from NEMS.

This calculation is addressed as follows. The coefficient $\alpha_{5}$ measures the effect of a change in WPI05. NEMS reports a change in WPI05 in each iteration, so the product of $\alpha 5$ and $\mathrm{dX}_{5}$ will capture that effect, including the implied effect on PCNGAS and the other deflators. However, suppose NEMS also reports a change in the retail price of gas, corresponding to a change in PCNGAS. If this change is greater than the implied change that would have occurred in the DRI model, then there is a greater effect on the macroeconomy than that captured in $\alpha_{5}$. This additional 
effect is captured by the following technique. A preprocessor model has been estimated to predict the change in the PC deflators and investment from changes in the corresponding wholesale prices. The preprocessor is a simple equation $\left(d X_{j}=b_{j} d Z_{k}\right.$, where $b_{j}$ is the coefficient PCPASS in the MAM code) relating percent changes from base of the four personal consumption energy price deflators $\left(d X_{j}\right)$ to percent changes in the relevant wholesale price (dZ ). For example, the PC deflator for natural gas is related to the wholesale price of natural gas and the PC deflator for electricity is related to the wholesale price of electricity. Thus, the preprocessor allows the calculation of what the DRI model would have predicted the PC deflator to be, given the wholesale price. The NEMS estimate of the PC deflator could be higher or lower than this. If it is higher, then an additional amount is added to the change in the macro variable. If it is lower, then the effect on the macro variable is reduced. In order to accomplish this, the model subtracts the change in PC deflators and investment variables from the preprocessor model from those changes passed to MAM from NEMS and sets the percent change from base, $\mathrm{dX}_{j}$ in equation (11) equal to this amount. In other words, for the four PC deflators, the following relationship is set

$$
d X j=d x_{j}^{N E M S} b_{j} * d z_{k}
$$

where $\mathrm{j}=1 . .4$ and $\mathrm{k}=1 . .5$

in Equation (11), where $d X_{j}^{(N E M S)}$ is the change from base passed from NEMS and $p^{*} d Z$ is the predicted change in $\mathrm{dX}_{\mathrm{j}}$ from the preprocessor model. ${ }^{23}$ By this means, the macroeconomic variables are adjusted to account for changes in the PC deflators coming from NEMS that differ from the investment. $Z_{1}$ is the wholesale price of coal; $Z_{2}$ is the wholesale price of natural gas; $Z_{3}$ is the wholesale price of electricity; $Z_{4}$ is the world oil price and $Z_{5}$ is the wholesale price of refined products. For wholesale prices, MAM uses NEMS industrial prices. 
values that would have been predicted by DRI and which are already included in the $\alpha_{5}$ coefficient in Equation (10).

To make the application of these additional feedback enhancements more flexible, user switches were added to allow the user to specify which independent variable (or combination of independent variables) to use in calculating macroeconomic feedback. For example, in AEO forecasts, the switches for wholesale energy prices (X4 in equation 10 above) are on (or in FORTRAN notation, 1) and the switches for all other variables $(X 1, X 2, X 3)$ are off (take the value of 0 ).

The first step in the solution of the National Submodule is to calculate the percentage changes of the independent variables in Equation (10). DDRIVER calculates such percentage changes, using NEMS energy prices (X1 through X4) that correspond to the appropriate DRI variable. The percentage changes from the DDRIVER equations are then applied to Equation (10) above.

\section{MAM Employment Submodule}

The response surface Employment Submodule characterizes employment changes for inclusion in NEMS. These changes are added to, or subtracted from, the baseline projections provided by the structural employment model to derive new employment levels. The response surface employment equations previously contained in the National Submodule of MAM related changes in employment directly to changes in energy prices from the integrating module of NEMS. The revised response surface Employment Submodule relates changes in employment to changes in gross output from the Interindustry Submodule of MAM. This change makes the model more intuitive - when an industry's output demand increases, its input usage generally increases as well. Labor is one input to the production process.

The Employment Submodule is constructed similarly to the Interindustry Submodule of MAM. Within MAM changes in employment are determined by changes in gross output. The response surface Employment Submodule is specified as a partial adjustment model. Increasing and decreasing employment is costly for businesses. Firms will not adjust employment to the ultimately 
desired level immediately when output demand changes, but will wait to see whether the demand change persists. For each sector, the equation for change in employment is:

$$
\Delta E_{i, t}=\left(\left(\beta_{1}+\left(\beta_{2} * t i m e\right)\right) * \Delta G O_{i, t}\right)+\left(\beta_{3} * \Delta E_{i, t-1}\right)
$$

where:

$$
\begin{aligned}
& \Delta E_{i, t}=\text { change in employment for industry } i \text { in period } t, \text { in millions of persons } \\
& \text { time }=\text { a time counter, which equals } 1 \text { in } 1995 \\
& \Delta G O_{i, t}=\text { change in gross output for industry } i \text { in period } t, \text { in millions of } \$ 1987 \\
& \Delta E_{i, t-1}=\text { change in employment for industry } i \text { in the previous period, in millions of } \\
& \text { persons }
\end{aligned}
$$

In order to estimate the coefficient matrices $\beta_{1}, \beta_{2}$, and $\beta_{3}$, each of the output aggregates contained in the Interindustry Submodule was increased within PCIO by 1 million dollars (\$1987) throughout the forecast period of the employment model while holding all other gross outputs constant. The resulting change from baseline levels of employment as projected by the structural employment model were regressed against the change in gross output and lagged change in employment.

Although only 30 disaggregated employment sectors are reported, the response surface model operates at the Interindustry Submodule level of disaggregation (45 sectors). Except for two employment sectors, each sector's change in employment is related to that sector's change in gross output only. Because of differences between the response surface and structural modeling systems, two of the 45 employment sectors (Agricultural Production - Crops, and Retail Trade) are each related to two gross output categories. Employment in the Agricultural Production -- Crops sector is based on gross output in both the Agricultural Production - Crops sector (equation 30) and the Other Agriculture including Livestock sector (equation 31). Employment in the Retail Trade sector is based on gross output in both the Retail Trade sector (equation 43) and the Services sector (equation 45).

The $\beta_{1}$ coefficient, which can be viewed as the base year (or constant) coefficient relating 
employment change to a 1 million dollar ( $\$ 1987$ ) output change, is positive for all industries, as would be expected. The purpose for the time counter is to capture the productivity trends contained in the structural employment model. The $\beta_{2}$ coefficient is generally negative, indicating that productivity increases over time for most industries. The $\beta_{3}$ coefficient is generally positive, indicating that most industries do not immediately adjust employment fully to the desired level when output demand changes.

\section{MAM Interindustry Submodule}

The Interindustry Submodule of the NEMS MAM is a response surface representation of the DRI Input-Output Model for the Personal Computer $(\mathrm{PCIO})^{24}$. The Interindustry Submodule of the NEMS MAM does not generate baseline forecasts of Industrial Gross Output. PCIO is used for this purpose. The role of the Interindustry Submodule is to calculate how Industrial Gross Outputs change when macroeconomic final demands change. Changes to macroeconomic final demands are determined within the National Submodule of MAM.

The Interindustry Submodule operates in a manner slightly different from a standard input-output model. The ways in which the two differ are fourfold:

1) The exogenous driver for a standard Input-Output model is a matrix of forecasted final demands. For PCIO the matrix consists of 47 final demands forecasted annually through the year 2020. The exogenous driver for the Interindustry Submodule is a matrix of forecasted changes from baseline levels in final demands. For the Interindustry Submodule the matrix consists of changes from baseline levels for $\mathbf{4 6}$ final demands forecasted through the year 2015.

2) The A matrix (direct requirements matrix) in the PCIO model is replaced by the $\alpha$ matrix.

24 The calculations performed by a standard input-output model, of which PCIO is an example, are described in the Alternative Macroeconomic Modeling Approaches section of this report. 
The $\alpha$ matrix shows the amount by which each industry's gross output changes for a change of $\$ 1$ in each final demand in the base year (1992) of the Interindustry Submodule.

3) There is no row scalar matrix, nor is there a bridge matrix, in the Interindustry Submodule. Instead a second matrix of coefficients (the $\beta$ matrix) is included which describes the way in which the relationships between industrial gross outputs and macroeconomic final demands change over time in the PCIO model. It represents the combined effect of both the changing bridge matrix and the changing row scalars in PCIO.

4) The output from a standard Input-Output model is a matrix of forecasted gross output levels by industry. For PCIO the matrix consists of gross output for 114 industries forecasted annually through the year 2020 . The output from the Interindustry Submodule is a matrix of forecasted changes from baseline levels in final demand. For the Interindustry Submodule the matrix consists of changes from baseline levels for 45 industries forecasted through the year 2015. These solution changes from baseline levels are then added to the baseline levels and passed to the NEMS integrating system for use by the energy modules and for report-writing purposes.

The response surfäce model responds to changes from baseline levels in macroeconomic final demand components and calculates consistent changes in interindustry activity. Each of the equations in the Interindustry Submodule has the same generic specification relating change in interindustry activity $i$ to change in final demand $j$ :

$$
\Delta I O_{i}=\left(\sum_{j=1}^{46}\left[\alpha_{i, j}+\left(\beta_{i, j} * \text { time }_{t}\right)\right] * \Delta F D_{j}\right)
$$

where 


\begin{abstract}
$\Delta \mathrm{IO}_{\mathrm{i}}$ is the change from baseline level in industrial gross output for sector $l, \alpha_{j}$ is the base-year coefficient which relates changes in final demand component $j$ to changes in industrial gross output for sector $i$, ( $i$ not necessarily equal to $j$ ), $\beta_{\mathrm{ij}}$ is the time-dependent coefficient of change for translating changes in final demand component $j$ into changes in interindustry activity for sector $I$, time $e_{t}$ is an annual time counter which equals 0 in the base year (1992), and $\triangle \mathrm{FD}_{\mathrm{j}}$ is the change from baseline level in final demand component $j$
\end{abstract}

In order to estimate the two coefficient matrices $\alpha$ and $\beta$, the first final demand component in the macroeconomic model was increased 1000 million dollars (\$1987) throughout the forecast period of PCIO while holding all other final demands constant. The resulting change from baseline levels of gross output for each of the 114 industries of PCIO was then calculated, and the changes aggregated to the level of industrial detail required for the Interindustry Submodule ( 45 sectors). The mapping of PCIO sectors to Interindustry Submodule sectors is shown in the following table. This process was repeated for each of the macroeconomic final demand categories of the National Submodule. The result of these controlled simulations of PCIO was 2070 time series of interindustry impacts, each relating change in gross output of a specific industrial sector to change in a particular final demand component.

Each of the 2070 output time series was divided by 1000 , the amount by which each macroeconomic final demand was incremented when running the PCIO model, resulting in multipliers relating change in industrial gross output to change in final demand. A linear regression was then performed on each of the multiplier time series, with time as the independent variable. The $\alpha_{i j}$ coefficients represent the amount that sector is output would change for a unit change in final demand $j$, for the base year of the simulation. Since the PCIO model is not static, time is included in the regressions. The $\beta_{i j}$ coefficients are designed to capture the effects of both the changing row scalars and the changing bridge matrix within PCIO. A linear time specification was chosen for the initial estimation of the Interindustry Submodule. 


\section{Table 3. Mapping of PCIO Sectors to MAM Interindustry Submodule}

Sectors, p. 1

\begin{tabular}{|c|c|}
\hline PCIO Sector & Interindustry Submodule Sector \\
\hline Other Agricultural Products & Agricultural Production - Crops (SIC 01) \\
\hline $\begin{array}{l}\text { Livestock and Products } \\
\text { Forestry and Fishery Products } \\
\text { Ag., Forestry, and Fishery Services }\end{array}$ & Other Agriculture Including Livestock (SIC 02,07-09) \\
\hline $\begin{array}{l}\text { Iron Ore Mining } \\
\text { Nonferrous Metals Mining } \\
\text { Stone/Clay Mining \& Quarrying } \\
\text { Chem. and Fertilizer Mineral Mining }\end{array}$ & Metal \& Other Non-metallic Mining (SIC 10,14) \\
\hline Coal Mining & Coal Mining (SIC 11, 12) \\
\hline $\begin{array}{l}\text { Crude Petroleum } \\
\text { Natural Gas } \\
\text { New Oil \& Gas Well Drilling } \\
\end{array}$ & Oil \& Gas Mining (SIC 13) \\
\hline $\begin{array}{l}\text { New Electric Utility Facilities } \\
\text { New Gas Utility Facilities } \\
\text { New Petroleum Pipelines } \\
\text { New Highways and Streets } \\
\text { Other New Construction } \\
\text { Maintenance \& Repair Construction }\end{array}$ & Construction (SIC 15-17) \\
\hline Food \& Kindred Products & Food \& Kindred Products (SIC 20) \\
\hline Tobacco Manufactures & Tobacco Products (SIC 21) \\
\hline $\begin{array}{l}\text { Fabric, Yarn \& Thread Mills } \\
\text { Miscellaneous Textile Goods }\end{array}$ & Textile Mill Products (SIC 22) \\
\hline $\begin{array}{l}\text { Apparel } \\
\text { Misc. Fabricated Textile Products }\end{array}$ & Apparel \& Other Textile Products (SIC 23) \\
\hline $\begin{array}{l}\text { Lumber \& Wood Products } \\
\text { Wood Containers }\end{array}$ & Lumber \& Wood Products (SIC 24) \\
\hline $\begin{array}{l}\text { Household Furniture } \\
\text { Other Furniture \& Fixtures }\end{array}$ & Furniture \& Fixtures (SIC 25) \\
\hline $\begin{array}{l}\text { Paper Mills, Exc. Building Paper } \\
\text { Paper \& Allied Products } \\
\text { Paperboard Containers \& Boxes } \\
\end{array}$ & Paper \& Allied Industries (SIC 26) \\
\hline Printing \& Publishing & Printing \& Publishing (SIC 27) \\
\hline Inorganic \& Organic Chemicals & $\begin{array}{l}\text { Inorganic Chemicals (SIC 281) - 29\% } \\
\text { Organic Chemicals (SIC 286) }-71 \%\end{array}$ \\
\hline
\end{tabular}

Energy Information Administration 


\section{Table 3. Mapping of PCIO Sectors to MAM Interindustry Submodule Sectors, p. 2}

\begin{tabular}{|c|c|}
\hline $\begin{array}{l}\text { Plastic Materials \& Resins } \\
\text { Synthetic Rubber } \\
\text { Cellulosic \& Noncellulosic Fibers }\end{array}$ & Plastic Materials \& Synthetics (SIC 282) \\
\hline $\begin{array}{l}\text { Fertilizers } \\
\text { Agricultural Chemicals, NEC }\end{array}$ & Agricultural Chemicals (SIC 287) \\
\hline $\begin{array}{l}\text { Miscellaneous Chemical Products } \\
\text { Drugs, Cleaning and Toilet Prep. } \\
\text { Paints \& Allied Products }\end{array}$ & Other Chemicals \& Allied (SIC 28, NEC) \\
\hline Petroleum Refining & Petroleum Refining (SIC 291) \\
\hline $\begin{array}{l}\text { Misc. Petroleum \& Coal Products } \\
\text { Paving Mixtures, Asphalt }\end{array}$ & $\begin{array}{l}\text { Asphalt, Coal \& Miscellaneous Products (SIC } \\
295 ; 299 \text { ) }\end{array}$ \\
\hline $\begin{array}{l}\text { Rubber Products } \\
\text { Miscellaneous Plastic Products }\end{array}$ & Rubber \& Miscellaneous Plastic Products (SIC 30) \\
\hline Leather \& Footwear & Leather \& Leather Products (SIC 31) \\
\hline Glass \& Glass Products & Glass \& Glass Products (SIC 321-323) - \\
\hline Hydraulic Cement & Cement, Hydraulic (SIC 324): \\
\hline Stone \& Clay Products & Other Stone, Clay \& Glass (SIC 32, NEC) \\
\hline $\begin{array}{l}\text { Coke Oven Products } \\
\text { Blast Furnaces \& Basic Steel }\end{array}$ & Blast Furnace \& Basic Steel (SIC 331) \\
\hline Primary Aluminum & Primary Aluminum (SIC 3334) \\
\hline $\begin{array}{l}\text { Steel Foundries, Heat Treating } \\
\text { Primary and Basic Nonferrous Metals }\end{array}$ & Other Primary Metals (SIC 33, NEC) \\
\hline $\begin{array}{l}\text { Ferrous and Nonferrous Forgings } \\
\text { Metal Containers } \\
\text { Fabricated Structural Metal Products } \\
\text { Screw Machine Products \& Fasteners } \\
\text { Automotive and Other Stampings } \\
\text { Other Fabricated Metal Products }\end{array}$ & Fabricated Metal Products (SIC 34) \\
\hline
\end{tabular}

Energy Information Administration 


\section{Table 3. Mapping of PCIO Sectors to MAM Interindustry Submodule Sectors, p. 3}

\begin{tabular}{|c|c|}
\hline $\begin{array}{l}\text { Engines \& Turbines } \\
\text { Farm \& Garden Machinery } \\
\text { Construction \& Mining Machinery } \\
\text { Oil Field Machinery } \\
\text { Materials Handling Machinery } \\
\text { Metalworking Machinery \& Equipment } \\
\text { Special Industry Machinery } \\
\text { General Industrial Machinery } \\
\text { Miscellaneous Nonelectrical Machinery } \\
\text { Office, Computing \& Account. Machinery } \\
\text { Service Industry Machinery }\end{array}$ & Industrial Machinery \& Equipment (SIC 35) \\
\hline $\begin{array}{l}\text { Electrical Machinery } \\
\text { Household Appliances } \\
\text { Electrical Lighting \& Wiring Equipment } \\
\text { Radio, TV, and Communications Equipment } \\
\text { Electronic Comp. \& Accessories } \\
\text { Misc. Electrical Machinery \& Equipment }\end{array}$ & Electronic \& Other Electric Equipment (SIC 36) \\
\hline $\begin{array}{l}\text { Motor Vehicles \& Equipment } \\
\text { Aircraft \& Parts } \\
\text { Ship \& Boat Building \& Repairing } \\
\text { Railroad Equipment } \\
\text { Miscellaneous Transportation Equipment } \\
\text { Ordnance \& Accessories }\end{array}$ & $\begin{array}{c}\text { Transportation Equipment (SIC 37) } \\
\text { (S) } \\
\end{array}$ \\
\hline $\begin{array}{l}\text { Instruments \& Supplies } \\
\text { Optical, Ophthalmic \& Photo Equipment }\end{array}$ & Instruments \& Related Products (SIC 38) \\
\hline Miscellaneous Manufacturing & Miscellaneous Manufacturing Industries (SIC 39) \\
\hline $\begin{array}{l}\text { Railroads \& Related Services } \\
\text { Passenger Transportation, NEC } \\
\text { Motor Freight } \\
\text { Water Transport. \& Related Services } \\
\text { Air Carriers \& Related Services } \\
\text { Pipelines, Except Natural Gas } \\
\text { Transportation Services, NEC } \\
\end{array}$ & Transportation Services (SIC 40-47) \\
\hline $\begin{array}{l}\text { Communications, Exc. Radio \& TV } \\
\text { Radio \& TV Broadcasting }\end{array}$ & Communications (SIC 48) \\
\hline Electric Utilities & Electric Utilities (SIC 491, pt 493) \\
\hline Gas Utilities & Gas Utilities (SIC 492, pt 493) \\
\hline Water \& Sewer Services & Water \& Sewer Services (SIC 494-497, pt 493) \\
\hline Wholesale Trade & Wholesale Trade (SIC 50,51) \\
\hline
\end{tabular}


Table 3. Mapping of PCIO Sectors to MAM Interindustry Submodule Sectors, p. 4

\begin{tabular}{|l|l|}
\hline Retail Trade & Retail Trade (SIC 52-57, 59, 739) \\
\hline $\begin{array}{l}\text { Finance \& Insurance } \\
\text { Real Estate \& Rentals }\end{array}$ & F.I.R.E. (SIC 60-63, 65-66, 153) \\
\hline $\begin{array}{l}\text { Personal Services, Exc. Automotive } \\
\text { Business Services } \\
\text { Eating \& Drinking Places } \\
\text { Automobile Repair \& Service } \\
\text { Movies \& Amusements } \\
\text { Medical, Educational Services, NPO }\end{array}$ & $\begin{array}{l}\text { Services (SIC 58, 70, 73, 75, 76, 78-80, 82-84, 86, } \\
89)\end{array}$ \\
\hline $\begin{array}{l}\text { Federal Government Enterprises } \\
\text { State \& Local Government }\end{array}$ & \\
\hline
\end{tabular}

\section{MAM Regional Submodule}

The Regional Submodule disaggregates the results of the National and Interindustry Submodules to the nine Census Division level of detail. AEO 1997 uses regional shares derived from simulations of the DRI Personal Computer Regional Model designed to be compatible with both the DRI U.S. Quarterly and PCIO models. Regional shares that vary over time for each macroeconomic growth case are included in NEMS for the AEO 1997 production runs. These regional shares are developed from simulations of the three full DRI models in integrated mode, then applying the appropriate regional shares to the macroeconomic growth case. 


\section{Appendix A: Model Input and Output Inventory}

\section{Introduction}

This Appendix describes the input data, parameter estimates, variables, and data calibrations that currently reside on the EIA RS-6000 designated for the execution of the National, Employment, Interindustry (including the Growth Industry Component of the Interindustry Submodule), and Regional Submodules of the Macroeconomic Activity Module (MAM). These data provide a detailed representation of drivers required to support macroeconomic activity forecasting in support of MAM. Appendix A also presents the primary outputs generated by MAM, and the MAM filenames residing on the EIA mainframe for the generation of NEMS scenarios. As described in the main text of this Volume, the National, Employment, and Interindustry Submodules of MAM are response surface approximations of large, proprietary econometric models developed by Data Resources, Inc.McGraw-Hill (DRI). Accordingly, the DRI modeling variables that are used to implement the response surface approximations are presented in this Appendix, along with the MAM modeling variables that are ultimately produced.

Table A-1 identifies the non-matrix MAM input data, including user-specified modeling switches and variable subscripts used in the MAM FORTRAN source code residing on RS-6000. The user-specified switches presented in Table A-1 enable the modeler to implement alternative growth path assumptions in the scenario development process.

Table A-2 defines the DRI baseline forecast that is input to MAM for the calculation of the final macroeconomic variables. The baseline forecast variables for MAM are defined as EBMAC MCAMMAC+MCNMMACREG+3,MNUMYR, corresponding to row $i$, the NEMS variable name, and the variable description. The baseline forecast variables are annual values expressed in billions of 1987 dollars except where noted in Table A-2. Table A-2 is arranged in the order of the array provided in the MAM input file on the EIA RS-6000. The index $i$ in Table A-2 indexes the 
NEMS variable that appears in the ith row of the array. The NEMS Name column in Table A-2 gives the NEMS variable name used in MAM, as opposed to the DRI variable names that are used in the full DRI models from which the MAM is developed.

Table A-3 defines the employment levels aggregated to the 2-digit SIC category which is passed as solution values to the NEMS common block. The Employment Module solves at a more disaggregated sectoring scheme but employment levels are aggregated to provide employment at the 2-digit SIC category.

Table A-4 defines EBIND, output forecast corresponding to row $\mathrm{i}$, and provides variable descriptions.

The MAM parameters are presented in Table A-5. Table A-5 provides descriptions of each parameter, including the dimensions of each parameter.

Before calling the National Submodule, MAM calculates each economic driver variable,

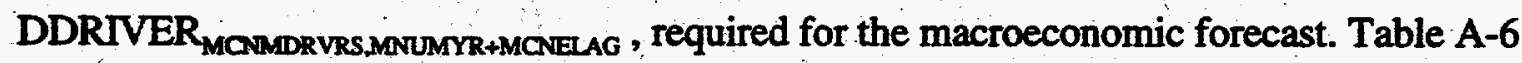
defines DDRIVER, the driver variable corresponding to row $i$, the DRI model mnemonic for each of these drivers that is used to develop the corresponding MAM variable presented in Table A-2, and the variable definition. For each activated driver variable, Table A-6 defines the variables used to calculate that driver. Equation (B-1) of Appendix B to this report is a representative structural equation for all of the energy retail price drivers.

The National Submodule calculates EPMAC $_{\mathrm{i}, M C T Y+M O N E}$, the percentage change in the macroeconomic variable i measured from the DRI baseline forecast value, where $\mathrm{i}=1,2, \ldots$ MCNMMAC+MCNMMACREG. Table A-2, numbers 1 through 109 describe the pertinent variables.

The Interindustry Submodule calculates $\mathrm{EDNND}_{\mathrm{i}, \mathrm{MCTY}}$, the change from the DRI baseline forecast 
of interindustry activity for sector $i$, where $i=1,2, \ldots$ MCNMND+MCNSERV (except for $i=14,32$, 33,38 , or 39). Table A-4 describes these variables. These industrial outputs grow according to the appropriate supply sources received from other NEMS energy modules.

The Growth Industries Component of the Interindustry Submodule calculates MCINDGROW $_{j, M N U M Y R}$ for $j=1,2, \ldots 5$, the growth rates for the industries corresponding to $i=14$, 32, 33, 38, and 39 as in EDIND above. Table A-7 describes MCINDGROW, the growth variable corresponding to row $\mathrm{j}$, the variable definition, and the corresponding row of EDIND.

The MAM outputs are described in Table A-8. The dimensions of each output are presented, along with the MAM mnemonic and subscript notation.

Table A-9 cross-references the MAM inputs, variables, parameters, and outputs with Appendix B of this report. The equation numbers appearing in Table A-9 represent the first or primary occurrence of each item. Variables may appear in numerous equations of the FORTRAN source code, so only the primary occurrence is provided in the table.

Table A-10 identifies the files used by MAM during the NEMS execution process. Table A-10 separates the files into input files and output file specifications, and describes the general contents of each file.

\section{Table A-1. Non-Matrix MAM Input Data}

Input Name

MCIYR

MCLHISYR $=6$

MCNELAG $=2$

MCNMDRVRS $=5$

MCNMFDVARS $=\mathbf{5 0}$
Input Variable Description

Current year subscript index; a value of 1 corresponds to 1990

Number of historical years, specifically 1990, 1991, 1992, 1993, 1994, and 1995

Number of years of endogenous lags in the forecast

Number of macroeconomic driver variables

Number of final interindustry demand variables

Model Documentation Report

Macroeconomic Activity Module of the National Energy Modeling System

A-3 


\begin{tabular}{|c|c|}
\hline MCNMIND $=35$ & Number of regionalized industry sectors in the forecast baseline \\
\hline MCNMMAC $=82$ & Number on non-regionalized macroeconomic variables in the baseline \\
\hline MCNMMACREG = 57 & Number of regionalized macroeconomic variables in the baseline \\
\hline MCNMSERV $=10$ & Number of non-regionalized service industry sectors in the forecast baseline \\
\hline MCNUMMNF $=29$ & Number of manufacturing variables in the baseline \\
\hline MCNUMREGS = 11 & $\begin{array}{l}\text { The nine Census Divisions, a placeholder for California (currently not in use), and } \\
\text { the national total of all Census Divisions }\end{array}$ \\
\hline NUMEMPL $=46$ & Number of Industrial Employment categories \\
\hline MNUMYR $=29$ & $\begin{array}{l}\text { Number of years available for the forecast period, specifically } 1990 \text { to } 2015,2020 \text {, } \\
2025 \text {, and } 2030 \text {. For the AEO 1997, only the period of } 1990-2015 \text { is used. }\end{array}$ \\
\hline MCNMFLTYPE $=14$ & Number of commercial floorspace types, including total \\
\hline
\end{tabular}

\section{Table A-2. DRI Baseline Forecast Data}

\begin{tabular}{|c|c|c|c|}
\hline & $i$ & NEMS Name & Input Macroeconomic Variable Description \\
\hline & 1. & $\mathrm{C} 92 \mathrm{C}$ & Personal Consumption Expenditure, Total, billions of chained $92 \$$ \\
\hline & 2. & IFIX92C & Total Fixed Investment; billions of chained $92 \$$ \\
\hline & 3. & INV92CCH & Inventory Change; billions of chained $92 \$$ \\
\hline$\cdot$ & 4. & G92C & $\begin{array}{l}\text { Government Consumption Expenditures \& Gross Investment; billions } \\
\text { of chained } 92 \$\end{array}$ \\
\hline & 5. & EX92C & Exports of Goods \& Services; billions of chained $92 \$$ \\
\hline & 6. & M92C & Imports of Goods \& Services; billions of chained $92 \$$ \\
\hline & 7. & GDP92C & Gross Domestic Product; billions of chained $92 \$$ \\
\hline & 8. & GDP92CRESID & Gross Domestic Product residual; billions of chained $92 \$$ \\
\hline & 9. & GNP92C & Gross National Product; billions of chained $92 \$$ \\
\hline & 10. & PCWGDP & Implicit Price Deflator, GDP; chained, 1992=1.0 \\
\hline & 11. & CDLV87 & Consumption of Motor Vehicles and Parts, Light Vehicles \\
\hline & 12. & CDMV\&P@L87 & Consumption of Motor Vehicles and Parts excl Light Vehicles \\
\hline & 13. & CDCMP87 & Consumption of Furniture and Household Equipment, Computers \\
\hline & 14: & CDFURN@CMP87 & Consumption of Furniture and Household Equipment, excl.Computers \\
\hline
\end{tabular}




\begin{tabular}{|c|c|c|}
\hline 15. & $\mathrm{CDO} 087$ & Consumption of Other Durables \\
\hline 16. & CNFUEL87 & Consumption of Fuel Oil and Coal \\
\hline 17. & CNFOOD87 & Consumption of Food \\
\hline 18. & CNCS87 & Consumption of Clothing and Shoes \\
\hline 19 & CNGAS87 & Consumption of Gasoline \& Oil \\
\hline 20 & CNOO87 & Consumption of Other Nondurables \\
\hline 21 & CSHHOPE87 & Consumption of Electricity \\
\hline 22 & CSHOUS87 & Consumption of Housing \\
\hline 23. & CSHHOPG87 & Consumption of Natural Gas \\
\hline 24. & CSHHOPO87 & Consumption of Other Household Operation \\
\hline 25. & CSTRANS87 & Consumption of Transportation Services \\
\hline 26. & CSOFI87 & Consumption of Free Financial Services \\
\hline 27. & CSO@FI87 & Consumption of Other Services, excl Free Financial Services \\
\hline 28. & CSMED87 & Consumption of Medical Care \\
\hline 29. & IPDER87 & Investment in Residential Producers' Durable Equipment \\
\hline 30. & ICR87 & Investment in Residential Structures \\
\hline 31. & ICNRPU87 & Investment in Non-Residential Structures, Public Utilities \\
\hline 32. & ICNRMI\&PET87 & Investment in Non-Residential Structures, Mining and Exploration \\
\hline 33 & ICNRB\&O87 & Investment in Non-Residential Structures, Buildings and Other \\
\hline 34. & IPDENROTHR87 & Investment in Non-Residential Producers' Durable Equipment, Other \\
\hline 35. & IPDENRAUT087 & $\begin{array}{l}\text { Investment in Non-Residential Producers' Durable Equipment, } \\
\text { Automobiles }\end{array}$ \\
\hline 36. & INV87CH & Total Inventory Change \\
\hline 37. & GF087 & Government Spending: Total Non-Defense \\
\hline 38. & GFML87 & Government Spending: Total Defense \\
\hline 39. & GSL87 & Government Spending: State \& Local Purchases \\
\hline 40. & EX87NLAO & Exports of Food; Feed, and Beverages \\
\hline 41. & EX87NLA1 & Exports of Industrial Supplies \& Materials \\
\hline 42. & EXINIA2BM & Exports of Computers \& Peripherals (Billions of Current Dollars) \\
\hline 43. & EX87NLA2@BM & Exports of Capital Goods excluding Autos, Computers, \& Peripherals \\
\hline 44. & EX87NIA3 & Exports of Autos \\
\hline 45 . & EX87NIA4 & Exports of Consumer Goods \\
\hline
\end{tabular}




\begin{tabular}{|c|c|c|}
\hline 46. & EX87NAO & Exports of Other Goods \\
\hline 47. & EXS87 & Exports of Services \\
\hline 48. & TYF87 & Exports of Factor Income \\
\hline 49. & M87NIA100 & Imports of Petroleum \& Products \\
\hline so. & M87NIAO & Imports of Food, Feed, and Beverages \\
\hline 51. & M87NIAI@PET & Imports of Industrial Supplies \& Materials excluding Petroleum \\
\hline 52. & MNIA2BM & Imports of Computers \& Peripherals (Billions of Current Dollars) \\
\hline 53. & M87NLA2@BM & Imports of Capital Goods excluding Autos, Computers, \& Peripheral \\
\hline 54. & M87NIA3 & Imports of Automobiles \\
\hline 55. & M87NIA4 & Imports of Consumer Goods \\
\hline 56. & M87NIA5 & Imports of Other Goods \\
\hline 57. & MS87 & Imports of Services \\
\hline 58. & PAYYF87 & Imports of Factor Income \\
\hline 59. & GDP87. & Gross Domestic Product (GDP) \\
\hline 60. & GNP87 & Gross National Product \\
\hline 61. & GDP87FE & Full Employment GDP \\
\hline 62. & PGDP & Implicit GDP price deflator $(1987=1.0)$ \\
\hline 63. & PEX & Implicit Price Deflator for Exports of Goods \& Services $(1987=1.0)$ \\
\hline 64. & PM & Implicit Price Deflator for Imports of Goods \& Services $(1987=1.0)$ \\
\hline 65. & RMGBS3NS & Average Market Rate of U.S. Govemment Three Month Bills \\
\hline 66. & RMMTGCCNS & Conventional Mortgage Commitment Rate \\
\hline 67. & RMPUAANS & Yield on AA Utility Bonds \\
\hline 68. & REALRMGBLUS & Real Average Yield on U.S. Govermment 10-Year Bonds. \\
\hline 69. & ECTWSP & Employment Cost Index, Wages \& Salaries (June 1989 = 1.0) \\
\hline 70. & JULCNF & Unit Labor Cost Index, Non-Farming Business Sector $(1982=1.0)$ \\
\hline 71. & SQTRCARSIMP & Unit Sales of Automobiles, Imported (Millions of Units) \\
\hline 72. & SQTRCARS & Unit Sales of Automobiles, (Millions of Units) \\
\hline 73. & SQDTRUCKSL & Truck Deliveries, Light Duty (Millions of Units) \\
\hline 74. & SQDTRUCKSH\&M & Truck Deliveries, Heavy and Medium Duty (Millions of Units) \\
\hline 75. & RUC & Unemployment Rate, All Civilian Workers \\
\hline 76. & EXCH & ghted Exc \\
\hline
\end{tabular}




\begin{tabular}{|c|c|c|}
\hline 77. & WPI & Producer Price Index $(1982=1.0)$ \\
\hline 78. & WPI14 & Producer Price Index, Transportation $(1982=1.0)$ \\
\hline 79. & CPI & Consumer Price Index $(1982-84=1.0)$ \\
\hline 80. & YD87 & Disposable Personal Income \\
\hline 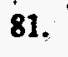 & WSD & Wage \& Salary Disbursements (Billions of Current Dollars) \\
\hline 82. & YP87 & Personal Income \\
\hline 83. & SHUMBL & Shipments of Mobile Homes (Millions of Units) \\
\hline 84. & HUSTS1 & Single-Family, Housing Starts (Millions of Units) \\
\hline 85. & HUSTS2\& & Multi-Family, Housing Starts (Millions of Units) \\
\hline 86. & KQMH & Stock of Mobile Homes (Millions of Units) \\
\hline 87. & KQHUSTS1 & Stock of Single-Family Housing (Millions of Units) \\
\hline 88. & KQHUSTS2\& & Stock of Multi-Family Housing (Millions of Units) \\
\hline 89. & $\mathbf{N}$ & Population Including Armed Forces Overseas (Millions) \\
\hline 90. & N16\& & Population Aged 16 and Over (Millions) \\
\hline 91 & MNFWGRT & Manufacturing Wage Rate (Nominal Dollars Per Hour) \\
\hline 92. & NMFFWGRT & Non-Manufacturing Wage Rate (Nominal Dollars Per Hour) \\
\hline & COMFLSPC & Total Commercial Floor Space (Billion Square Feet) \\
\hline 94. & KAMUSE & Commercial Floor Space, Amusement (Billion Square Feet) \\
\hline & KAUTO & Commercial Floor Space, Automóbile Sales (Billion Square Feet) \\
\hline 96. & KDORM & Commercial Floor Space, Dormitories (Billion Square Feet) \\
\hline 97. & KEDUC & Commercial Floor Space, Education (Billion Square Feet) \\
\hline 98. & KHEALTH & Commercial Floor Space, Health (Billion Square Feet). \\
\hline 99. & KHOTEL & Commercial Floor Space, Hotel (Billion Square Feet) \\
\hline 100. & KMFG & Commercial Floor Space, Manufacturing (Billion Square Feet) \\
\hline 101. & KMISCNR & Commercial Floor Space, Miscellaneous Non-Residential (Billion Square Feet) \\
\hline 102. & KOFFICE & Commercial Floor Space, Office (Billion Square Feet) \\
\hline 103. & KPUB & Commercial Floor Space, Public (Billion Square Feet) \\
\hline 104. & KREL & Commercial Floor Space, Religion (Billion Square Feet) \\
\hline 105. & KSTORES & Commercial Floor Space, Stores (Billion Square Feet) \\
\hline 106. & KWARE & Commercial Floor Space, Warehouse (Billion Square Feet) \\
\hline 107. & PEXNIA2BM & Implicit Price Deflator, Exports of Computers and Peripherals $(1987=1.0)$ \\
\hline 108. & PMNLA2BM & Implicit Price Deflator, Imports of Computers and Peripherals $(1987=1.0)$ \\
\hline \multirow[t]{2}{*}{109.} & RMCOF & Implicit Price Deflator, Investment in Non-Residential, Producers' Durable \\
\hline & & Equipment, Office $(1987=1.0)$ \\
\hline
\end{tabular}


Table A-3. Variables Projected by the Employment Submodule

\begin{tabular}{|c|c|c|}
\hline Varmble Name & COMMON Block Name & Description \\
\hline EEA & MC_EMPNA(I,1,MCIYR) & Total Non-Agricultural Employment \\
\hline EC. & MC_EMPNA(I,2,MCTYR) & Construction Employment \\
\hline EGF & MC_EMPNA(1,3,MCIYR) & Federal Government Employment \\
\hline EFR & MC_EMPNA(1,4,MCIYR) & Finance, Insurance, and Real Estate Employment \\
\hline EMI & MC_EMPNA(1,5,MCTYR) & Mining Employment \\
\hline ESV & MC_EMPNA(L,6,MCIYR) & Services Employment \\
\hline EGSL & MC_EMPNA(1,7,MCIYR) & State \& Local Government Employment \\
\hline $\mathbf{E R}$ & MC_EMPNA(1,8,MCTYR) & Transportation, Communications, \& Public Utilities Employment \\
\hline ETR & MC_EMPNA(1,9,MCTYR) & Retail Trade Employment \\
\hline ETW & MC_EMPNA(1,10,MCTYR) & Wholesale Trade Employment \\
\hline E24 & MC_EMPNA(L,11,MCTYR) & Lumber \& Wood Products Employment \\
\hline E25 & MC_EMPNA(L,12,MCTYR) & Furniture \& Fixtures Employment \\
\hline E32. & MC_EMPNA(I,13,MCTYR) & Stone, Clay, \& Glass Employment \\
\hline E33 & MC_EMPNA(L,14,MCTYR) & Primary Metals Employment \\
\hline E34 & MC_EMPNA(I,15,MCTYR) & Fabricated Metal Products Employment \\
\hline E35 & MC_EMPNA(L,16,MCTYR) & Machinery (except Electrical) Employment. \\
\hline E36 & MC_EMPNA(L,17,MCIYR) & Electrical Machinery Employment \\
\hline E37 & MC_EMPNA(I,18,MCTYR) & Transportation Equipment Employment \\
\hline E38 & MC_EMPNA(L,19,MCIYR) & Instruments Employment \\
\hline E39 & MC_EMPNA(I,20,MCIYR) & Miscellaneous Manufacturing Employment \\
\hline E20 & MC_EMPNA(I,21,MCTYR) & Food \& Products Employment \\
\hline E21 & MC_EMPNA(I,22,MCTYR) & Tobacco Manufactures Employment \\
\hline $\mathbf{E 2} 2$ & MC_EMPNA(L,23,MCIYR) & Textile Mill Products Employment \\
\hline E23 & MC_EMPNA(I,24,MCTYR) & Apparel \& Other Textile Products Employment \\
\hline E26- & MC_EMPNA(I,25,MCTYR) & Paper \& Prodicts Employment \\
\hline E27 & MC_EMPNA(L,26,MCIYR) & Printing \& Publishing Employment \\
\hline E28 & MC_EMPNA(1,27,MCTYR) & Chemicals \& Allied Protucts Employment \\
\hline E29 & MC_EMPNA(I,28,MCIYR) & Petroleum Products Employment \\
\hline $\mathbf{E 3 0}$ & MC_EMPNA(1,29,MCIYR) & Rubber \& Miscellaneous Proctucts Employment. \\
\hline E31 & MC_EMPNA(L,30,MCIYR) & Leather \& Products Employment \\
\hline EAG & MC_EMPNA(1,31,MCIYR) & Agricultural Employment \\
\hline
\end{tabular}

Model Documentation Report 


\section{Table A-4. DRI Baseline Industrial Model Inputs}

I Input Industrial Output Variable Description

1 Food \& Kindred Products (SIC 20)

2 Tobacco Products (SIC 21)

3 Textile Mill Products (SIC 22)

4 Apparel \& Other Textiles. (SIC 23)

5 Lumber \& Wood Products. (SIC 24)

6 Furniture \& Fixtures (SIC 25)

7 Paper \& Allied Industries (SIC 26)

8 Printing \& Publishing (SIC 27)

9 Inorganic Chemicals (SIC 281)

10 Organic Chemicals (SIC 286)

11 Plastic Materials \& Synthetics (SIC 282)

12 Agricultural Chemicals (SIC 287)

13 Other Chemicals \& Allied (SIC 28, nec)

14 Petroleum Refining (SIC 291)

15 Asphait, Coal, \& Miscellaneous Products (SIC 295, 299)

16 Rubber \& Miscellaneous Plastic Products (SIC 30)

17 Leather \& Leather Products (SIC 31)

18 Glass \& Glass Products (SIC 321, 322, 323)

19 Cement, Hydraulic (SIC 324)

20 Other Stone, Clay, \& Glass Products (SIC 32, nec)

21 Blast Furnace \& Basic Steel (SIC 331)

22 Primary Aluminum (SIC 3334)

$23 \quad$ Other Primary Metals (SIC 33, nec)

24 Fabricated Metal Products (SIC 34)

25 Industrial Machinery \& Equipment (SIC 35)

26 Electronic \& Other Electric Equipment (SIC 36)

27 Transportation Equipment (SIC 37)

28 Instruments \& Related Products (SIC 38)

Model Documentation Report Macroeconomic Activity Module of the National Energy Modeling System 


\author{
29 Miscellaneous Manufacturing Industries (SIC 39) \\ 30 Agricultural Production, Crops (SIC 01) \\ 31 Other Agricultural Production Including Livestock (SIC 02, 07, 08, 09) \\ 32. Coal Mining (SIC 11, 12) \\ 33 Oil \& Gas Mining (SIC 13) \\ 34 Metal \& Other Mining (SIC 10, 14) \\ 35. Construction (SIC 15, 16, 17) \\ 36 Transportation Services (SIC 40, 41, 42, 43, 44, 45, 46, 47) \\ 37 Communications (SIC 48) \\ 38. Electric Utilities (SIC 491, part of 493) \\ 39 Gas Utilities (SIC 492, part of 493) \\ 40 Water \& Sewer Services (SIC 494, 495, 496, 497, part of 493) \\ 41 Wholesale Trade (SIC 50,51) \\ 42 Retail Trade (SIC 52, 53, 54, 55, 56, 57, 59, 739). \\ 43 Finance, Insurance, Real Estate (SIC 60, 61, 62, 63, 65, 66, 153) \\ 44 Services (SIC 58, 70, 73, 75, 76, 78, 79, 80, 82, 83, 84, 86, 89) \\ 45 Government Enterprises (SIC part of 41, 431)
}

\title{
Table A-5. Parameters used in MAM
}

\begin{tabular}{ll} 
Parameter Name & Parameter Description \\
\hline ECIND $_{i j}$ & Base year coefficient which translates changes in the final demand component $j$ \\
& into changes in interindustry activity for sector $i$ (for $i=1,2,3, \ldots$ MCNMIND + \\
MCNMSERV and $j=1,2,3, \ldots$ MCNMFDVARS) & Predictor coefficient $\mathrm{j}$ corresponding to the macroeconomic variable $i$ (for $i=1$, \\
& $2,3, \ldots$ MCNMMAC + MCNMMACREG and $j=10$ contemporaneous \\
ECMAC & coefficients +10 one-year-lag coefficients +10 two-year lag coefficients + two \\
endogenous lags, where 10 corresponds to the number of MAM driver variables \\
as represented in Table A-5 below). See Table A-2 numbers 1 through 109 for a \\
description of these variables.
\end{tabular}


$\mathrm{ECNDCH}_{\mathrm{ij}}$

REGSHRS $_{\mathrm{ijwarrR}}$

ECEMP:
Time-dependent coefficient of change for translating changes in the final demand component $j$ into changes in interindustry activity for sector $i$ (for $i$ and $j$ as in ECIND above)

Percent share for region $j$ of macroeconomic variable $i$ in year $\operatorname{MCTYR}$ (for $j=1$, 2, 3,... MCNUMREGS and $i=1,2,3, \ldots$ MCNMMACREG) and percent share for region $j$ of industrial demand $i$ in year MCTYR ( for $j$ as above and $i=$ MCNMMACREG+1, MCNMMACREG+2, ... MCNMMACREG+MCNMIND) Predictor coefficient of change for translating changes in industrial activity for sector $i$ and $j$ th explanatory variable $(j=1 . .3)$

\section{Table A-6. MAM Driver Variables}

i DRI mnemonic

1

PCSHHOPE

PELRS

MCTYR

MCNELAG $=2$

MCADJ

MCPGDP87

PCBPRICE

BDRIVER

PCPASS

PCWPI05

INFDSW
Calculated Variable Definition

Implicit Price Deflator, Consumer Spending, Electricity

Variables used to calculate PCSHHOPE follow.

Price of Residential Electrical Service Corresponding to the Final

Demand Deflator

NEMS System Current Year Subscript Index

Number of Years of Endogenous Lags in the Forecast

User Specified Adjustment Variable

1987 Base GDP Deflator

1992 Value for PELRS

Baseline Value of the Driver Variable

Adjustment Factor to Prevent Double Counting the Effect Captured by the WPI05 Coefficient

Percentage Change in the WPI054 (corresponding to the electricity price) term of the WPI05 from baseline value

Switch Controlling Feedback for Individual Driver Variables 
PNGRS

PCNFUEL

PDSRS

PCNGAS

PDSTR

QDSTR

PMGTR

QMGTR

5

WPI05

PCLIN

PNGLN

PELIN
Implicit Price Deflator, Consumer Spending, Natural Gas

Variables used to calculate PCSHHOPG follow.

Price of Residential Natural Gas Service Corresponding to the Final Demand Deflator

Other Variables used to Calculate PCSHHOPG are analogous to the variables used to calculate PCSHHOPE above (listed in the table beginning with MCTYR and ending with INFDSW), but the subscripts and definitions of the PCSHHOPG variables correspond to natural gas instead of electricity.

Implicit Price Deflator, Consumer Spending, Fuel Oil and Coal Variables used to calculate PCNFUEL follow.

Price of Residential Distillate Service Corresponding to the Final Demand Deflator

Other Variables used to Calculate PCNFUEL are as in PCSHHOPE above (listed in the table beginning with MCIYR and ending with INFDSW), but the subscripts and definitions of the PCNFUEL variables correspond to fuel oil and coal instead of electricity. Implicit Price Deflator, Consumer Spending, Motor Gasoline including Diesel Fuel, and Oil.

Variables used to calculate PCNGAS follow.

Price of Distillate for Transportation

Quantity of Distillate for Transportation

Price of Motor Gas for Transportation

Quantity of Motor Gas for Transportation

Other Variables used to Calculate PCNGAS are as in PCSHHOPE above (listed in the table beginning with MCIYR and ending with INFDSW), but the subscripts and definitions of the PCNGAS variables correspond to motor gasoline, diesel fuel, and oil instead of electricity.

Producer Price Index, Fuels and Related Products and Power Industrial Price of Steam Coal, 1987 dollars Industrial Price of Natural Gas, 1987 dollars Industrial Price of Electricity, 1987 dollars

Model Documentation Report Macroeconomic Activity Module of the National Energy Modeling System 


\begin{tabular}{ll} 
IT_WOP & $\begin{array}{l}\text { World Oil Price, } 1987 \text { dollars } \\
\text { WPIBY }\end{array}$ \\
& Base Year (1992) Price of the Respective Component used to \\
WPIWT & generate WPI05 (Electricity, Coal, Oil, or Natural Gas) \\
BPRICE & Portion of Total WPI05 for the Respective Component \\
BPRICE(5) & 1992 Value of each WPI05 Component's Producer Price Index \\
MCPGDP87 & Base Year (1992) Price of the WPI05 Component \\
MCADJ & 1987 Base GDP Deflator \\
BDRIVER & User Specified Adjustment Variable \\
INDSW & Baseline Value of the Driver Variable \\
\hline
\end{tabular}

\section{Table A-7. Variables Calculated in MAM}

\begin{tabular}{lll} 
j & Calculated Variable Definition & i \\
\hline 1 & Growth in Coal Mining & 32 \\
2 & Growth in Oil and Gas Mining & 33 \\
3 & Growth in Petroleum Refining & 14 \\
4 & Growth in Gas Utilities & 39 \\
5 & Growth in Electric Utilities & 38
\end{tabular}

\section{Table A-8. MAM Model Outputs}

\begin{tabular}{|c|c|}
\hline Output Variable Name & Output Variable Description \\
\hline ESIND $_{j, 1 M C T R R}$ & $\begin{array}{l}\text { Industrial output forecast for sector } i \text { in region } j \text { in year } M C I Y R \text { for } j=1,2,3, \ldots \\
\text { MCNUMREGS and } i=1,2,3, \ldots \text { MCNMIND. See Table A-4 numbers } 1 \text { through } \\
35 \text { for a description of these variables. }\end{array}$ \\
\hline $\mathrm{ESIND}_{36, \mathrm{M} \mathrm{MCTR}}$ & $\begin{array}{l}\text { Industrial output forecast for Chemicals \& Allied Products (SIC 28); } \\
\text { Sum of ESIND }\end{array}$ \\
\hline
\end{tabular}




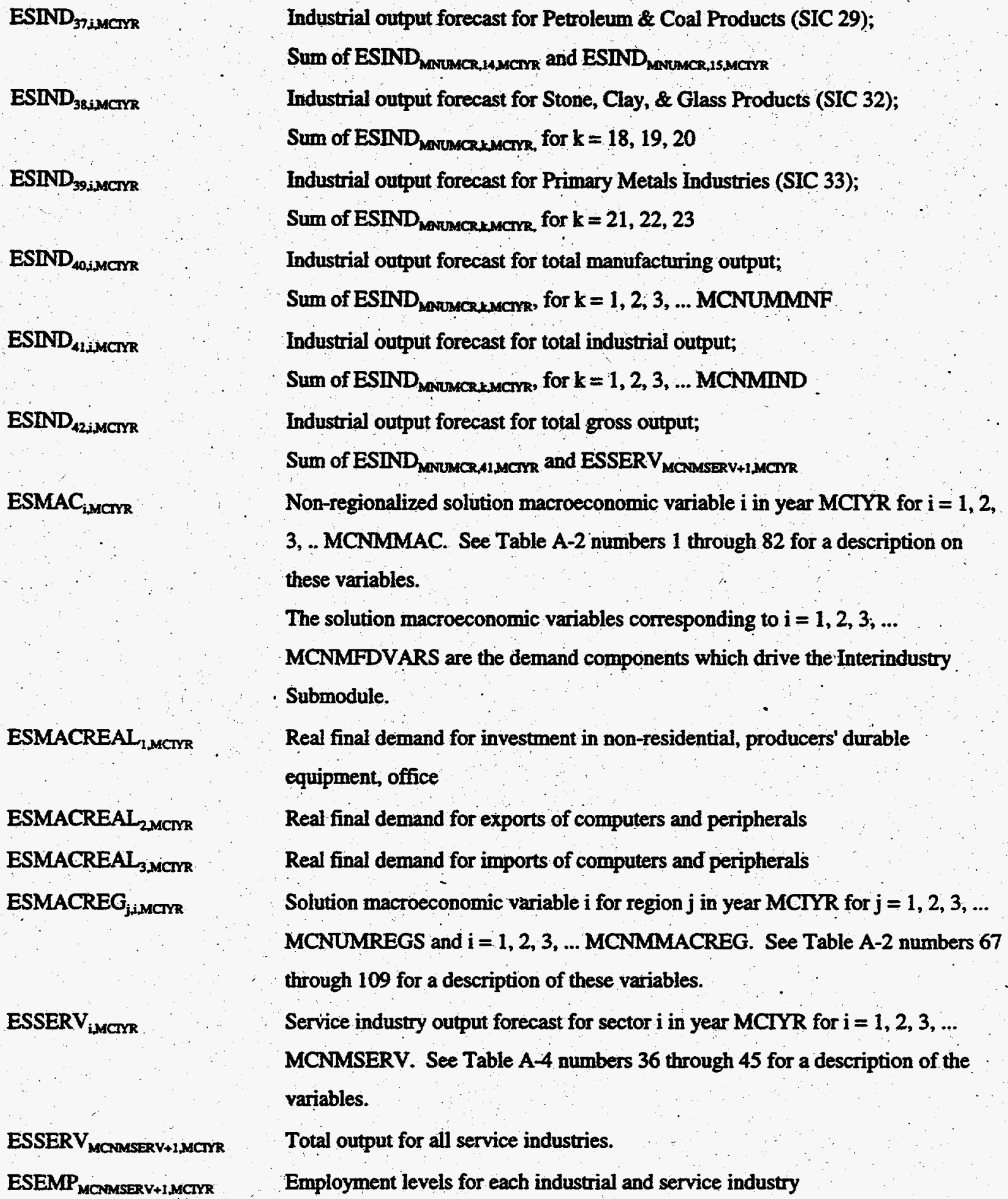


Table A-9 provides a cross reference between variable name, variable type, and number of the main equation containing the variable. (Variables may appear in numerous equations.)

\section{Table A-9. Cross-Reference with Appendix B Equations}

\begin{tabular}{|c|c|c|}
\hline Variable & Calculation Methodology & $\begin{array}{l}\text { Equation Containing } \\
\text { Primary Occurrence }\end{array}$ \\
\hline DDRIVER & Calculated in MAM & (B-1) \\
\hline EBIND, mavamomacNusERVMNUMYYR & $\begin{array}{l}\text { Input from MACINTER in } \\
\text { the NEMS common }\end{array}$ & (B-15) \\
\hline EBINDOLD MONMAD+MCNMSERVMNUMYR & Storage & (B-25) \\
\hline EBEMP $_{\text {MCMAMND+MCNMSERV-1,1MANUMYRR }}$ & Input/MACINTER & (B-12) \\
\hline EBMAC GACNAMAC+MCNMAACREG+3MANAMYR & Input/MACINTER & (B-6) \\
\hline ECIND MOMMND+MCNMSERV,MOMMPVARS & Parameter/MACINTER & (B-13) \\
\hline ECEMP ${ }_{\text {NOMEMPL }+2,3}$ & Parameter/MACINTER & (B-12) \\
\hline ECMAC & Parameter/MACINTER & (B-5) \\
\hline ECNDCH ${ }_{\text {MCNMND+MCNMSERVMCNMFDVARS }}$ & Parameter/MACINTER & (B-13) \\
\hline EDIND MONGMD+MONMSERVMANUMR & Calculated in Interindustry & (B-13) \\
\hline EDEMP $_{\text {NUMEMPL + 2MCTRR }}$ & Calculated in Employment & (B-12) \\
\hline EPMAC MCINMAC+MCNMMACREG,MNUMYR+MONEAO & Calculated in National & (B-5) \\
\hline ESIND & Output/MACWNTER & (B-15) \\
\hline 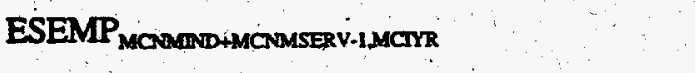 & Output/MACINTER & (B-12) \\
\hline ESMAC MCNmancmanumYr & Output/MACINTER & (B-6) \\
\hline ESMACREAL ${ }_{3, M N U M Y R}$ & OUtput/MACINTER & (B-8) \\
\hline ESMACREG MCNUMREGSMCNMANACREGMNUMYR & OUtput/MACINTER & $(B-7)$ \\
\hline ESSERV MOMMSERV + 1 MNTMYR & Output/MACINTER & (B-14) \\
\hline MCINDGROW & Calculated in Growth & (B-24) \\
\hline$\because \quad \because \cdots \quad \cdots$ & Industry & \\
\hline REGSHRS MCNUMREGS-2MCNMMACREG+MCNMMDDANUMYR & Parameter/MACINTER & (B-34) \\
\hline MCIYR & InputMACINTER & (B-1) \\
\hline
\end{tabular}


MCLFISYR

Parameter Input from

MCNELAG

NEMS Global Data

Structure (GDS)

MCNMDRVRS

Parameter Input from GDS

MCNMFDVARS

Parameter Input from GDS

MCNMIND

Parameter Input from GDS

MCNMMAC

Parameter Input from GDS

MCNMMACREG

Parameter Input from GDS

MCNMSERV

Parameter Input from GDS

Parameter Input from GDS

MCNUMMNF

Parameter Input from GDS

MCNUMREGS

Parameter Input from GDS

MNUMCR

Parameter Input from GDS

MNUMYR

Parameter Input from GDS

N/A

\section{MAM File Descriptions}

Table A-10 identifies the files used by MAM during the NEMS execution:

\section{Table A-10. MAM Input and Output File Specification}

\begin{tabular}{|c|c|c|}
\hline Filename: & File Description & Input or Output \\
\hline MCPARMS & Parameter file & Inpurt \\
\hline MCDNADJ & Adjustment factor file & Input \\
\hline MCBBASE . & Baseline values of the driver variables & Input \\
\hline MCECIND & Industrial coefficient file & Input \\
\hline MCECMAC & Macro coefficient file & Input \\
\hline MCBASE & Macroeconomic baseline scenario file & Input \\
\hline MCRGSHR & $\begin{array}{l}\text { Regional share coefficients from DRI } \\
\text { Regional Model }\end{array}$ & Input \\
\hline MACOUTI & Results file & Output \\
\hline MACOUT2 & Results file & Outpur \\
\hline
\end{tabular}




\section{Appendix B. Mathematical Description}

\section{Introduction}

Appendix B provides a detailed mathematical description of equations, transformations, and other computations for the National, Employment, Interindustry (including the Growth Industry Component of the Interindustry Submodule), and Regional Submodules of the MAM used to generate the AEO 1997 production runs of the NEMS system. It also provides a commented version of the important subroutines in FORTRAN code used to generate the AEO97 runs.

\section{The National Submodule}

The National Submodule of the MAM is a response surface representation of the DRI U.S. Quarterly Macroeconomic Model and is used in the AEO 1997 production runs of NEMS to provide each of the energy supply, demand, and conversion submodules with key macroeconomic final demand component forecasts.

Before calling the National Submodule, MAM calculates the macroeconomic driver variables, DDRIVER, as described in Table A-6 of Appendix A of this report. A representational equation for all the energy retail price drivers, the driver variable corresponding to the PCSHHOPE variable described in Table A-6 of Appendix A of this report, follows:

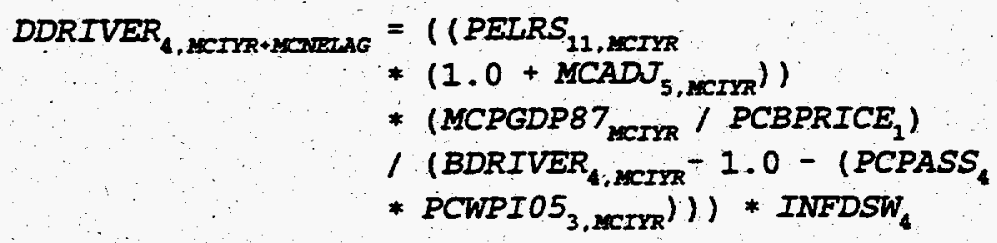


PCPASS Description. As discussed previously, the MAM National Submodule is a reduced form, or response surface, representation of the DRI Quarterly Macroeconomic Model. The fundamental premise of MAM is to treat the DRI model as a black box which, when fed certain inputs, generates certain outputs. The outputs are then regressed on the inputs to create the response surface.

To create the outputs from the DRI model, called pseudo data, the DRI model is executed numerous times varying the designated input variables, that are ultimately used as the independent variables in the response surface equation. Some of the simulations used to generate the pseudo data were created by allowing the world price of oil to change. This is a truly exogenous variable that directly affects the domestic energy supply price (WPI05). When these simulations were run, the personal consumption (PC) deflators for fuels (PCNFUEL, PCNGAS, PCSHHOPE, and PCSHHOPG) were not constrained. That is, the model was allowed to change these variables as WPI05 changed. This approach was adopted because, if they had been held constant, the DRI model would have given very strange results with respect to the macroeconomic variables of interest, e.g., GDP, disposable income, interest rates, etc. Similarly, when the energy consumption deflators were varied, WPI05 and the other explanatory variables were allowed to vary. Thus, the variables on the right hand side of the regression are not truly exogenous, although they are exogenized when the DRI model is run.

This problem was addressed as follows. For those simulations in which WPI05 varies, $\mathrm{dX}_{\mathrm{j}}$ was set to zero (the percent change from base) in the resulting output data set for the remaining explanatory variables, even though they are not zero in the original model output. Similarly, when the energy consumption deflators are varied, no variables are constrained in the model run, but the deviations of WPI05 and the other explanatory variables from the base are set to zero, thus holding them at the baseline. Consequently, the coefficients on WPI05 contain all the effects of a change in the energy supply price, including the effects that occur through changes in the energy price deflators. 
The result is an equation of the form

$$
d Y_{t}=\sum_{j=1}^{5} \alpha_{j} d X_{j t}+\sum_{j=1}^{5} \beta_{j} d X_{j, t-1}+\sum_{j=1}^{5} Y_{j} d X_{j, t-2}+\delta_{1} d Y_{t-1}+\delta_{2} d Y_{t-2}
$$

where $d Y$ and $d X_{j}$ refer to the percent change from base of the dependent and independent variables respectively. The independent variables are:

$\begin{array}{ll}\text { X1=PCSHHOPE } & \text { (PC deflator for electricity) } \\ \text { X2=PCSHHOPG } & \text { (PC deflator for natural gas) } \\ \text { X3=PCNFUEL } & \text { (PC deflator for heating oil) } \\ \text { X4=PCNGAS } & \text { (PC deflator for gasoline) } \\ \text { X5=WPI05 } & \text { (wholesale price deflator for fuels) }\end{array}$

As stated previously, the purpose of the MAM is to link the macroeconomy to the energy sector. The whole simulation process begins with the specification of a base macroeconomic case. However, once NEMS begins iterating, it computes its own estimates of the relevant fuel prices. These prices are received by MAM from NEMS, aggregated to WPI05, multiplied by the coefficient $\alpha_{5}$ in the above equation and the resulting change in the macroeconomic variable is passed back to NEMS.

The coefficients on variables $\mathrm{X} 1-\mathrm{X} 5$ provide the ability to calculate the effects of various energy policies. For example, a tax on gasoline would affect the personal consumption deflator for gasoline directly, but it would not directly affect the wholesale price of gasoline. A change in the wholesale price of gasoline, on the other hand, would affect the price at the pump, which would directly impact the PC deflator for gasoline. The coefficient $\alpha_{s}$ estimates the entire effect of a change in the wholesale price of fuel. Therefore, the modeler does not want to include the effect 
of changes in the deflators when they arise out of a change in the wholesale price. However; NEMS calculates its own estimates of the retail prices of the various fuels. Changes in these prices will have macroeconomic consequences. Thus, a method to calculate the macroeconomic impacts of changes in the retail prices of fuels when they come from NEMS, and are not the result of an exogenous policy effects, is required. This potential for double-counting is the crux of the problem that is addressed in the MAM through the use of the PCPASS variable.

This problem is addressed as follows. The coefficient $\alpha_{5}$ measures the effect of a change in WPI05. NEMS has reports a change in WPI05 in each iteration, so the product of $\alpha_{5}$ and dX, captures that effect, including the implied effect on PCNGAS, the other deflators, and investment. However, suppose that NEMS also reports a change in the retail price of gas, corresponding to a change in PCNGAS. If this change is greater than the implied change that would have occurred in the DRI model, then there is a greater effect on the macroeconomy than that captured in $\alpha_{5}$. This additional effect is captured by the following technique. A preprocessor model has been estimated to predict the change in the PC deflators and investment from changes in the corresponding wholesale prices. The preprocessor is a simple equation $\left(\mathrm{dX}_{j}=\mathrm{b}_{j} \mathrm{dZ} \mathrm{Z}_{\mathrm{k}}\right.$ ) relating percent changes from base of the four PC deflators $\left(\mathrm{dX}_{j}\right)$ to percent changes in the relevant wholesale price $\left(\mathrm{dZ}_{\mathrm{k}}\right)$. For example, the PC deflator for natural gas is related to the wholesale price of natural gas. Thus, the preprocessor allows the calculation of the DRI model prediction of the PC deflator given the wholesale price. The NEMS estimate of the PC deflator could be higher or lower than this. If it is higher, then an increment to the change in the macro variable is required. If it is less, then a decrement to the effect on the macro variable is required. So, the predicted change in PC deflators and investment variables from the preprocessor model are subtracted from those changes passed to MAM from NEMS and the percent change from base, $\mathrm{dX}_{\mathrm{j}}$ in the above equation is set equal to this amount. In other words, for the four PC deflators, the following relationship is set:

$$
d X_{j}=d X_{j}^{(N E M S)}-b_{j}^{*} d Z_{k}
$$


in the previous equation where $d X_{j}^{\text {NEMS) }}$ is the change from base passed from NEMS and $b_{j}{ }^{*} d Z_{k}$ is the predicted change in $\mathrm{dX}_{j}$ from the preprocessor model. By this means, the macroeconomic variable is adjusted to account for changes in the PC deflators and investment variables coming from NEMS that are different from the values that would have been predicted by DRI and which are already included in the $\alpha_{5}$ coefficient in the previous equation.

Equation (B-1) corresponds to Equation (10) in the main text of this report. The driver variable corresponding to WPI05, the producer price index for fuels and related products and power, is calculated as follows:

$$
D D R I V E R_{5, M C I Y R+M C N E C A G}=\frac{\left(\left(W P I 05_{M C I Y R} *\left(1.0+M_{C A D J_{14, M C T Y R}}\right)\right)\right.}{\left(B D R I V E R_{5, M C I Y R}-1.0\right) * I N F D S W_{5}}
$$

MAM then calls the National Submodule. Equation (B-4) corresponds to the discussion surrounding Equation (10) in the main text of this report. In calculating the percent change from the DRI baseline for the macroeconomic variable $i$, the National Submodule captures the (approximate) dynamic effect of lagged exogenous variables by including the effects of ten contemporaneous coefficients, ten one-year-lag coefficients, ten two-year-lag coefficients, and two endogenous lags of dependent variables as follows:

\section{If MCIYR > MCLHISYR}

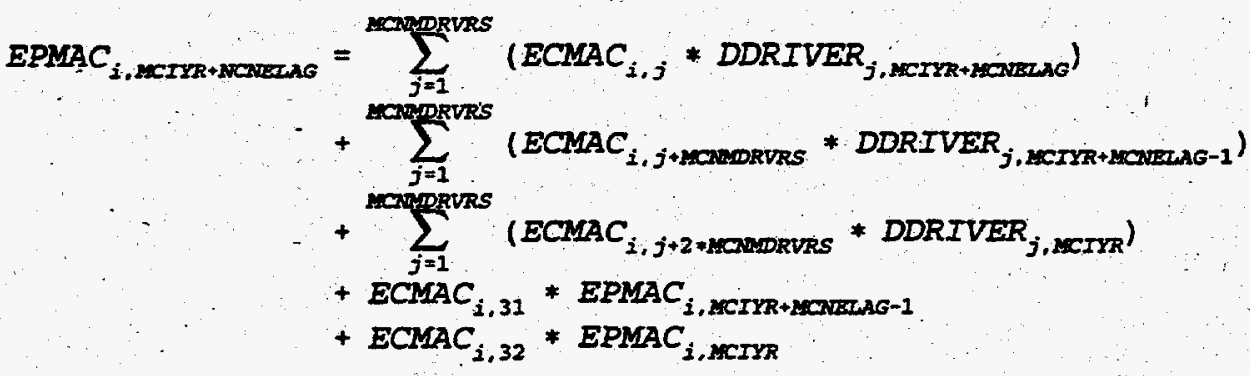


Equation (B-5) corresponds to Equation (10) in the main text of this report. Using the percent change from the DRI baseline for the current year plus the two-year endogenous lag, the National Submodule estimates the solution macroeconomic variables (non-regionalized and regionalized) as follows:

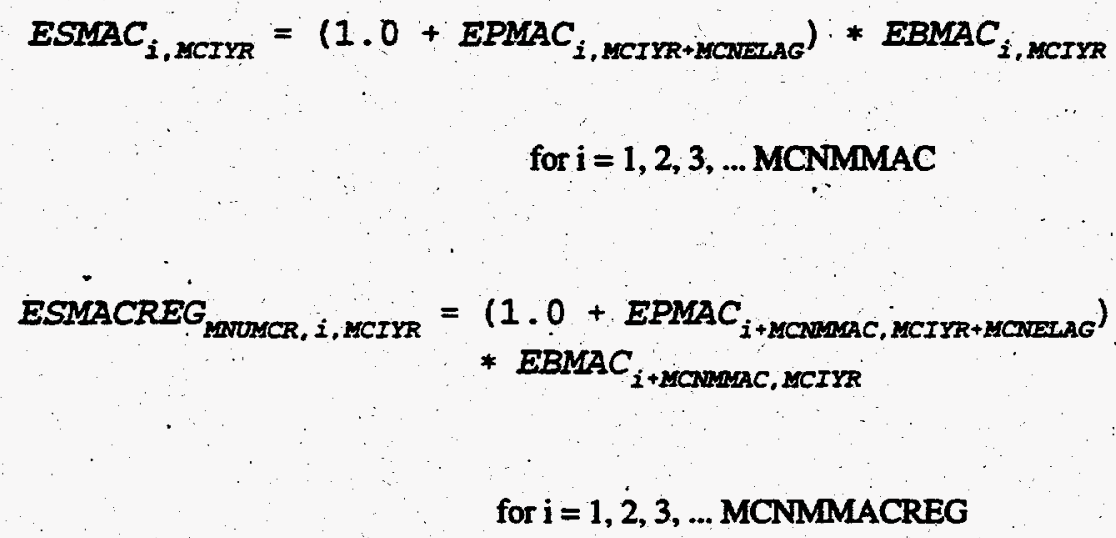

Equations (B-6) and (B-7) correspond to the discussion surrounding Equations (10) and (11) in the main text of this report. Using the solution and DRI baseline macroeconomic variables, the National Submodule computes three real final demands as follows:

$$
\begin{aligned}
\text { ESMACREAL }_{1, \text { MCIYR }}= & \text { ESMAC }_{22, M C T Y} / \text { EBMAC }_{\text {MCNMOAC+MCNMMACREG }+3, \text { MCTYR }} \\
& \text { (Investment in non-residential, durable, office equipment) } \\
\text { ESMACREAL }_{2, \text { MCIYR }}= & \text { ESMAC }_{30, \text { MCIYR }} / \text { EBMAC }
\end{aligned}
$$

(Exports of computers and peripherals)

$$
\text { ESMACREAI }_{3, \text { MCIYR }}=\text { ESMAC }_{40, \text { MCIYR }} / \text { EBMAC }
$$


(Imports of computers and peripherals)

Equations (B-8), (B-9), and (B-10) are not discussed explicitly in the main text of this report, but they are treated in a manner similar to that discussed surrounding Equation (8) in the main text. 


\section{The Employment Submodule}

The Employment Submodule is a response surface version of the DRI Econometric Model of Employment by Industry. The Employment Submodule calculates the employment impacts of altered energy market conditions based on the following causal relationships. When energy prices change, the level and composition of macroeconomic final demands are affected. In turn, the level and composition of interindustry gross outputs required to satisfy the new final demands are changed. Finally, faced with new demands for their products, industries will adjust the number of workers employed. The response surface Employment Submodule represents this last link in the chain.

The Employment Submodule is constructed similarly to the Interindustry Submodule of MAM. Within MAM changes in employment are determined by changes in gross output. The response surface Employment Submodule is specified as a partial adjustment model. Increasing and decreasing employment is costly for businesses. Firms will not adjust employment to the ultimately desired level immediately when output demand changes, but will wait to see whether the demand change persists. For each sector, the equation for change in employment is:

$$
\Delta E_{i, t}=\left(\left(\beta_{1}+\left(\beta_{2} * t i m e\right)\right) * \Delta G O_{i, t}\right)+\left(\beta_{3} * \Delta E_{i, t-1}\right)
$$

where:

$$
\begin{aligned}
& \Delta E_{i, t}=\text { change in employment for industry } i \text { in period } t, \text { in millions of persons } \\
& \text { time }=\text { a time counter, which equals } 1 \text { in } 1995 \\
& \Delta G O_{i, t}=\text { change in gross output for industry } i \text { in period } t, \text { in millions of } \$ 1987 \\
& \Delta E_{i, t-1}=\text { change in employment for industry } i \text { in the previous period, in millions of } \\
& \text { persons }
\end{aligned}
$$

If MCTYR > MCLHISYR 


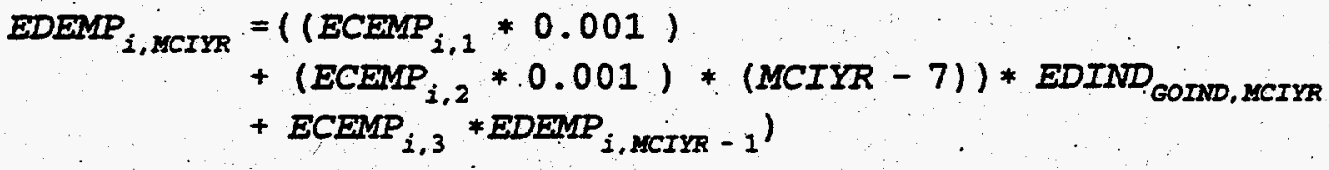

for $i=1,2,3, \ldots$ MNUMEMP $L+2$

EDEMP is the calculated change in employment levels resulting when there is a change in the sector's industrial output. ESEMP is the addition of the old employment level (before any change in industrial output) and EDEMP. Equations (B-11) and (B-12) correspond to the discussion surrounding Equation (12) in the main text of this report. 


\section{The Interindustry Submodule}

- The Interindustry Submodule of MAM is a response surface representation of the DRI-PCIO model which responds to changes from baseline levels in macroeconomic final demand components and calculates consistent changes in interindustry activity.

If MCIYR > MCLHISYR

$$
\begin{aligned}
& E D I N D_{i, M C I Y R}=\sum_{j=1}^{\text {MCNMFPVARS }}\left(\left(E_{C I N D_{i, j}}+E C N D C H_{i, j}\right.\right. \\
& \text { * (MCIYR - MCLHISYR)) } \\
& \text { * (ESMAC } \left.\left.j_{j, M C T Y R}-E B M A C_{j, M C I Y R}\right)\right)
\end{aligned}
$$

for $i=1,2,3, \ldots$ MCNMIND + MCNMSERV (except for $i=14,32,33,38$, or 39)

Equations (B-13) and (B-14) correspond to the discussion surrounding Equation (13) in the main text of this report. The Interindustry Submodule next estimates the industrial output forecast for the 10 non-regionalized service industries and the 35 regionalized industries (along with selected composite industrial outputs) as follows:

$$
\begin{aligned}
& \text { ESSERV }_{i-\text { MONIND, MCTYR }}=\text { EBIND }_{i, \text { MCTYR }}+\text { EDIND }_{i, \text { MCIYR }} \\
& \text { for } i=M C N M I N D+1, M C N M I N D+2, M C N M I N D+3, \ldots \\
& \text { MCNMIND+MCNMSERV (except for } \mathrm{i}=38 \text { or } 39 \text { ) } \\
& E S I N D_{\text {MNCUYCR, } i, M C I Y R}=E B I N D_{i, \text { WCIYR }}+E D I N D_{i, M C I Y R}
\end{aligned}
$$




$$
\text { for } i=1,2,3, \ldots \text { MCNMIND (except for } i=14,32 \text {, or } 33 \text { ) }
$$

$$
E S I N D_{\text {MAVTICR, 36, MCTYR }}=\sum_{i=9}^{13} \text { ESIND }_{\text {MNONCR, } i, \text { MCTYR }}
$$

(National total of chemical and allied products in year MCIYR)

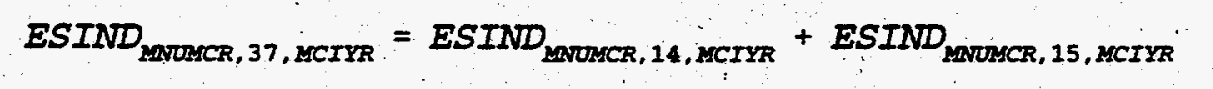

(National total of petroleum and coal products in year MCIYR)

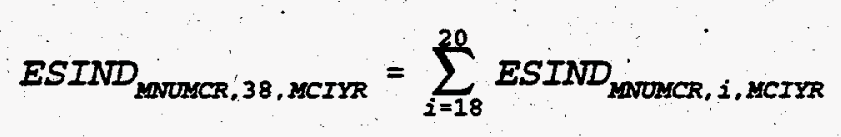

(National total of stone, clay, and glass products in year MCTYR)

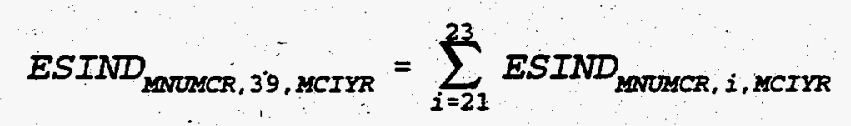

(National total of primary metals industries in year MCIYR)

ESIND ${ }_{\text {MNOMCR, 40,MCIYR }}=\sum_{i=1}^{\text {MCNOZMNF }}$ ESIND

(National total of all manufacturing output in year MCTYR)

$$
\text { ESIND }_{\text {LNONCR, 41, MCIYR }}=\sum_{i=1}^{\text {MCNMIDD }} \text { ESIND }
$$

(Total national industrial output, manufacturing and non-manufacturing, in year MCTYR) 


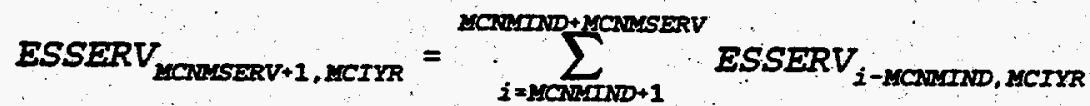

(B-22)

(Total national service industry output in year MCTYR)

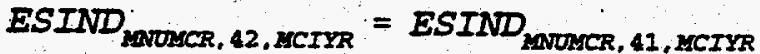

$$
\begin{aligned}
& \text { + ESSERV MONYSERV+1, MCIYR }
\end{aligned}
$$

(Total national gross output, industries and service industries, in year MCTYR)

Equations (B-15) through (B-23) provide supporting detail for the discussion surrounding Equation (13) in the main text of this report. 


\section{The Growth Industry Submodule}

Petroleum Refining, Coal Mining, Oil and Gas Mining, Electric Utilities, and Gas Utilities (the industry sectors corresponding to $i=14,32,33,38$, and 39 respectively) are all benchmarked in DRI historical years, but change at rates calculated from selected NEMS energy variables instead of changing at the rates applied to other industries in the Interindustry Submodule. Figure 4 in Chapter 4 of the main text of this report illustrates the flow of the Growth Industry Submodule, providing additional detail regarding the growth paths and dependencies of these growth paths. Table A-7 also describes MCINDGROW.

For MCTYR > MCLHISYR:

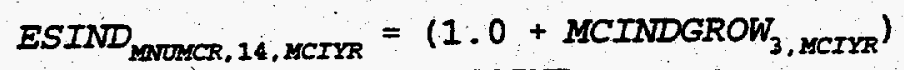

$$
\begin{aligned}
& \text { * ESIND } \text { MNOMCR, 14, MCIYR-1 } \\
& \text { ESIND }_{\text {MNUMCR, 32, MCIYR }}=(1.0+\text { MCINDGROW } 1, \text { MCIYR }) \\
& \text { * ESIND } \text { MNONCR, 32, MCIYR-1 } \\
& \text { ESIND }_{\text {MNOXCR, 33, MCIYR }}=(1.0+\text { MCINDGROW }, \text { MCIYR }) \\
& \text { * ESIND MNOMSR, } 33, \text { MCTYR-1 }
\end{aligned}
$$

For MCIYR $<=$ MCLHISYR:

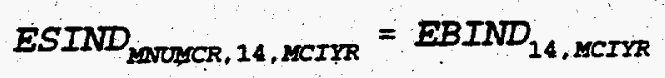




$$
\begin{aligned}
& E S I N D_{\text {LNONCR, 32, MCIYR }}=E B I N D_{32, \text { MCTYR }} \\
& E S I N D_{\text {MNAMCR, 33,MCTYR }}=E B I N D_{33, \text { MCTYR }}
\end{aligned}
$$

For MCTYR > MCLHISYR:

$$
\begin{aligned}
& \text { ESSERV }_{38-M O N T N, \text { MCIYR }}=(1.0+\text { MCINDGROW } 5, \text { MCIYR }) \\
& \text { * ESSERV } 38 \text { - MCAMIND, MCIYR-1 } \\
& \text { ESSERV }_{39-M C N M C N D, M C I Y R}=\left(1.0+\text { MCINDGROW }{ }_{4, M C I Y R}\right) \\
& \text { * ESSERV 39-MCRIIND, MCIYR-1 }
\end{aligned}
$$

For MCIYR $<=$ MCLHISYR

$$
\begin{aligned}
& \text { ESSERV } 38-\text { MCNRIND, MCIYR }=E B I N D_{38, M C T Y R} \\
& \text { ESSERV }_{39-\text { MCNRIND, MCIYR }}=E \text { EIND }_{39, \text { MCIYR }}
\end{aligned}
$$

The Growth Industry Submodule is not further described in the main text of this report, except for the illustration of this Submodule in Figure 4 of the main text, so the equations presented in this section are not supporting additional text. 


\section{The Regional Submodule}

The Regional Submodule of the MAM apportions the national totals of the regionalized variables computed in the National and Interindustry Submodules into shares for each of the nine Census Divisions as follows:

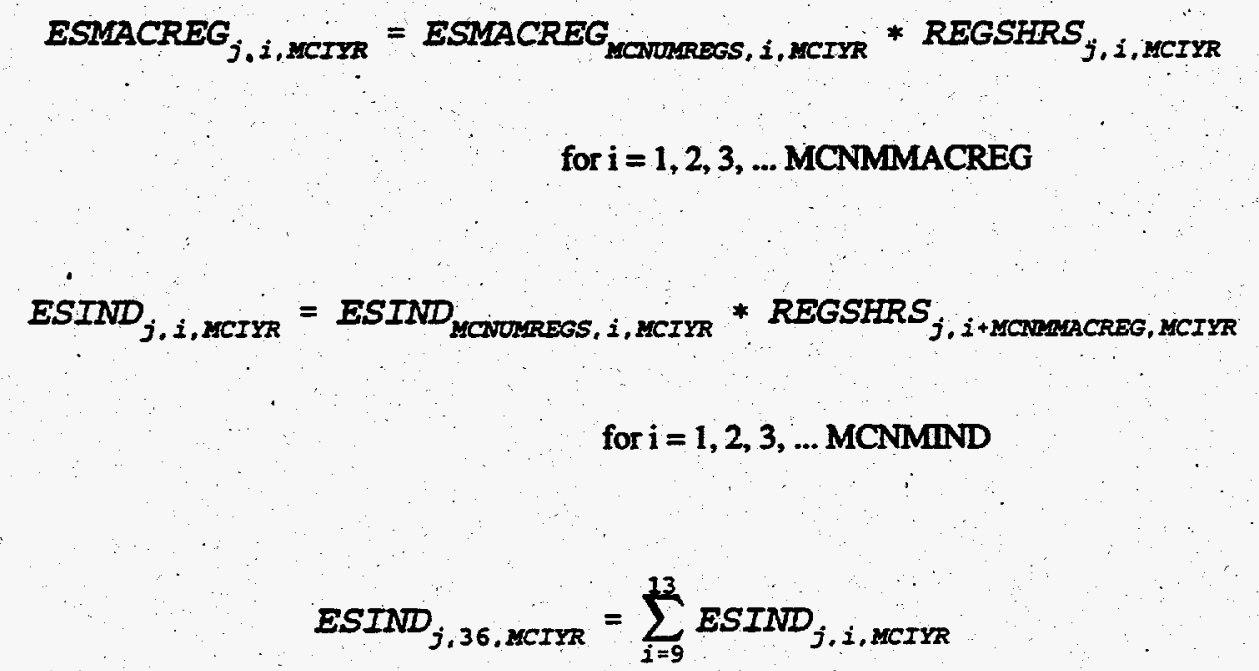

(Total chemical and allied products in region $\mathrm{j}$ in year MCIYR)

$E S I N D_{j, 37, \text { MCIYR }}=\operatorname{ESIND}_{j, 14, M C T Y R}+E S I N D_{j, 15, \text { MCIYR }}$

(Total of petroleum and coal products in region $\mathrm{j}$ in year MCTYR)

$$
\operatorname{ESIND}_{j, 38, \text { MCTYR }}=\sum_{i=18}^{20} E S I N D_{j, i, M C T Y R}
$$

(Total of stone, clay, and glass products in region $\mathrm{j}$ in year MCTYR)

$$
E S I N D_{j, 39, \text { MCIYR }}=\sum_{i=21}^{23} E S I N D_{j, i, 4 C I Y R}
$$




$$
\operatorname{ESIND}_{j, 40, \mathrm{MCIYR}}=\sum_{i=1}^{\text {MCNDJPNF }} \operatorname{ESIND}_{j, i, \mathrm{MCTYR}}
$$

(Total manufacturing output in region $\mathrm{j}$ in year MCIYR)

$$
\operatorname{ESIND}_{j, 41, \text { MCIYR }}=\sum_{i=1}^{\operatorname{MCNYND}} \operatorname{ESIND}_{j, i, M C I Y R}
$$

(Total industrial output, manufacturing and non-manufacturing, in region $\hat{j}$ in year MCIYR)

where

$\mathrm{j}=1,2,3, \ldots$ MCNUMREGS-2

Equations (B-35) through (B-42) provide supporting equations for the discussion provided on pp. 69-70 of the main text of this report.

\section{Important Subroutines in MAM Code}

There are six subroutines in MAM of which four (MAC, MACROSUB, INDUSTSUB and EMPLOYMENT) are important in calculating the solution values of macroeconomic concepts in MAM. Included below is a commented version of the Fortran code of these four major subroutines used to generate the AEO97 macroeconomic forecast.

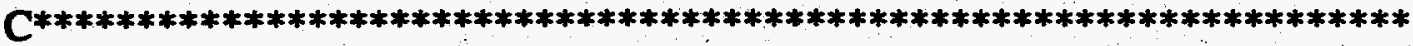

SUBROUTINE MAC

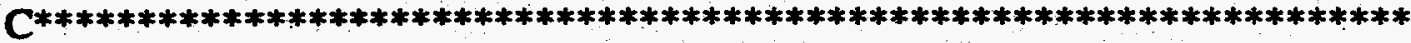

C The MAC subroutine directs the execution of the Macroeconomic

C Activity Module (MAM). It does so by setting parameters, computing
} 

C driver variables, calling the remaining subroutines, and writing
C to the COMMON block solution values of non-regional and regional
C macro variables. The other subroutines called by MAC are:
C
C READMAC - reads MAM parameter, coefficient, baseline and
C adjüstment values.
C MACROSUB - runs a response surface model for non-regional
C and regional macroeconomic variables.
C. INDUSTSUB - runs a response surface model for industrial and
C service outputs.
C EMPLOYMENT - runs a response surface model for employment.
C MACOUTPUT - writes to files MACOUT1 and MACOUT2 parameter,
C coefficient, baseline, adjustment, and solution
C values for MAM.

$C * * * * * * * * * * * * * * * * * * * * * * * * * * * * * * * * * * * * * * * * * * * * * * * * * * * * * * * * * * * * * * * * * * * *$
C Create aggregate energy price index from industrial coal, natural gas,
C electricity, world oil, and total petroleum prices.
C
C where:
C MCPGDP - PCWGDP price deflator, $1987=1.0$.
C PCLIN - price of coal, industrial.
C WPIBY(1) = .9500, base coal price, wpi051, 1992.
C WPIWT(1) $=.0452$, coal share of wpi05.
C BPRICE(1) - base coal price used in wpi05, 1992.
C PNGIN - price of natural gas, industrial.
C WPIBY(2) = .7590, base natural gas, wpi053, 1992.
C WPIWT(2) $=.2191$, natural gas share of wpi05.
C BPRICE(2) - base natural gas price used in wpi05, 1992. 

C PELIN - price of purchased electricity, industrial.
C WPIBY(3) $=1.2630$, base electricity price, wpi054, 1992 .
C WPIWT(3) $=.2476$; electricity share of wpi05.
C BPRICE(3) - base electricity price used in wpi05, 1992.
C IT_WOP - world oil price.
C WPIBY(4) $=.5800$, base world oil price, wpi0561, 1992 .
C WPIWT(4) $=.1527$, crude petroleum share of wpi05.
C BPRICE(4) - base world oil price used in wpi05, 1992.
C PTPIN - price of total petroleum, industrial.
C $\operatorname{WPIBY}(5)=.6460$, base refined petroleum price, wpi057, 1992.
C WPIWT(5) $=.3354$, refined petroleum share of wpi05.
C BPRICE(5) - base petroleum price used in wpi05, 1992.
C BPRICE(6) - PCWGDP price deflator for 1992, $1987=1.0$.

WPI05(MCTYR $)=$

1 (PCLIN(11,MCIYR)*(1.0+MCADJ(10,MCTYR)))*MCPGDP(MCIYR)

2 *WPIBY(1)*WPIWT(1)/BPRICE(1)/BPRICE(6)

$3+(\mathrm{PNGIN}(11, \mathrm{MCTYR}) *(1.0+\mathrm{MCADJ}(11, \mathrm{MCTYR}))) * \mathrm{MCPGDP}(\mathrm{MCTYR})$

4 *WPIBY(2)*WPIWT(2)/BPRICE(2)/BPRICE(6)

$5+($ PELIN $(11, M C T Y R) *(1.0+M C A D J(12, M C T Y R))) * M C P G D P(M C I Y R)$

6 *WPIBY(3)*WPIWT(3)/BPRICE(3)/BPRICE(6)

7 +(IT_WOP(MCIYR,1)*(1.0+MCADJ(13,MCIYR)))*MCPGDP(MCIYR)

8 *WPIBY(4)*WPIWTT(4)/BPRICE(4)/BPRICE(6)

$9+(\operatorname{PTPIN}(11, \mathrm{MCIYR}) *(1.0+\mathrm{MCADJ}(14, \mathrm{MCIYR}))) * \mathrm{MCPGDP}(\mathrm{MCTYR})$

1 *WPIBY(5)*WPIWT(5)/BPRICE(5)/BPRICE(6)

C. Calculate changes from baseline but restrict years prior to

C forecast to baseline values.

IF (MCTYR .LE. MCLHISYR .OR. MACFDBK .EQ. 0) THEN 
DO $20 \mathrm{I}=1,11$

DDRIVER(I,MCIYR $)=0.0$

20 CONTINUE

ELSE

C Calculate individual changes to the WPI05 components.

C Used to avoid double counting the effect captured by WPI05.

C WPI051 - coal.

PCWPI05 $(1$, MCIYR $)=(\operatorname{PCLIN}(11, \mathrm{MCTYR}) *(1.0+\operatorname{MCADJ}(10, \mathrm{MCTYR})))$ 1

/ BDRIVER(11,MCIYR) - 1.0

C WPI053 - gas fuels.

PCWPI05 $(2$, MCIYR $)=(\operatorname{PNGIN}(11, M C I Y R) *(1.0+\operatorname{MCADJ}(11, \mathrm{MCTYR})))$

1

/ BDRIVER(12,MCTYR) - 1.0

C WPI054 - electric power.

PCWPI05 $(3, M C T Y R)=(\operatorname{PELIN}(11, \mathrm{MCIYR}) *(1.0+\mathrm{MCADJ}(12, \mathrm{MCIYR})))$

1

/ BDRIVER(13,MCIYR) - 1.0

C WPIO561 - crude petroleum.

PCWPI05(4,MCIYR $)=($ IT_WOP(MCIYR, 1$) *(1.0+$ MCADJ $(13, M C I Y R)))$

1

/ BDRIVER(14,MCIYR) - 1.0

C WPI057 - refined petroleum products.

PCWPI05(5,MCIYR) $=(\operatorname{PTPIN}(11, \mathrm{MCTYR}) *(1.0+\mathrm{MCADJ}(14, \mathrm{MCIYR})))$

1 .

/ BDRIVER(15,MCTYR) - 1.0

C Calculate \% change from baseline for the four PC's.

C PCSHHOPE

DDRIVER $(4, M C I Y R+M C N X L A G P C)=($

1

(PELRS(11,MCIYR)*(1.0+MCADJ(5,MCIYR)))

2 *MCPGDP(MCIYR)/PCBPRICE(1)/BDRIVER(4,MCIYR)-1.0

3

- (PCPASS(4) * PCWPI05(3,MCIYR)))*INFDSW(4) 


\section{PCSHHOPG}

DDRIVER $(5, \mathrm{MCIYR}+\mathrm{MCNXLAGPC})=($

1 (PNGRS(11,MCIYR)*(1.0+MCADJ(6,MCIYR)))

2 *MCPGDP(MCIYR)/PCBPRICE(2)/BDRIVER(5,MCIYR)-1.0

$3 \quad$-(PCPASS(5) * PCWPI05(2,MCIYR))) *INFDSW(5)

C PCNFUEL

DDRIVER $(6, M C T Y R+M C N X I A G P C)=($

$1 \quad$ (PDSRS(11,MCIYR)*(1.0+MCADJ(7,MCIYR)))

2 *MCPGDP(MCIYR)/PCBPRICE(3)/BDRIVER(6,MCIYR)-1.0

3 - (PCPASS(6) *PCWPI05(4,MCIYR)))*INFDSW(6)

C PCNGAS

DDRIVER $(7, M C T Y R+M C N X I A G P C)=($

1 (((PDSTR(11,MCIYR)*(1.0+MCADJ(8,MCIYR)))

$2 *$ (QDSTR(11,MCIYR)/(QDSTR(11,MCIYR)+QMGTR(11,MCIYR))))

$3+((\operatorname{PMGTR}(11, \mathrm{MCIYR}) *(1.0+\mathrm{MCADJ}(9, \mathrm{MCTYR})))$

$4 *(Q M G T R(11, M C T Y) /(Q D S T R(11, M C T Y R)+Q M G T R(11, M C T Y R))))$

5 *MCPGDP(MCIYR)/PCBPRICE(4)/BDRIVER(7,MCIYR)-1.0

$6 \quad-($ PCPASS(7) * PCWPI05(4,MCIYR)))*INFDSW(7)

C- Calculate change from baseline for WPI05.

DDRIVER(8,MCIYR+MCNXIAGW)=((WPI05(MCIYR)*(1.0+MCADJ(15,MCIYR))) 1 /BDRIVER(8,MCTYR)-1.0)*INFDSW(8)

C Calculate change from baseline for WPI05 given alternate specification

C WPI05\{0 TO 5\}.

DDRIVER(11,MCIYR+5)=((WPI05(MCIYR)*(1.0+MCADJ(15,MCIYR)))

/BDRIVER(8,MCIYR)-1.0)*INFDSW(8)

Model Documentation Report

Macroeconomic Activity Module of the National Energy Modeling System 


\section{ENDIF}

C Call the Macroeconomic Submodule.

CALL MACROSUB

C Call the Interindustry Submodule.

\section{CALL INDUSTSUB}

C Call the Regional Submodule.

CALL REGIONSUB

C Call the Employment Submodule.

CALL EMPLOYMENT

$C * * * * * * * * * * * * * * * * * * * * * * * * * * * * * * * * * * * * * * * * * * * * * * * * * * * * * * * * * * * * * * * * * *$

\section{SUBROUTINE READMAC}

$C * * * * * * * * * * * * * * * * * * * * * * * * * * * * * * * * * * * * * * * * * * * * * * * * * * * * * * * * * * * * * * * * * *$

C The READMAC subroutine reads many separate files for parameters,

C coefficients, and for baseline and adjustment values used by the

C Macroeconomic Activity Module (MAM). These files only need to be

C read once in a run, so this subroutine is executed for the first

C iteration of the first year. Files read include:

C

C mcparms - parameter values of Macroeconomic Activity Module.

C mcinadj - adjustment values for macroeconomic driver variables.

C mcibass - baseline values for macroeconomic driver variables.

C mcecind - coefficients for industrial output.

C mcecmac - coefficients for non-regional and regional macroeconomic 

C variables.
C mcecemp - coefficients for industrial employment.
C mcbass - baseline values for non-regional and regional macroeconomic
C variables, industrial output, and employment.
C
C Two files, mcibass and mcbass, have separate values for each of three
C possible scenerios: high, moderate, and low economic growth.

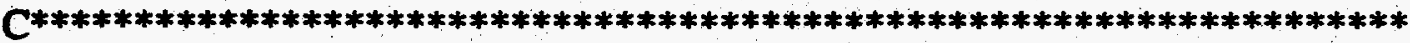
$C^{*}$

\section{SUBROUTINE MACROSUB}
$C * * * * * * * * * * * * * * * * * * * * * * * * * * * * * * * * * * * * * * * * * * * * * * * * * * * * * * * * * * * * * * * * * *$
C The MACROSUB subroutine contains response surface models for investment,
C wholesale prices, consumer prices.

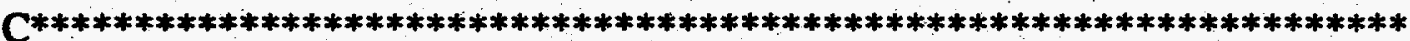

C Use coefficient estimates along with percent changes in

C price and supply-side variables to project change in

C macroeconomic' forecast variables.

C Add three to number of non-regional and regional variables

C for price deflators.

DO 290 I = 1, MCNMMAC+MCNMMACREG+3

C ******* Begin the WPI05 Model

C Initialize percent change in wholesale prices by setting

C EPMACW and ALTCMACW to zero.

EPMACW(I,MCIYR+MCNELAGW) $=0.0$

C Set number of lagged endogenous variables to zero for the 
C alternative RSM specification.

ALTPMACW(L,MCTYR+0) $\quad=0.0$

C If sim year is greater than historical year then aggregate

C percent change in wholesale prices for exogenous and endogenous

C variables.

IF (MCTYR :GT. MCLHISYR) THEN

C If using specification: WPI05 $\{0$ to 2$\} y\{1$ to 2$\}$.

IF (SWITCHEC(I) .EQ. 1) THEN

DO $330 \mathrm{~J}=1,1+\mathrm{MCNXLAGW}$

EPMACW(I,MCIYR+MCNELAGW $)=E P M A C W(1, M C I Y R+M C N E L A G W)$

$1 \div \quad+$ ECMACW(I,J)

2

* DDRIVER(8,MCIYR+MCNXIAGW+1-J)

330 CONTINUE

DO $340 \mathrm{~J}=1$, MCNELAGW

EPMACW $(1, M C I Y R+M C N E L A G W)=$ EPMACW $(I, M C I Y R+M C N E L A G W)$

+ ECMACW(I,(MCNXILAGW+1)+J)

2

* EPMACW(I,MCIYR+MCNELAGW-J)

\section{CONTINUE}

C Else use specification: WPI05 (0 to 5).

ELSE

C For the alternative specification there are five lagged

C exogenous variables and zero lagged endogenous variables.

DO $342 \mathrm{~J}=1,1+5$

ALTPMACW(I,MCIYR+0) = ALTPMACW(I,MCIYR+0)

+ ALTCMACW(I,J)

2

* DDRIVER(11,MCIYR+5+1-J)

342 CONTINUE 
ENDIF

ENDIF

C. Begin the PC Model

C Initialize percent change in consumer prices by setting EPMACPC to zero.

EPMACPC $($ LMCIYR+MCNELAGPC $)=0.0$

C If sim year is greater than historical year then aggregate

C percent change in consumer prices for exogenous and endogenous variables.

IF (MCTYR .GT. MCLHISYR) THEN

DO 350 PCNUM $=1,4$

DO $360 \mathrm{~J}=1,1+\mathrm{MCNXLAGPC}$

EPMACPC(I,MCTYR+MCNELAGPC) = EPMACPC(I,MCTYR+MCNELAGPC)

1

2

3

360

350
+ ECMACPC(PCNUM,I,J)

* DDRIVER(PCNÜM+3,

MCIYR+MCNXIAGPC+1-J) CONTINUE

CONTINUE

DO $370 \mathrm{~J}=1, \mathrm{MCNELAGPC}$

EPMACPC(I,MCIYR+MCNELAGPC) = EPMACPC (I,MCIYR+MCNELAGPC)

1

+ ECMACPC(NUMPCS+1,I,J)

2

* EPMACPC(I,MCTYR+MCNELAGPC-J)

C Estimate the macroeconomic variables based on sum of percent change

C of consumer prices, wholesale prices driver variables from baseline.

DO $420 I=1$, MCNMMAC

C If using specification: WPIO5\{0 to 2$\}$ y $\{1$ to 2$\}$ 
IF (SWTTCHEC(I) .EQ. 1) THEN

ESMAC $(1, M C I Y R)=(1.0+E P M A C I(1, M C I Y R+M C N E L A G I)$

1

+ EPMACPC(L,MCTYR+MCNELAGPC)

2

+ EPMACW(I,MCIYR+MCNELAGW)

3

* EBMAC(I,MCTYR)

C Else use specification: WPIO5 $\{0$ to 5$\}$.

C For the alternative specification there are five lagged

C exogenous variables and zero lagged endogenous variables.

ELSE

ESMAC $(I, M C T Y R)=(1.0+E P M A C I I, M C T Y R+M C N E L A G)$

1

+ EPMACPC(I,MCIYR+MCNELAGPC)

2

+ ALTPMACW(I,MCIYR+0)

3

* EBMAC(I,MCIYR)

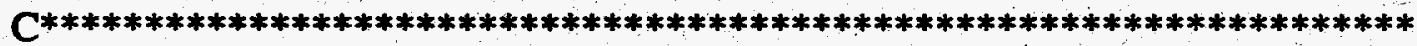

SUBROUTINE INDUSTSUB

$C * * * * * * * * * * * * * * * * * * * * * * * * * * * * * * * * * * * * * * * * * * * * * * * * * * * * * * * * * * * * * * * * * *$

C The INDUSTSUB subroutine contains surface model for industrial

C and services output.

$C^{* * * * * * * * * * * * * * * * * * * * * * * * * * * * * * * * * * * * * * * * * * * * * * * * * * * * * * * * * * * * * * * * * * *}$

C Calculate changes in industrial and service output (EDIND).

C Compute change in industrial outputs.

DO $460 \mathrm{I}=1, \mathrm{MCNMIND+MCNMSERV}$

C If the industry is petroleum refining (SIC 291), coal mining (SIC 11,12),

C oil \& gas mining (SIC 13), electric utilities (SIC 491), or gas utilities

C (SIC 492) then call GROWINDUST subroutine to compute change in

C industrial outputs. 
IF (I.EQ. 14 .OR. I.EQ. 32 .OR. I.EQ. 33 .OR. I .EQ. 38

1 .OR. I.EQ. 39) THEN

CALL GROWINDUST(I)

\section{ELSE}

C Add changes to the industrial baseline to produce an industrial

C and service output forecast. Execute IF statement if I counter

C is less than or equal to number of industries. Otherwise,

C execute ELSE statement for services.

IF (I.LE. MCNMIND) THEN

$\operatorname{ESIND}(11, \mathrm{I}, \mathrm{MCIYR})=\mathrm{EBIND}(1, \mathrm{MCTYR})+\operatorname{EDIND}(\mathrm{L}, \mathrm{MCTYR})$

ELSE

ESSERV(I-MCNMIND,MCTYR)=EBIND(I,MCIYR) + EDIND(1,MCTYR)

ENDIF

C End IF statement sorting petroleum refining, coal mining, oil and gas

C min̄ing, electric utilities, and gas utilities from rest of industries

$\mathrm{C}$ and services.

ENDIF

C Aggregate solution and baseline values for first 29 industrial categories

C of total manufacturing output, ES TOT MANUF OUTPUT.

IF (I .LE. MCNUMMNF) THEN

$\operatorname{ESIND}(11, \mathrm{MCNM} N \mathrm{ND}+5, \mathrm{MCIYR})=\operatorname{ESND}(11, \mathrm{MCNMIND}+5, \mathrm{MCIYR})$

1

+ ESIND(11,I,MCIYR)

EBIND(MCNMIND+15,MCIYR) $=$ EBIND(MCNMIND+15,MCIYR)

1

+ EBIND(1,MCIYR)

ENDIF 
C Aggregate solution and baseline values for industrial services categories

C 36 to $\mathbf{4 5}$ for total service output, TS TOT SERVICE OUTPUT.

IF (I.GT. MCNMIND .AND. I .LE. MCNMIND+MCNMSERV) THEN

ESSERV(MCNMSERV+1,MCIYR) = ESSERV $(M C N M S E R V+1, M C I Y R)$

1

+ ESSERV(I-MCNMIND,MCIYR)

EBIND(MCNMIND+18,MCIYR $)=$ EBIND(MCNMIND+18,MCIYR $)$

1 + EBIND(L,MCIYR)

ENDIF

C Aggregate solution and baseline values for first 35 industrial categories

C for total industrial output, ES TOT IND OUTPUT.

IF (I .LE. MCNMIND) THEN

ESIND(11,MCNMIND+6,MCIYR) = ESIND(11,MCNMIND+6,MCIYR)

1

$+\operatorname{ESIND}(11, \mathrm{I}, \mathrm{MCIYR})$

EBIND(MCNMIND+16,MCIYR) $=\mathrm{EBIND}(\mathrm{MCNMIND+16,MCIYR})$

1

+ EBIND(I,MCIYR)

C Sum total industrial output and total service output of total gross output

C for solution and baseline, ES TOT GROSS OUTPUT.

$\operatorname{ESIND}(11, \mathrm{MCNMIND}+7, \mathrm{MCIYR})=\operatorname{ESIND}(11, \mathrm{MCNMIND}+6, \mathrm{MCTYR})$

1

+ ESSERV(MCNMSERV+1,MCIYR)

EBIND(MCNMIND+17,MCIYR) $=$ EBIND $(M C N M I N D+16, M C I Y R)$

1

+ EBIND(MCNMIND+18,MCIYR)

C Sum industrial categories 9 through 13 composing SIC code 28 for

C solution and baseline, ESIND CHMALL(28). 


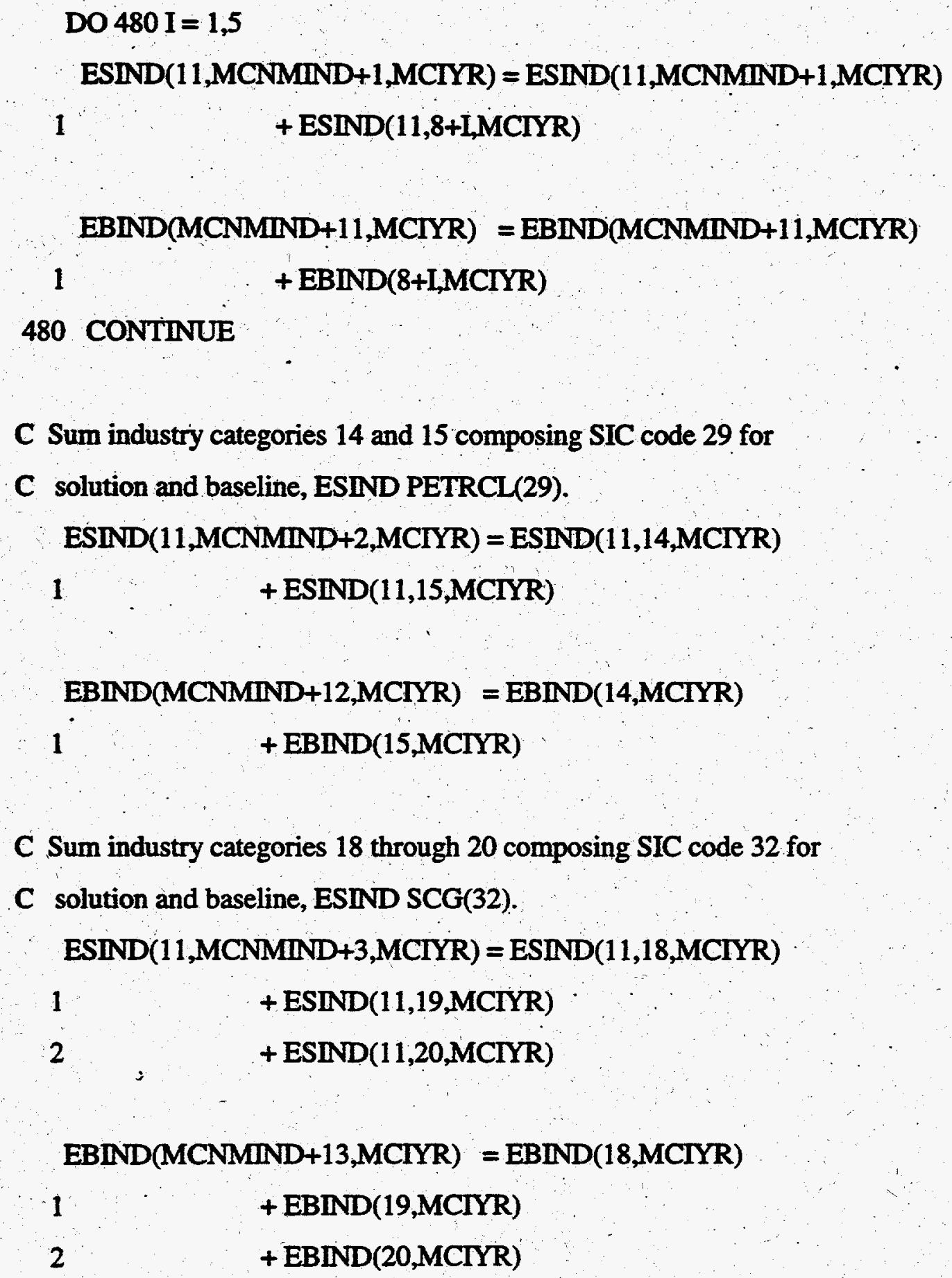

C Sum industry categories 14 and 15 composing SIC code 29 for

C solution and baseline, ESIND PETRCL(29).

$\operatorname{ESIND}(11, \mathrm{MCNMIND}+2, \mathrm{MCIYR})=\operatorname{ESIND}(11,14, \mathrm{MCIYR})$

1

$+\operatorname{ESIND}(11,15, \mathrm{MCIYR})$

EBIND(MCNMIND+12,MCIYR) $=\operatorname{EBIND}(14, \mathrm{MCIYR})$

$1+\operatorname{EBIND}(15, \mathrm{MCIYR})$

C Sum industry categories 18 through 20 composing SIC code 32 for

C solution and baseline, ESIND SCG(32).

$\operatorname{ESIND}(11, \mathrm{MCNMIND}+3, \mathrm{MCIYR})=\operatorname{ESIND}(11,18, \mathrm{MCIYR})$

$1+\operatorname{ESIND}(11,19, \mathrm{MCIYR})$

$2+\operatorname{ESIND}(11,20, \mathrm{MCTYR})$

EBIND(MCNMIND+13,MCIYR) $=\mathrm{EBIND}(18, \mathrm{MCIYR})$

$1+\operatorname{EBIND}(19, \mathrm{MCTYR})$

$2+\operatorname{EBIND}(20, \mathrm{MCIYR})$

C Sum industry categories 21 through 23 composing SIC code 33 for

C solution and baseline, ESIND PRIMET(33).

$\operatorname{ESIND}(11, \mathrm{MCNMIND}+4, \mathrm{MCIYR})=\operatorname{ESIND}(11,21, \mathrm{MCIYR})$ 


$$
\begin{array}{ll}
1 & +\operatorname{ESIND}(11,22, \mathrm{MCIYR}) \\
2 & +\operatorname{ESIND}(11,23, \mathrm{MCTYR})
\end{array}
$$

$$
\begin{aligned}
& \text { EBIND(MCNMIND+14,MCIYR) = EBIND(21,MCIYR) } \\
& 1 \quad+\text { EBIND(22,MCIYR) } \\
& 2 \quad+E B I N D(23, M C I Y R)
\end{aligned}
$$

C End of subroutine INDUSTSUB. Return to calling subroutine MAC.

\section{RETURN}

END

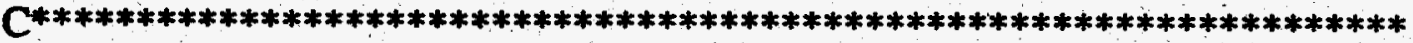

\section{SUBROUTINE GROWINDUST(I)}

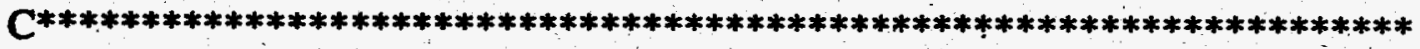

C The GROWINDUST subroutine computes changes in industrial outputs

C for the following industries: petroleum refining (SIC 291), coal

C mining (SIC 11,12), oil \& gas mining (SIC 13), electric utilities

C (SIC 491), or gas utilities (SIC 492).

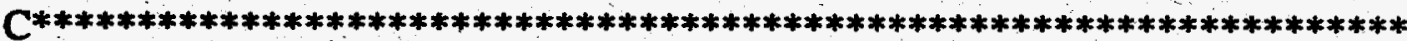

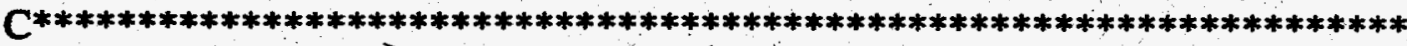

\section{SUBROUTINE REGIONSUB}

$C * * * * * * * * * * * * * * * * * * * * * * * * * * * * * * * * * * * * * * * * * * * * * * * * * * * * * * * * * * * * * * * * * *$

C The REGIONSUB subroutine computes regional shares for the regional

C macroeconomic variables based on the baseline values of the

C regional macroeconomic variables. These shares are then used to

C "share out", at the regional level, the regional macroeconomic

C variables measured at the national level.

Model Documentation Report Macroeconomic Activity Module of the National Energy Modeling System 
C. Apply the regional shares to the national level to create regional

C levels consistent with the national level from the national submodule.

$C * * * * * * * * * * * * * * * * * * * * * * * * * * * * * * * * * * * * * * * * * * * * * * * * * * * * * * * * * * * * * * * * * *$ SUBROUTINE EMPLOYMENT

$C * * * * * * * * * * * * * * * * * * * * * * * * * * * * * * * * * * * * * * * * * * * * * * * * * * * * * * * * * * * * * * * * * * *$

C The EMPLOYMENT subroutine is a response surface model for employment.

$C * * * * * * * * * * * * * * * * * * * * * * * * * * * * * * * * * * * * * * * * * * * * * * * * * * * * * * * * * * * * * * * * * *$

C Initialize index GOIND to account for differences in degree of information

C for agriculture and services. There are coefficient estimates splitting into

C agriculture and services (ECEMP.) There is no similar split in agriculture

C and services for the change in industrial output (EDIND) and for the

C employment baseline (EBEMP.) The GOIND index is used to multiply the same

C change in industrial output for agriculture and services by the more

C detailed employment coefficients. GOND is also used to aggregate the

C detailed impacts on agriculture and services so there is but a single

C category for each (ESEMP.)

GOND $=1$

C Initialize the change in employment for the current industry and year.

EDEMP(EMPIND,MCIYR) $=0.0$

C If employment industry is "Ag1EmpVAg2GO", "SerEmpVSerGO", or "S\&L Govt"

C then reduce GOIND by 1 .

IF (EMPIND .EQ. 31 :OR. EMPIND .EQ. 46

1

.OR. EMPIND .EQ. 48) THEN

GOIND $=$ GOIND -1 


\section{ENDIF}

C Compute the change in employment.

EDEMP(EMPIND,MCIYR $)=(($ ECEMP(EMPIND,1) $)$

$1+($ ECEMP(EMPND,2))*(MCIYR-7))*EDIND(GONND,MCIYR)

2 + ECEMP(EMPIND,3)*EDEMP(EMPIND,MCIYR-1)

GOND $=$ GOND +1

C End DO loop through employment categories.

\section{CONTINUE}

C End IF block for sim year greater than historical year.

ENDIF

C Compute the solution values for employment remembering there are

C changes in employment for splits in agriculture and in services.

C These changes are summed to create the solution values for agriculture

C and services. The GOND index is used to sum agriculture (30 and 31 )

C and servics (45 and 46.$)$

GOND $=1$

C Add two to number of employment categories for breakdown of services

C and agriculture.

DO 580 EMPIND = 1, NUMEMPL+2

C The change in the second categories of the split in agriculture (Ag1EmpVAg2GO)

C and in services (SerEmpVSerGO) is added to the solution for total agriculture

C [AGR(01)] and for total services [SVCES(MANY)] resulting from the first

C categories of agriculture (Ag1EmpVAg1GO) and services (SerEmpVSerGO). 
C Therefore, the IF statement is executed if the industry is number 31 or

C number 46. These are the second categories of agriculture and of services:

IF (EMPIND .EQ. 31 .OR. EMPIND .EQ. 46) THEN

GOIND $=$ GOIND -1

ESEMP(11,GOIND,MCIYR) = ESEMP(11,GOIND,MCIYR)

1 + EDEMP(EMPIND,MCIYR)

C Execute the ELSE statement for industries that are not the second categories

C of agriculture and of services.

ELSE

$\operatorname{ESEMP}(11$, GOIND,MCIYR $)=\operatorname{ESEMP}(11, \mathrm{GOIND}, M C I Y R)$

1

+ EBEMP(GOIND,MCIYR)

2

$$
\text { + EDEMP(EMPIND,MCIYR) }
$$

ENDIF

C Aggregate the employment categories as manufacturing, non-manufacturing,

C services, and total.

IF (EMPIND .NE. 30 .AND. EMPIND .NE. 45) THEN

C Manufacturing employment; categories 1 through 29.

IF (GOIND .LE. MCNMIND-6) THEN

$\operatorname{ESEMP}(11,47, \mathrm{MCIYR})=\mathrm{ESEMP}(11,47, \mathrm{MCIYR})+\mathrm{ESEMP}(11, \mathrm{GOIND}, \mathrm{MCIYR})$

EBEMP(47,MCIYR) =EBEMP(47,MCIYR) +EBEMP(GOIND,MCIYR)

ENDIF

C Non-manufacturing employment; categories 30 through 35.

IF (GOIND .GT. MCNMIND-6 AND. GOIND .LE. MCNMIND) THEN

$\operatorname{ESEMP}(11,48, M C I Y R)=\operatorname{ESEMP}(11,48, M C I Y R)+\operatorname{ESEMP}(11, \mathrm{GOIND}, M C I Y R)$

$\operatorname{EBEMP}(48, M C T Y R)=\operatorname{EBEMP}(48, M C I Y R)+\operatorname{EBEMP}(G O N N D, M C I Y R)$

Model Documentation Report

Macroeconomic Activity Module of the National Energy Modeling System 


\section{ENDIF}

C Service employment; categories 36 through 46.

IF (GOND.GT. MCNMTND) THEN

ESEMP(11,49,MCIYR)=ESEMP(11,49,MCIYR)+ESEMP(11,GOIND,MCIYR)

EBEMP(49,MCIYR) =EBEMP(49,MCIYR) +EBEMP(GOIND,MCIYR)

ENDIF

C Total non-agricultural employment:Manufacturing, Non-manufacturing and Service.

IF (GOND .NE. 30 .AND. GOIND .NE. 31) THEN

$$
\text { ESEMP(11,50,MCIYR) = ESEMP(11,50,MCIYR) }
$$

1

+ ESEMP(11,GOND,MCIYR)

$\operatorname{EBEMP}(50, M C T Y R)=\operatorname{EBEMP}(50, M C T Y R)$

1

+ EBEMP(GOND,MCIYR) 


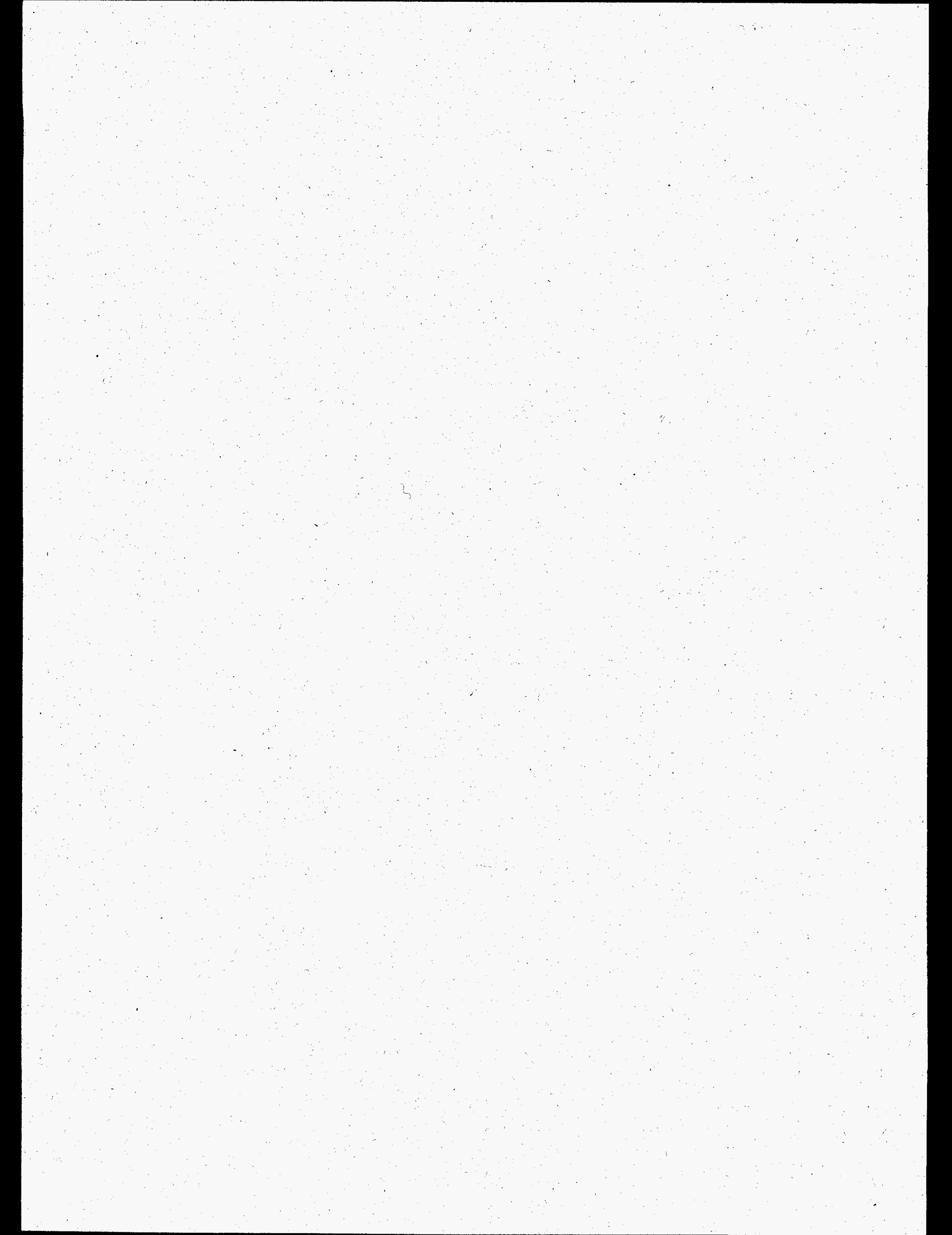




\section{Appendix C. Bibliography}

\section{Introduction}

This Appendix provides a bibliography of sources from the literature used in the theoretical and analytical design, development, implementation, and evaluation of MAM. The references supplied here are supplemented by additional detail including page citations, in the body of this report.

\section{References}

Almon, C. "The INFORUM Approach to Interindustry Modeling," Economic Systems Research, Vol. 3, No. 1, 1991.

Attanasi, E.D., and E.K. Green. "Economics of Coal Resource Appraisal: Strippable Coal in the Ilinois Basin." Southern Economic Journal, 47, 1981, pp. 742-752.

Ballard, C., and D. Fullerton, John Shoven, and John Whalley. A General Equilibrium Model for Tax Policy Evaluation, The University of Chicago Press, 1985.

Box, G.E.P. and N.R. Draper. Empirical Model-Building and Response Surfaces. New York, John Wiley \& Sons, 1987.

Brinner, R., "Philosophy and Properties of the DRI Model of the U.S. Economy," Quarterly Model of the U.S. Economy: Version US89A.

Chiang, A. Fundamental Methods of Mathematical Economics. Third Edition. New York: 
McGraw-Hill, 1984.

Connaughton, J., and R. Madsen. "A Comparison of Regional Forecasting Techniques," The Review of Regional Studies, 1991, pp. 4-9.

Data Resources/McGraw-Hill Inc. "An Overview of DRIs Regional Information Service."

— "Preliminary Model Documentation for the DRI World Model," Prepared December 10, 1990.

_ "Regional Information Service RIS Model: Structure and Use." DRI/McGraw-Hill Internal Document.

Energy Information Administration, "Integration Methodology of the National Energy Modeling System," DRAFT, June 28, 1991.

_-"Components and Linkages of the National Energy Modeling System," DRAFT, July 1, 1991.

_ "Model Documentation: Mini-Macroeconomic Personal Computer Model (PCMAC)," Model Documentation Report for the Annual Energy Outlook 1991.

_- National Submodule Component Design Report," May 1992.

Farrell, C., and W. Hall. "Measuring and Forecasting Local Economic Activity: A Status Report," The Review of Regional Studies, 1991, pp. 34-38.

Griffin, J. "Long-Run Production Modeling with Pseudo Data: Electric Power Generation." Bell Journal of Economics, 8, 1977a, pp 112-127. 
- "The Econometrics of Joint Production: Another Approach." Review of Economics and Statistics, 59, 1977b, pp. 389-397.

- "Joint Production Technology: The Case of Petrochemicals." Econometrica, 46, 1978, pp. 379-396.

_ "Statistical Cost Analysis Revisited." Quarterly Journal of Economics, 93, 1979, pp. 107129.

— "Alternative Functional Forms and Errors of Pseudo Data Estimation: A Reply." Review of Economics and Statistics, 62, 1980, pp. 327-328.

Hewings, G. Regional Input-Output Analysis. Sage Publications: London, 1985.

Hudson, E., and D. Jorgenson. "U.S. Energy Policy and Economic Growth, 1975-2000." The Bell Journal of Economics, Autumn 1974, p. 461-514.

- The Economic Impact of Policies to Reduce U.S. Economic Growth." Review of Income and Wealth, Vol. 1, No.3, (November 1978), p. 205-229.

Hoffman, K., and D. Jorgenson. "Economic and Technological Models for Evaluation of Energy Policy." The Bell Journal of Economics, p. 444-466.

Isard, W. Methods of Regional Analysis. Cambridge: The MIT Press, 1960.

Jorgenson, D., and P. Wilcoxen. "Environmental Regulation and U.S. Economic Growth." Energy and Environmental Policy Center discussion paper, E-89-14, Harvard University, November 1989. 
Krikelas, A. "Why Regions Grow: A Review of Research on the Economic Base Model,". Economic Review, Federal Reserve Bank of Atlanta, July/August 1992, pp. 16-29.

Kolstad, C.D, and F.A. Wolak, "Competition in Interregional Taxation: The Case of Western Coal." Journal of Political Economy, 91, 1983, pp. 443-460.

Kort, J., J. Cartwright, and R. Beemiller. "Linking Regional Economic Models for Policy Analysis," Regional Economic Analysis Division, Bureau of Economic Analysis, Department of Commerce, July 1984.

Maddala, G.S. and R.B. Roberts. "Alternative Functional Forms and Errors of Pseudo Data Estimation." Review of Economics and Statistics, 62, 1980, pp. 323-327.

McCarthy, M. "LIFT: INFORUM's Model of the U.S. Economy," Economic Systems Research, Vol. 3, No. 1, 1991.

McCarthy, M. "A Model for Examining the Energy-Economy Interactions in the Wharton World Model," WEFA, December 1982.

Meade, D., Description and User Guide for PC-IO, Data Resources/McGraw Hill, Washington, DC, August 30, 1990.

Miller, R., and P. Blair. Input-Output Analysis: Foundations and Extensions. Englewood Cliffs, New Jersey: Prentice-Hall, 1985.

Oxford Economic Forecasting, "World Model Overview," Oxford Economic Forecasting, Templeton College, Oxford U.K.

Pindyck, R., and D. Rubinfeld. Econometric Models \& Economic Forecasts, Second Edition. 
New York: McGraw-Hill, 1981.

Ross, M. and R. Hwang, A Model for Long-Term Industrial Energy Forecasting (LIEE), Lawrence Berkeley Laboratory, February 1992.

Sav, G.T. "The Engineering Approach to Economic Production Functions Revisited: An Application to Solar Processes." Journal of Industrial Economics, 32, 1984, pp. 21-35.

"Tax Incentives for Innovative Energy Sources: Extensions of E-K Complementarity." Public Finance Quarterly, 15, 1987, pp. 417-427.

Scarf, H., and J. Shoven. Applied General Equilibrium Analysis, Cambridge University Press, 1984.

Shoven, J., and J. Whalley. "Applied General-Equilibrium Models of Taxation and International Trade: An Introduction and Survey." Journal of Economic Literature, Vol. XXII (September 1984), p. 1007-1051.

Treyz, G.I., D.S. Rickman, and G. Shao. "The REMI Economic-Demographic Forecasting and Simulation Model," International Regional Services Review, Vol. 14, No. 3, 1992.

U.S. Department of Commerce. "A Preview of the Comprehensive Revision of the National Income and Product Accounts: Definitional and Classification Changes," Survey of Current Business, Volume 71, Number 9, September 1991, 23-31.

U.S. Department of Commerce. "Benchmark Input-Output Accounts for the U.S. Economy, 1982," Survey of Current Business, Volume 71, Number 7, July 1991, 30-71.

U.S. Department of Commerce. "Regional Multipliers: A User Handbook for the Regional 
Input-Output Modeling System (RIMS-II). Bureau of Economic Analysis, May 1986.

WEFA Group. "The Wharton World Econometric Model," Revised, December 1984. 


\section{Appendix D. Model Abstract}

\section{Model Name:}

Macroeconomic Activity Module of the National Energy Modeling System

\section{Model Acronym:}

MAM

\section{Description:}

MAM is comprised of four Submodules: National, Employment, Interindustry, and Regional. The National Submodule is a response surface approximation of the proprietary U.S. Quarterly Macroeconomic Model developed by Data Resources/McGraw-Hill, Inc. (DRI). The U.S. Quarterly Model is a 1,200 equation econometric specification that forecasts macroeconomic driver variables at the national level of detail.

The Employment Submodule is a response surface approximation of the DRI Econometric Model of Employment by Industry. The DRI Econometric Model of Employment by Industry, on which the response surface Employment Submodule is based, uses interindustry gross output from DRT's Personal Computer Input-Output (PCIO) Model as its major input when determining employment.

The Interindustry Submodule is a response surface approximation of the DRI Personal Computer Input-Output (PCIO) Model. The DRI PCIO Model is a detailed input-output representation of interindustry linkages that works in tandem with the full DRI U.S. Quarterly Model.

The Regional Submodule consists of a set of shares at the nine Census Division level of detail developed from simulations of DRT's U.S. Quarterly Macroeconomic Model, PCIO Model, and Regional Model. The regional shares included as the Regional Submodule of MAM are used to 
disaggregate the national results generated by the National and Interindustry Submodules of MAM to the nine Census Division level of detail.

\section{Purpose of the Model:}

MAM links the National Energy Modeling System (NEMS) to the rest of the economy by providing industrial sector activity and macroeconomic inputs to the energy modules of NEMS. Macroeconomic variables such as GDP, disposable income, prices, interest rates, and unemployment drive energy demands and are important determinants of energy prices and quantities. Conversely, changes in energy supplies and prices impact GDP, prices, interest rates, and other macroeconomic variables. MAM responds to changes in energy supplies and prices to generate forecasts of approximately 170 macroeconomic variables for use in various energy modules within NEMS.

\section{Most Recent Model Update:}

June 1996.

\section{Part of Another Model?}

National Energy Modeling System (NEMS).

\section{Model Interfaces:}

MAM provides sectoral macroeconomic driver variables including housing starts, commercial floorspace, and interindustry projections to the NEMS Residential Sector, Commercial Sector, and Industrial Sector Demand Modules. MAM provides financial indicators such as interest rates to both the demand and supply modules of NEMS. 


\section{Official Model Representative:}

. Kay A. Smith, Economist

Office of Integrated Analysis and Forecasting

Energy Demand and Integration Division

Integrated Economic International Forecasting Branch

(202) $586-1455$

\section{Documentation:}

Model Documentation Report: Macroeconomic Activity Module (MAM) of the National Energy Modeling System, December 1993.

\section{Archive Media and Installation Manual(s):}

The MAM has been archived on a drive comparable. The MAM will be archived on IBM RS6000 series, 590 as part of the National Energy Modeling System production runs that generated the AEO1997.

\section{Energy System Described:}

Domestic macroeconomic sector.

\section{Coverage:}

- Geographic: Nine Census Divisions.

- Time Unit/Frequency: Annual, 1990 through 2015 
- Products: Forecasts of domestic macroeconomic driver variables, at the national, interindustry, and nine Census Division levels of detail.

Economic Sectors: National macroeconomic activity.

\section{Modeling Features:}

- Model Structure: MAM is composed of four Submodules: National, Interindustry Employment, and Regional. The four Submodules are executed sequentially in the order presented, and subsequent Submodules build upon the results of previously-executed Submodules.

Modeling Techniques: The National Employment; and Interindustry Submodules of MAM are econometric response surface representations of large proprietary econometric models. The Regional Submodule of MAM is composed of shares developed from simulations of large econometric macroeconomic, interindustry, and regional models.

Special Features: None.

\section{Non-DOE Input Sources:}

DRI Input data from the DRI U. S. Quarterly Macroeconomic Model, the DRI PCIO Model, and the DRI Regional Model.

\section{DOE Input Sources:}

MAM relies upon the DRI Input data to generate the baseline growth path. Alternative growth paths are developed based on alternative economic driver variable growth path assumptions. DOE data is not used to develop the MAM. 


\section{Computing Environment:}

- Hardware Used: IBM RS-6000 590 series, IBM-compatible personal computers

- Operating Systems: UNIX; MS-DOS

- Languages/Software Used: FORTRAN,

- Memory Requirement: 1 megabyte

- Storage Requirement: 20 megabytes

- Estimated Run Time: $3.0 \mathrm{cpu}$ seconds for a 1990-2015 run in non-iterating NEMS mode

- Special Features: None.

\section{Independent Expert Reviews Conducted:}

None.

\section{Status of Evaluation Efforts by Sponsor:}

None. 


\section{Appendix E. Data Quality and Estimation}

\section{Introduction}

This Appendix discusses the data quality and estimation procedures performed to construct the response surface Macroeconomic Activity Module (MAM) included in the National Energy Modeling System (NEMS) and used to generate the 1997 Annual Energy Outlook (AEO94). Four issues are addressed in this Appendix: world oil price scenario results, the pseudo data generation methodology and procedure, the regional share estimates used in the MAM generated through simulations of the full scale DRI models (discussed in Chapter 1 of the main text of this report), and the regression parameters and diagnostics resulting from the simulation process.

\section{World Oil Price Scenario Results}

The value of response surface models lie in how well they approximate the larger model. For comparison purposes, two identical experiments were run using the full DRI Quarterly Model and the NEMS MAM response surface model. One experiment changed the world oil price by $20 \%$ compared to base immediately. The second experiment increased world oil price by $20 \%$. - by the end of the forecast period, increasing it by $1 \%$ each year. Figures E-1 through E-4 show the results of these two experiments. 
Figure E-1. PCOF Coefficient Check, YD87

\section{Real Disposable Income Coeff. Check Percent change from base}

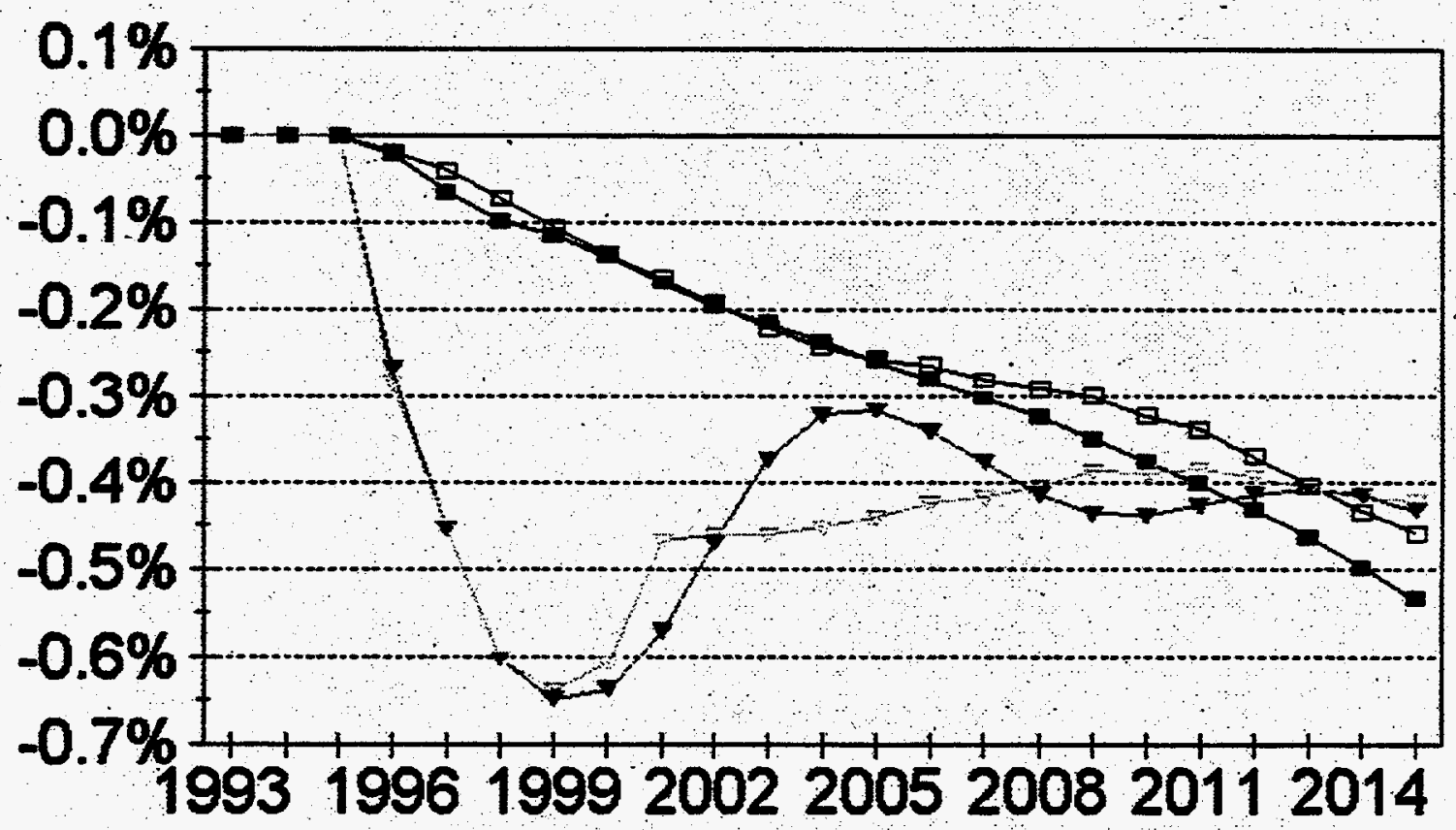

$\rightarrow$ - DRI Model: Ramped oil price increase $\rightarrow$ DRI:Immediate oil price increase

$\because$ MAM: Ramped oil price increase _ - MAM: Immediate oil price increase 
Figure E-2. PCOF Coefficient Check, GDP87FE

\section{GDPFE Coefficient Check Percent change from base}

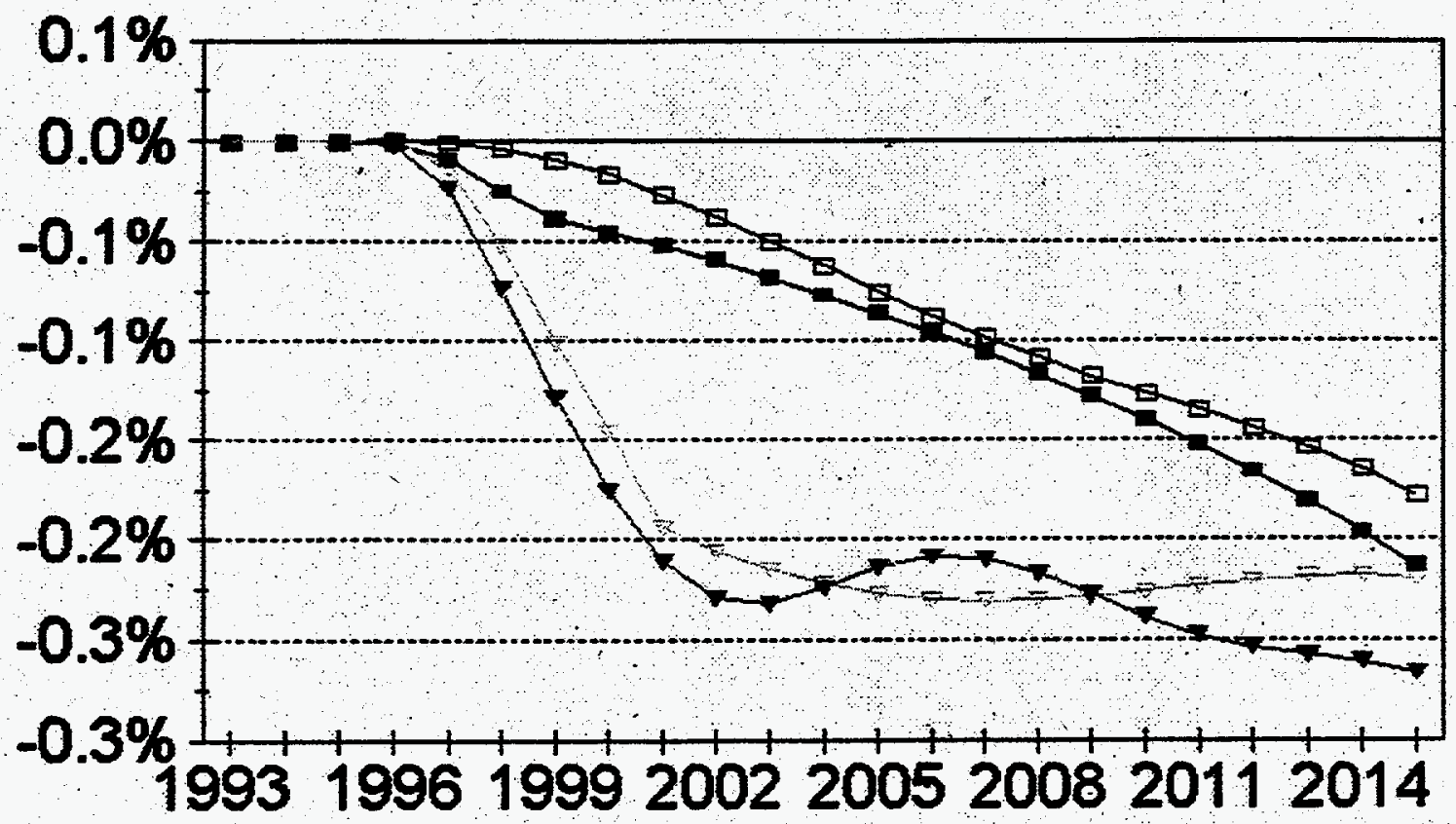

$\rightarrow$ DRI Model: Ramped oil price increase - DRl Immediate oil price increase

- MAM: Ramped oil price increase - MAM: Immediete oll price increase 
Figure E-3. PCOF Coefficient Check, GDP87.

\section{CDP Coefficient Check \\ Percent change from base}

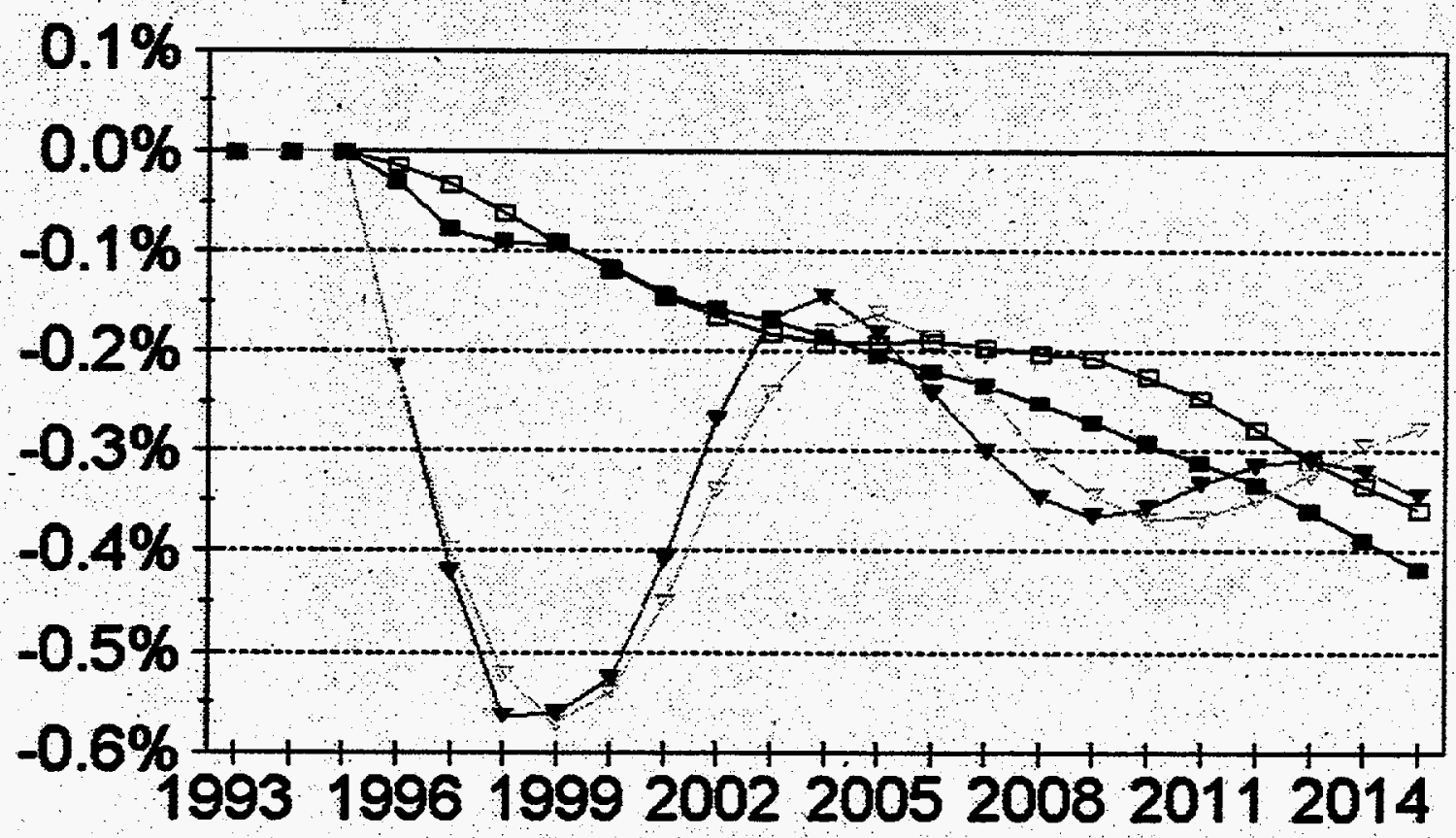

- DRI Model: Ramped oil price increase - DRlimmediate oil price increase

$\rightarrow$ MAM: Ramped oil price increase

- MAM: Immediate oil price increase 
Figure E-4. PCOF Coefficient Check, CPI .

\section{Consumer Price Coefficient Check Percent change from base}

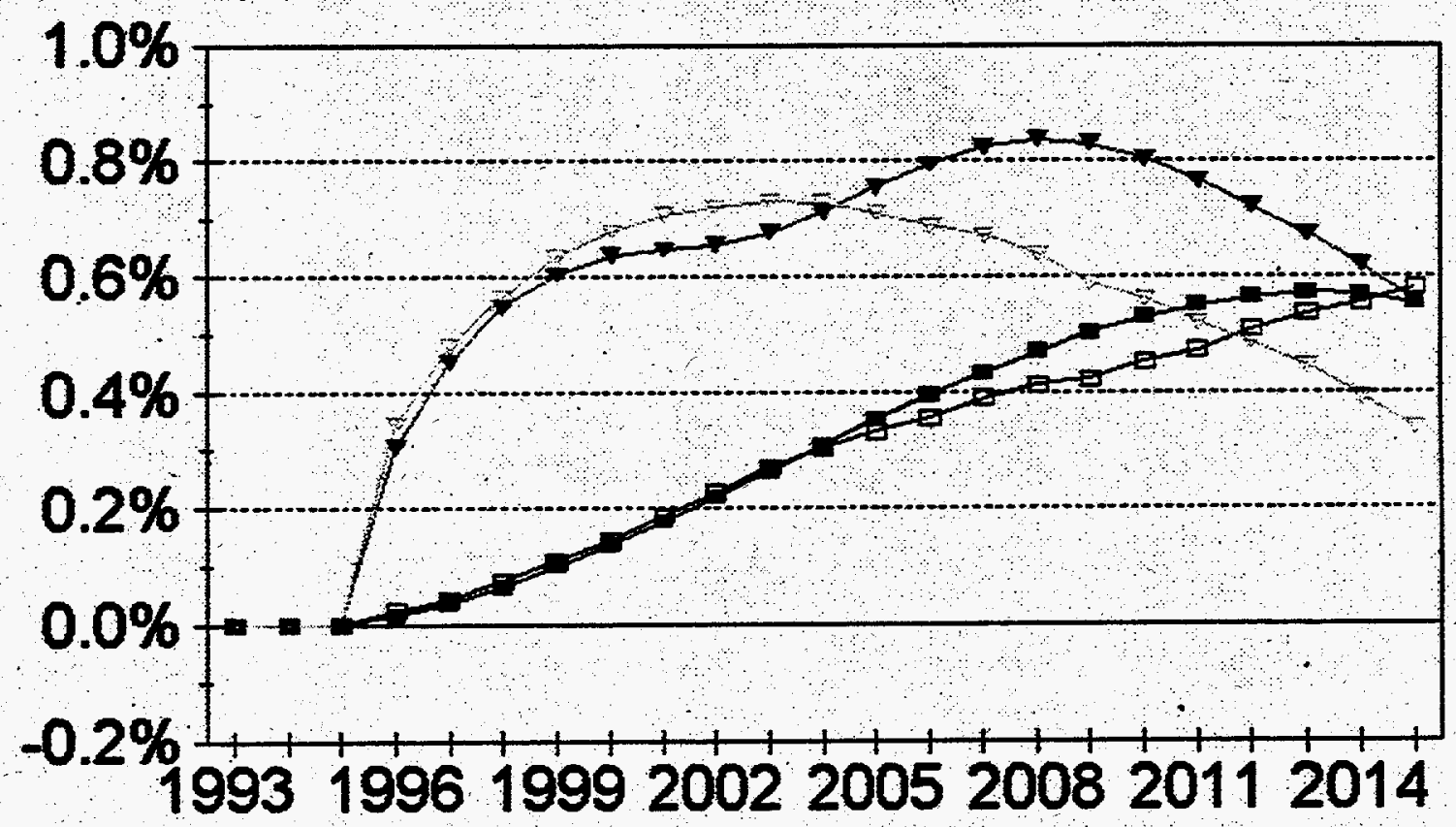

$\rightarrow$ DRI Model: Ramped oil price increese - - DRl Immediate oil price increase

- MAM: Ramped oil price increase

- MAM: Immediate oil price increase 


\section{Pseudo Data Generation Methodology}

\section{National Submodule}

This section presents the procedure used to develop the pseudo data for the response surface approximation of the DRI full scale models included as the NEMS MAM. The observations on which the response surface model are estimated are pseudo data generated by repeated runs of the DRI U.S. Quarterly Model for various values of the input variables. The first task was to generate a "base case" or "most likely scenario" for the macroeconomic variables. This case was developed using the February 1996 DRI 25-year long term forecast, "TREND25YR0296" as the base case. Changes start in 1996 and continue through 2020. The time paths of the changes in input variables follow two paths - immediate and ramped. In the immediate cases, the world oil price rises above baseline by a specific percentage amount and remains above baseline by this percentage throughout the simulation period. In the ramped cases, the full amount of the change is in place within five years, thereafter maintained for the remainder of the forecast period. Changes in WPIO5 are created by varying the world price of crude oil, an exogenous variable in the DRI model, according to typical scenarios contained in the Annual Energy Outlook, as well as typical energy tax scenarios considered in past analyses.

Although the DRI model includes an equation for exchange rates, the pseudo data simulation froze the exchange rate at baseline levels and forced a one-for-one pass through of changes in domestic interest rates on foreign interest rates. This procedure was adopted because the MAM is primarily a national model.

A $\$ 100$ real carbon tax simulation was used as the upper bound of percentage changes in the personal consumption deflators for energy and excise taxes. The upper bounds of the changes included $\$ 400$ billion for excise tax, $37 \%$ for the world oil price, $32 \%$ for the personal consumption deflator for fuel oil, $22 \%$ for the deflator for motor gasoline, $26 \%$ for the deflator for electricity, $17 \%$ for the deflator for natural gas, $\$ 10$ billion of real investment in mining and petroleum structures, $\$ 20$ billion of real investment in public utilities, and $\$ 10$ billion of real 
pollution abatement equipment. Once these upper bounds of changes were chosen, four additional simulations were created using percentages of these maximum changes. For all prices, equal percentage increases and reductions were made. For example, the upper bound of the personal consumption deflator for motor gasoline was a $22 \%$ increase and $22 \%$ decrease relative to the baseline deflator and the additional simulations changing the motor gasoline deflator were $80 \%, 60 \%, 40 \%$, and $20 \%$ of the largest increase. Thus, the personal consumption deflator for motor gasoline was increased (and reduced) by $22 \%, 17 \%, 13 \%, 9 \%$, and $4 \%$ relative to baseline levels.

\section{Employment Submodule}

In order to estimate the coefficient matrices, each of the output aggregates contained in the Interindustry Submodule was increased within PCIO by 1 million dollars ( $\$ 1987)$ throughout the forecast period of the employment model while holding all other gross outputs constant. The resulting change from baseline levels of employment as projected by the structural employment model were regressed against the change in gross output and lagged change in employment.

Although only 30 disaggregated employment sectors are reported, the response surface model operates at the Interindustry Submodule level of disaggregation (45 sectors). Except for two employment sectors, each sector's change in employment is related to that sector's change in gross output only. Because of differences between the response surface and structural modeling systems, two of the 45 employment sectors (Agricultural Production - Crops, and Retail Trade) are each related to two gross output categories. Employment in the Agricultural Production Crops sector is based on gross output in both the Agricultural Production - Crops sector and the Other Agriculture including Livestock sector. Employment in the Retail Trade sector is based on gross output in both the Retail Trade sector and the Services sector.

The $\beta_{1}$,coefficient, which can be viewed as the base year (or constant) coefficient relating employment change to a 1 million dollar (\$1987) output change, is positive for all industries, as 
would be expected. The purpose for the time counter is to capture the productivity trends contained in the structural employment model. The $\beta_{2}$ coefficient is generally negative, indicating that productivity increases over time for most industries. The $\beta_{3}$ coefficient is generally positive, indicating that most industries do not immediately adjust employment fully to the desired level when output demand changes.

\section{Interindustry Submodule}

In order to estimate the two coefficient matrices $\alpha$ and $\beta$, the first final demand component in the macroeconomic model was increased 1000 million dollars (\$1987) throughout the forecast period of PCIO while holding all other final demands constant. The resulting change from baseline levels of gross output for each of the 114 industries of PCIO was then calculated, and the changes aggregated to the level of industrial detail required for the Interindustry Submodule (45 sectors). The mapping of PCiO sectors to Interindustry Submodule sectors is shown in Table 3 in the main text of this report. This process was repeated for each of the macroeconomic final demand categories of the National Submodule. The result of these controlled simulations of PCIO was 2070 time series of interindustry impacts, each relating change in gross output of a specific industrial sector to change in a particular final demand component.

Each of the 2070 output time series was divided by 1000 , the amount by which each macroeconomic final demand was incremented when running the PCIO model, resulting in multipliers relating change in industrial gross output to change in final demand. A linear regression was then performed on each of the multiplier time series, with time as the independent variable. The $\alpha_{i j}$ coefficients represent the amount that sector i's output would change for $a$ unit change in final demand $j$, for the base year of the simulation. Since the PCIO model is not static; time is included in the regressions. The $\beta_{i j}$ coefficients are designed to capture the effects of both the changing row scalars and the changing bridge matrix within PCIO. A linear time specification was chosen for the initial estimation of the 
Interindustry Submodule.

\section{Regional Share Estimates}

As discussed previously, regional share estimates were developed by simulating the full scale DRI models. The shares are used in the NEMS MAM to disaggregate the results of the National and Interindustry Submodules to the Census Division level of detail, for those variables required on a regional basis as discussed in Chapter 1 of the main text of this report.

\section{Supporting Data Availability}

The regression coefficients and diagnostics developed using the DRI full-scale models to develop the National, Employment, and Interindustry Submodules of the MAM reside in electronic form on floppy diskettes. In addition, the regional share estimates developed for the MAM Regional Submodule are stored on floppy diskettes. Diskettes are available from Ms. Kay Smith, Economist, as referenced in the Model Contact discussion in Chapter 1 of the main text of this report. 